\title{
The family Dolichopodidae (Diptera) of the Pilbara region, Western Australia in its Australasian biogeographic context, with the description of 19 new species
}

\author{
Daniel J. Bickel \\ Australian Museum, 6 College Street, Sydney, New South Wales 2010, Australia. \\ Email: danb@austmus.gov.au
}

\begin{abstract}
The Dolichopodidae (Diptera) of the Pilbara Region (here also including Barrow Island and Cape Range), Western Australia are described, keyed and illustrated. The fauna comprises 41 species, including three with generic names only, being represented by females or badly damaged males. The following 19 species are newly described: Pseudoparentia canalicula sp. nov., Pseudoparentia niharae sp. nov., Paraclius manglar sp. nov., Medetera junensis sp. nov., Corindia gascoynensis sp. nov., Thinophilus eboricoxa sp. nov., Thinophilus yarraloola sp. nov., Chaetogonopteron capricorne sp. nov., Chaetogonopteron vexillum sp. nov., Sympycnus colliepa sp. nov., Sympycnus lacrimulus sp. nov., Sympycnus pistillus sp. nov., Sympycnus weano sp. nov., Sympycnus ephydroides sp. nov., Sympycnus hamulitarsus sp. nov., Diaphorus karijini sp. nov., Diaphorus garnetensis sp. nov., Chrysotus austrotropicus sp. nov. and Chrysotus pilbarensis sp. nov. Paraclius obtusus Hardy, 1939 is regarded as a new senior synonym of Paraclius albodivisus Parent, 1941, syn. nov. The Pilbara fauna is treated in the context of the wider Australian fauna, and many extralimital records are included. Many Pilbara species are found across tropical northern Australia, and sometimes into adjacent Melanesia. However, some species have a trans-continental distribution south of the monsoonal belt and also occur in central Northern Territory and subtropical interior Queensland suggesting a biogeographic track that now comprises favorable relictual habitats in a largely arid region. The Millstream site along the Fortescue River is particularly rich in species, and it is the only known locality of the isolated monotypic genus Pilbara Bickel.
\end{abstract}

KEYWORDS: Diptera, Dolichopodidae, taxonomy, biogeography, Pilbara, Australasia

\section{INTRODUCTION}

The Dolichopodidae, or long legged flies, comprise a rich cosmopolitan family of Diptera that is often abundant in warm moist habitats (see Bickel 2009a for general review). Dolichopodids are often cursorial on foliage, tree trunks, mud flats, and river rocks, even though they are good fliers. Adults are predators on soft-bodied invertebrates such as mites, thrips, psocids, aphids, small nematocerous flies, and oligochaetes. The larvae are maggot-like and found in such habitats as soil, rotted vegetation, mud, under bark, and tree holes. Most larvae are predators or scavengers, although the medeterine Thrypticus is phytophagous. Dolichopodids are known for their elaborate male secondary sexual characters (MSSC), assumed to aid in species recognition during courtship.

The Dolichopodidae include many large (500+ species) genera of cosmopolitan distribution. Some of these genera (Sympycnus and Chrysotus, for example) are poorly defined with uncertain limits. Further, homoplasy is frequently encountered and derived characters can have variable expression among closely related species, which confound the study of such genera at the world level. Therefore, some of the genera presented below should be regarded as paraphyletic and/or symplesiomorphic species complexes that cannot be strongly defined. However, such genera are important in that they hold many common and readily identifiable species.

I was asked to contribute to this volume as a result of identifying Diptera collected in the Barrow Island project. Although I had seen only relatively small samples from Barrow Island, the Dolichopodidae, my family of specialty, were of interest. I therefore felt it was necessary to treat those species in the context of the larger Pilbara fauna which is well represented by collections 
gathered during various ANIC expeditions. And since the Pilbara fauna itself is only part of the still larger northern Australian fauna, it was necessary to consider the wider distributions of the Pilbara species using the large collections at the ANIC, AMS and other institutions. This revealed that many species have ranges not only across tropical Australia, but sometimes into adjacent Melanesia. In addition, I have keyed some widespread taxa not currently known from the Pilbara but likely to occur there based on their presence in adjacent regions.

For such an arid region south of the main monsoonal belt, the Pilbara has a remarkably rich fauna of Dolichopodidae, even though it lacks many genera found in the more mesic habitats of eastern Australia. Many species appear to be associated with watercourses that have a semipermanent flow, and of these, the Millstream site on the Fortescue River is particularly rich and hosts some notable relictual elements.

\section{MATERIALS AND METHODS}

This study is based on institutional holdings of Pilbara and northern Australian Dolichopodidae. Any reference to the repository of material cited in the text uses the institutional abbreviations designated here: (AMS)-Australian Museum, Sydney; (ANIC)-Australian National Insect Collection, CSIRO Entomology, Canberra; (BMNH)Natural History Museum, London; (BPBM)-Bishop Museum, Honolulu; (CAS)-California Academy of Sciences, San Francisco; (IRSN)-Institut Royale des Sciences Naturelles, Brussels; (SAM)-South Australian Museum, Adelaide; (QDPI)-Queensland Department of Primary Industries, Indooroopilly; (QMB)-Queensland Museum, Brisbane; (WAM)Western Australian Museum, Perth.

Species are defined primarily on the basis of male characters, especially the genitalia and male secondary sexual characters (MSSC). In describing the hypopygium, 'dorsal' and 'ventral' refer to morphological position prior to genitalic rotation and flexion. Morphological terminology follows McAlpine (1981), except male hypopygium where terms of Cumming et al. (1995) are followed. Common features are listed in the introductory descriptions and are not repeated in species descriptions unless needing clarification. Measurements are in millimeters and were made on representative specimens. Body length is measured from the base of the antennae to the tip of the seventh abdominal segment. Wing length is from the base to the wing apex, and wing width is measured from the junction of $R_{1}$ with the costa to the opposite side of the wing, perpendicular to the wing's long axis. The $\mathrm{CuAx}$ ratio is the length of the $\mathrm{m}-\mathrm{cu}$ crossvein/ distal section $\mathrm{CuA}$. The position of features on elongate structures such as leg segments is given as a fraction of the total length, starting from the base. The relative lengths of the podomeres should be regarded as representative ratios and not measurements. The ratios for each leg are given in the following formula and punctuation: trochanter + femur; tibia; tarsomere 1/ 2/ 3/ 4/ 5.

The following abbreviations and terms are used: MSSC-Male secondary sexual character(s), the non-genitalic characters found only on the male body; I, II, III: pro-, meso-, metathoracic legs; C, coxa; T, tibia; F, femur; ac, acrostichal setae; ad, anterodorsal; av, anteroventral; dc, dorsocentral setae; dv, dorsoventral; hm, postpronotal setae; National Park, notopleural setae; pa, postalar setae; $\mathrm{pd}$, posterodorsal; $\mathrm{pm}$, presutural supra-alar setae; ppl, proepisternal setae; pv, posteroventral; sa, postsutural supra-alar setae; sr, presutural intraalar setae; $\mathrm{t}$, tarsus; $\mathrm{t}_{1-5}$, tarsomeres 1 to 5 .

\section{KEY TOTHE DOLICHOPODIDAE OFTHE PILBARA REGION, WESTERN AUSTRALIA}

This key treats males of all species of Dolichopodidae known to occur in the Pilbara Region. Also included [within brackets] are widespread taxa currently unknown from the Pilbara but likely to occur there based on their presence in adjacent regions.

1. Vertex usually strongly excavated on either side of ocellar tubercle, or if weakly excavated, vein $M$ distinctly branched, with $M_{2}$ present at least as a fold on membrane; scutum short, about as wide as long; hypopygium exerted and distinctly pedunculate; posterior mesonotum never flattened.......... Sciapodinae

2

Vertex usually not excavated, vein $\mathrm{M}_{2}$ absent [also see couplet 3]; other characters various 13

2. Vein $\mathrm{M}_{2}$ absent, without fold or indication on membrane; dc setae strong on both sexes...... 3

Vein $\mathrm{M}_{2}$ present, even if as fold or indication on membrane; males with anterior dc often weak and hair-like.... .5

3. Vertex deeply excavated; ac setae present; base of hypopygium enclosed by segment 7; hypandrium narrow; epandrial lobe usually flattened and ovate; surstylus with 3-4 overlapping arms; cercus curved and tapering, phallus elongate, without dorsal angle; tibiae without major setae

Mesorhaga Schiner...... 
Vertex very shallowly excavated; ac very short or absent; hypopygium free from segment 7; lateral scutellar setae small or absent; cercus short and forked; male It ${ }_{1}$ with pale basoventral pile (Figures $2 \mathrm{c}-\mathrm{d}$ ).

Pilbara octava Bickel

4. Coxa I and femora yellow; cercus unbranched, as single tapering curved arm or distally expanded and truncate, and at most with shallow excavation; cercus clavate distally (no Figure)

Mesorhaga longipenis Bickel

Coxae and femora mostly dark brown-green; postvertical and antennal pedicel setae pale; lateral frons with pale hairs (Figure 2a) . Mesorhaga flavicoma Bickel

5. Arista usually apical on triangular 1st flagellomere and usually long, more than half body length; tibiae often with strong setae, especially TI; cross-vein $\mathrm{dm}$-cu often sinuous; cercus usually deeply forked; male frons often with hairs on lateral slope; pedicel often with long ventral and dorsal setae Chrysosoma Guérin-Méneville. ... 6

Arista usually distinctly dorsal on subrectangular 1st flagellomere, and rarely longer than head width; tibial chaetotaxy often weak, especially on males; $\mathrm{m}$-cu usually straight. .. 7

6. Male costa unmodified; TIII always with smooth black swollen callus at $1 / 5$, with posterior slit-like excavation; arista simple; FI usually with long pale ventral setae; IIt ${ }_{1-3}$ with curved av setae; IIt $_{4-5}$ unmodified; tergum 7 with long curved subapical setae (Figure 1d).. .Chrysosoma nobile Parent

Male costa with 1 or 2 rows of short curled, somewhat flattened setae; TIII sometimes with posterior callus; wing in both sexes with subapical spot or clouding; arista apical in males, but often distinctly dorsal arista in females; male arista and 1st flagellomere sometimes fused and flattened (monsoonal Australia, not Pilbara) ..

[Chrysosoma proliciens Group]

7. $\mathrm{M}_{2}$ arcuate and forming a broad U-shape with $\mathrm{M}_{1}$; male IIIt $_{3-5}$ usually flattened and pad-like ventrally; male often with crocheted cilia on costa; male TIII often with callus or irregularity.
$\mathrm{M}_{2}$ straight or curved, but usually not forming U-shape Figure with $\mathrm{M}_{1}$; male costa rarely with row of crocheted cilia; male TIII rarely with callus or irregularity; male $\mathrm{IIIt}_{3-5}$ sometimes flattened and pad-like. 10

8. Lateral scutellar setae reduced to tiny hairs or absent; legs without major setae; ac highly reduced or absent; 4 dc present, all strong; femora mostly bare. Pseudoparentia Bickel. 9

Lateral scutellars usually strong, more than $1 / 2$ length of medians; posterior two dc strong, anterior dc reduced to weak hairs; all tibiae brown to dark brown; TII and IIt without short porrect setae; FI with short pale av and pv setae; cercus with fan-shaped ventral projection which bears long marginal setae (Figure 1e).............Parentia vulgaris Bickel

9. Leg II tarsomeres 1-2 with dorsal groove with fine internal transverse banding, and tarsomeres 4-5 expanded as black flag; TIII near $1 / 2$ with posteroventral excavation with row of $4-5$ black posteroventral setae along excavation (MSSC); cercus with an elongate flagelliform arm. (Figures 3a-c)...

Pseudoparentia canalicula sp. nov.

Leg II unmodified; TIII near $1 / 2$ very slightly flattened and with small depression bare of vestiture just beyond $1 / 2$ (MSSC); IIIt $_{3-4}$ very slightly flattened; cercus enlarged and triangular, and with pale yellow setae (Figures 3d-e) ................... Pseudoparentia niharae sp. nov.

10. Dc setae all strong in both sexes; strong vertical setae present on both sexes; female FI usually with stout basoventral setae; face and clypeus wide; lateral scutellar setae present; rather stout bodied, cercus divided into distinct dorsal and ventral sections; antenna yellow; head and thoracic setae yellow (Figure 2b) .......

.Dytomyia flaviseta Bickel

Males with some anterior dc weak and hairlike; vertical setae in males usually strongly reduced, or lateral frons with dense hairs; female FI rarely with strong basoventral setae; male clypeus narrowed and free from eye margin; body sometimes appearing delicate, legs elongate and mostly yellow; tibia I with single strong curved posterior seta on apical quarter.

Ambylpsilopus Bigot. 
11. Male IIIt $_{3-5}$ flattened and pad-like; male with $4 \mathrm{dc}$, wing apex rounded, with large circular brown spot; vein $\mathrm{M}_{2}$ absent and $\mathrm{M}_{1}$ almost parallel with $\mathrm{R}_{4+5}$; cercus elongate with digitiform basal projection bearing strong pale setae (Figures $1 \mathrm{~b}-\mathrm{c}$ )

Ambylpsilopus putealis Bickel

Male IIIt unmodified; $5 \mathrm{dc}$ present with anterior three dc reduced to weak hairs; male wing unmodified 12

12. Arista apical or dorsoapical, length more than $2 \frac{1}{2}$ times head height; pair of long posterior setae arising from tergite 6 ; It $_{1}$ with strong basoventral seta; surstylus yellow; cercus with 3 distinctive leaf-shaped setae (Figures $1 \mathrm{f}-\mathrm{g}$ ) . Ambylpsilopus gressitti Bickel

Arista dorsal and never more than $1 \frac{1}{2}$ times head height; male abdominal segment 7 prolonged, longer than segment 6; hypopygium reduced in size, hypandrium with left lateral arm reduced or absent (Figure 1a) ........Ambylpsilopus fortescuia Bickel

13. Antennal scape with setae on dorsal surface; male hypopygium pedunculate and enlarged, and projecting forward under preabdomen; femora II and III with strong anterior preapical setae; all tibiae with strong setae; posterior mesonotum not flattened.

Dolichopodinae. 14

Antennal scapescape bare; without the above combination of characters. 19

14. Basitarsus III with strong dorsal seta; vein $\mathrm{M}$ with distinct break, joined by perpendicular "crossvein", from which stub veins project basad and distad; male tibia I with curved projecting posteroapical seta, about half length basitarsus I; terga 1 and 3-5 metallic green and with lateral ovate area of silvery pruinosity, tergum 2 laterally dark brown, without silvery pruinosity; postabdomen

[Dolichopus ziczac group of species]

Basitarsus III without dorsal setae; vein $\mathrm{M}$ unbroken; other features various 15

15. Vein $\mathrm{M}$ with gentle arch converging towards $\mathrm{R}_{4+5}$; clypeus usually rounded below, reaching eye margin; femur III with 4 anterodorsal setae in distal third; face with dense golden pruinosity; scape and pedicel yellow, first flagellomere black; scape distinctly longer than pedicel; coxa I dark brown; TI with strong pv setae; basitarsus I bare of setae but with yellow ventral pile

.[Tachytrechus tessellatus (Macquart)]
Vein $\mathrm{M}$ with strong, almost 45 degree bend towards $\mathrm{R}_{4+5}$ (e.g., Figure $4 \mathrm{f}$ ); clypeus with lower margin usually straight; femur III usually with 1 , rarely 2 , anterodorsal setae in distal third...

Paraclius Loew 16

16. Femora yellow 17

Femur III with distinct apical brown maculation; femur II with both strong posterior subapical seta and short pv seta... 18

17. Femur II withsingle strong anterior preapical seta but lacking posterior preapical seta, and with 2-3 strong ventral setae in basal fifth; anterior thorax with transverse matt brown band, followed posteriorly by silvery pruinose band; abdominal terga 1-5 dark green with lateral silvery pruinose patches; cercus triangular in shape (Figure 4e).... Paraclius sexmaculatus Bezzi

Femur II with 2 strong preapical anterior setae, shorter posterior seta at $4 / 5$, and with field of some 25-30 long anteroventral hairs from base to 3/5; mesonotum metallic bronze over ac band, over humeral area, and on lateral mesonotum; abdominal terga mostly dark metallic green with dusting of grey pruinosity; hypopygium (Figure 5a); epandrial lobe with modified forked seta at $1 / 3$; cercus rounded and tapering cone-like distally (Figures 4a, f) ... Paraclius trisetosus Parent

18. Femur III with brown infuscation only dorsoapically; first flagellomere almost ovate, and with subapical dorsal arista; hypopygium (Figure 5b); cercus rounded, ovate, shining black with only short setae (Figure $4 b$ ).

Paraclius obtusus Hardy

Femur III dark brown along distal third; first flagellomere rounded subtriangular, with apical arista; hypopygium (Figure 5c); cercus thick digitiform with abundant strong setae (Figures 4c-d) ............. Paraclius manglar sp. nov.

19. Posterior mesonotum distinctly flattened and slightly depressed, from one-third to one-half of surface between dorsocentral setae, and distinct from curved anterior mesonotum; dorsal postcranium usually distinctly concave; femur II and III bare of major anterior preapical setae; male genitalic capsule ovate to pyriform, on peduncle formed by exerted haired segment 7 Medeterinae. 
Posterior mesonotum not flattened, or at most only slightly flattened immediately anteriad of scutellum; dorsal postcranium flat or even slightly convex; other characters various

20. Wing vein $\mathrm{M}$ distinctly curving towards $R_{4+5}$ beyond $\mathrm{dm}-\mathrm{cu}$ crossvein, and $\mathrm{R}_{2+3}$ and $M$ nearly equidistant at level of crossvein $\mathrm{dm}-\mathrm{cu}$ and at wing apex; coxa III with one lateral seta; 2 strong dc bordering mesoscutal depression, strongly contrasting with short anterior setae; halter yellow; antenna entirely black; lateral scutellar setae $3 / 4$ length of medians (Figures $7 a-b$ )

Medetera junensis sp. nov.

$\mathrm{R}_{4+5}$ and M parallel to apex; coxa III with two lateral setae; femur II with strong posterior subapical seta.

21

21. Female oviscapt sclerotized, blade-like and laterally compressed; surstylus strongly deflexed, usually lying conformably with similarly deflexed cerci; $\mathrm{CuAx}$ ratio < 0.5, i.e., $\mathrm{dm}-\mathrm{cu}$ distant from posterior wing margin ... Thrypticus Gerstäcker ...................................... 22

Female oviscapt broad, cylindrical, with dorsal spines; $\mathrm{CuAx}$ ration $>0.5$, i.e., $\mathrm{dm}-\mathrm{cu}$ relatively close to posterior wing margin ......... Corindia Bickel ..... 23

22. Hypandrium beyond flexion triangular, broad basally, tapering distally, and heavily melanized; surstylus with 2 distal short setae and strong ventral seta at 2/3 (Figure 6a). Thrypticus australis Bickel

Hypandrium beyond flexion parallelsided, narrow, with only slight basal melanization; surstylus relatively long, as long as epandrium (no Figure) Thrypticus fortescuensis Bickel

23. Antenna entirely dark brown; hypopygium; all coxae, trochanters and femora brown; surstylus elongate and cleft distally, with curved dorsal outer arm and shorter ventral arm with apical setae; cercus comprising rounded setose basal mound from which projects distolateral arm bearing apical setae (Figures 6d-e).

[Corindia gascoynensis sp. nov.]

Antennal scape and pedicel yellow or redyellow; other features various
24. Body length $>2.0 \mathrm{~mm}$; coxa I and femora brown at least to apices (Figure 6b).

Corindia collessi Bickel

Body length $<1.5 \mathrm{~mm}$; coxa I and all femora mostly yellow (Figure 6c).

Corindia capricornis Bickel

25. Pair of large postvertical setae usually present on dorsal postcranium, out of line with the postorbital series; abdomen often dorsoventrally flattened; crossvein $\mathrm{dm}-\mathrm{cu}$ equal to or longer than distal section of $\mathrm{CuA}$; male face usually wide; fronto-clypeal suture distinct, at least laterally; clypeus usually produced anteriorly; palps usually large in both sexes, and covered with short setae; eyes pubescent; hypopygium encapsulated ventrally near at abdominal apex

Hydrophorinae.

Postvertical setae, if present, near vertex, and usually small; abdomen usually ovate, and rarely dorsoventrally flattened; other characters various 29

26. Acrostichal setae absent; coxa III with strong lateral seta; hypopygium cylindrical, projecting anteriorly under abdomen, and partially enclosed by postabdominal tergites; notopleuron with single strong seta; abdomen distinctly dorsoventrally flattened; palp often very large and triangular (e.g., Figure 8f) ........ Thinophilus Wahlberg ........................................ 27

Acrostichal setae distinctly present, even if very short; coxa III bare of major setae; hypopygium globular at apex of abdomen; male sternite 4 often forming hood for hypopygial apex; metanotum about twice as long as wide; other features various; femur I strongly swollen at base, usually with strong black ventral setae (Figure 6f).

.Hydrophorus praecox (Lehmann)

27. Femur I and tibia I with numerous long ventral hairs; surstylus elongate and tapering and subapically curved; cercus elongate and slightly clavate distally, and with white marginal and apical setae; small, body and wing length $<2.5 \mathrm{~mm}$ (Figures $8 \mathrm{c}-\mathrm{e}$ ) ...

....Thinophilus splendens Grootaert and Meuffels

Femur I and tibia I without long ventral hairs; body and wing length distally, and with white marginal and apical setae; small, body and wing length $>3.0$. 28 
28. Postabdominal tergal segments shining metallic blue/violet (in striking contrast to the anterior four abdominal terga); cerci large and curved, bladelike (Figures 8f-g).

..Thinophilus yarralolla sp. nov.

All abdominal terga metallic green with bronze reflections and covered with dense grey pruinosity; cercus narrow digitiform, white with pale white hairs; leg I tarsomere 1 with ventral row of 8 short erect peg-like black setae (Figures 8a-b) ........ Thinophilus eboricoxa sp. nov.

29. Hypopygium external, on elongate peduncle formed by segment 7; FII and FIII without anterior preapical setae; clypeus usually with four projecting seta, arista apical; male tergum 1 wide, and distinctly wider than thorax; small, less $1.3 \mathrm{~mm}$ in length; arista within distinct indentation on first flagellomere (Figures 7c-d) Acropsilus protractus Robinson

Hypopygium usually partially encapsulated by preceding abdominal segments; without remaining combination of characters .. 30

30. Femur II and/or III with distinct anterior preapical seta; antenna usually set high on head, about 1/4 distance from vertex; head various in anterior view, higher than wide; anal angle often reduced or lost; tibia I often with ad row of short setae (serration) on distal half... ..31

FII and FIII without anterior preapical seta, or such apparent preapicals indistinct from background setal field; antenna usually near middle of head, $2 / 5$ to $1 / 2$ distance from vertex; head almost circular in anterior view, about as wide as high; anal angle often well developed (both sexes); male tarsomere 5 sometimes with enlarged pulvilli; tibia I without ad setal serration ....

Diaphorinae..... . .41

31. Males with vein $M$ shortened and ending in the membrane halfway between the $\mathrm{dm}-\mathrm{cu}$ crossvein and the wing apex; head subcircular in anterior view, and slightly wider than high; coxae II and III mostly yellow; basal two thirds of FIII yellow; lower postorbitals yellow (Figure 12a). Phrudoneura collessi Bickel
Males with vein $M$ reaching wing margin near apex; head generally ovate in anterior view, distinctly higher than wide...

Sympycninae s.s..... 32

32. Male with leg III tarsomere 1 longer than tarsomere 2, and tarsomere 2 bearing digitiform projection (clidium) with diagnostic shape and setation....

Chaetopogonopteron de Meijere.... 33

Male with leg III tarsomere 1 usually shorter than tarsomere 2, and tarsomere 2 without digitiform projection........ Sympycnus Loew...35

33. Arista with flattened nodes at $2 / 3$ and apex; FI with short pale basoventral setae; tibia I with elongate median grove bearing silvery pruinosity; FIII with anterior subapical swollen

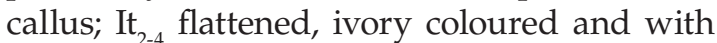
dorsal crest of ivory coloured hairs; frons with dense grey pruinosity (Figures 9a-b, e) ............ ... Chaetogonopteron bartaki Olejní ek and Kubík

Arista simple, unmodified; TI without groove, FIII without callus; other features various ....34

34. FI with swollen base with 2 long black ventral setae with some adjacent hairs at 1/10; tibia I bare; It $_{3-4}$ black and It $_{5}$ whitish; leg III tarsomere 1 with strong ventral seta, and tarsomere 2 with bent clidium bearing expanded apical seta (Figures 9d, g). ..Chaetogonopteron capricorne sp. nov.

FI with 3 short black ventral setae in basal fifth; tibia in apical half with distally increasing ventral setae; leg I tarsomeres 4-5 black expanded into apical flag; tibia II with ventral row of 15-18 long curved setae from $1 / 5$ to apex, and apically swollen with strong curved black apicoventral setae; TIII with long posterior seta near $1 / 2$ and distally with ventral row of curved overlapping yellowish setae (Figures 9c, f)

Chaetogonopteron vexillum sp. nov.

35. Crossvein $\mathrm{dm}-\mathrm{cu}$ perpendicular to long axis of wing, joining veins $\mathrm{M}$ and $\mathrm{CuA}$ at angle; males often with costa thickened to $R_{1}$.... [Teuchophorus Loew]

Crossvein $\mathrm{dm}-\mathrm{cu}$ oblique to long axis of wing, and joining veins $\mathrm{M}$ and $\mathrm{CuA}$ at almost right angles; males without thickened costa ... Sympycnus Loew 36 
36. Ac setae present, as apparent single row ..... 37

Ac setae absent 40

37. Male arista with widened apical flag; leg I tarsomere 1 with 2 strong ventral setae in basal third, and longer than distal leg I tarsomeres combined; femur II with 2-3 long pale ventral setae in basal quarter . 38

Male arista bare, not widened other features various

38. First flagellomere subtriangular; arista thin and with tear-shaped apical flag; leg I tarsomere 2 curved and flattened, with ventral concave excavation (Figures 10a-c)...... Sympycnus lacrimulus sp. nov.

First flagellomere prolonged and rather broad; arista thick with lanceolate apical flag; leg I tarsomere 2 unmodified (Figures 10d-f).

Sympycnus pistillus sp. nov.

39. Tibia I bare except for long curved apical ventral seta; anterior claw on leg I tarsomere 5 thickened and enlarged, recurved back on itself; large, body length $>2.5$ (Figures 12b-d).

Sympycnus hamulitarsus sp. nov.

Tibia I with ad serration of 3-4 short black setae in distal third, with curved subapical seta; claw on leg I unmodified; body length < $2.5 \mathrm{~mm}$ (Figures 11a-c)

Sympycnus ephydroides sp. nov.

40. Thorax with distinct metallic blue-violet band between dc rows; first flagellomere rounded and short; tibia I with strong ad setal serration along distal quarter; surstylus with broad expanded ventral lobe which bears 3 strong spine-like apical setae; cercus short and truncated (Figures 12e-g).

Sympycnus colliepa sp. nov.

Dorsal thorax uniformly brown with some metallic reflection; first flagellomere short triangular; tibia I with short weak ad serration on distal third; cercus elongate curved triangular, and tapering distally (Figures 11d-e)........ Sympycnus weano sp. nov.
41. Male eyes often dorsally holoptic, joined dorsally across head, covering frons; male face parallel-sided; males often with enlarged pulvilli on tarsus I; male abdominal sternite 8 often with four strong projecting setae; upper part of proepisternum with setae................. 42

Males not dorsally holoptic, frons wide and clearly visible; male face narrowed below or parallel-sided; male rarely with enlarged pulvilli; setae on male sternite 8 not stronger than those on tergite 6; upper part of proepisternum bare

Chrysotus Meigen

42. Costa not extending beyond tip of $\mathrm{R}_{4+5}$; distal vein $\mathrm{M}$ broken or weakened, with distal section often displaced; males frons wide, eyes not dorsally holoptic

[Asyndetus Loew]

Costa ending at apex of vein $M$; vein $M$ unbroken; wing veins $R_{4+5}$ and $M$ subparallel in both sexes

Diaphorus Meigen. 43

43. TIII distinctly yellow; TI dorsally bare; only tarsus I with enlarged pulvilli; lower calypter with fan of yellow setae; internal arm arising medially from ventral surstylar arm strongly curved, U-shaped; cercus short subtriangular (Figures 13a-b) ......... Diaphorus karijini sp. nov.

TIII distinctly brown or brownish; TI with distinct dorsal setae; both tarsi I and II have enlarged pulvilli, but tarsus III unmodified, with only short pulvilli; lower calypter with fan of black setae; internal arm arising medially from ventral surstylar arm only gently curved; cercus on "stalk" and projecting from epandrium (Figures 13c-e) ... Diaphorus garnetensis sp. nov.

44. First flagellomere asymmetrically cordate (MSSC), covered in short fine hairs; coxa I, femora, and tibiae pale yellow, FIII with 2 brownish av setae along distal fifth; halter pale yellow (Figures 14d-g).

Chrysotus austrotropicus sp. nov.

First flagellomere subrectangular; coxae and rest of legs dark brown; femur III with row of 7-10 strong setae along length; halter dark brown (Figures $14 \mathrm{a}-\mathrm{c}$ ).

Chrysotus pilbarenis sp. nov. 

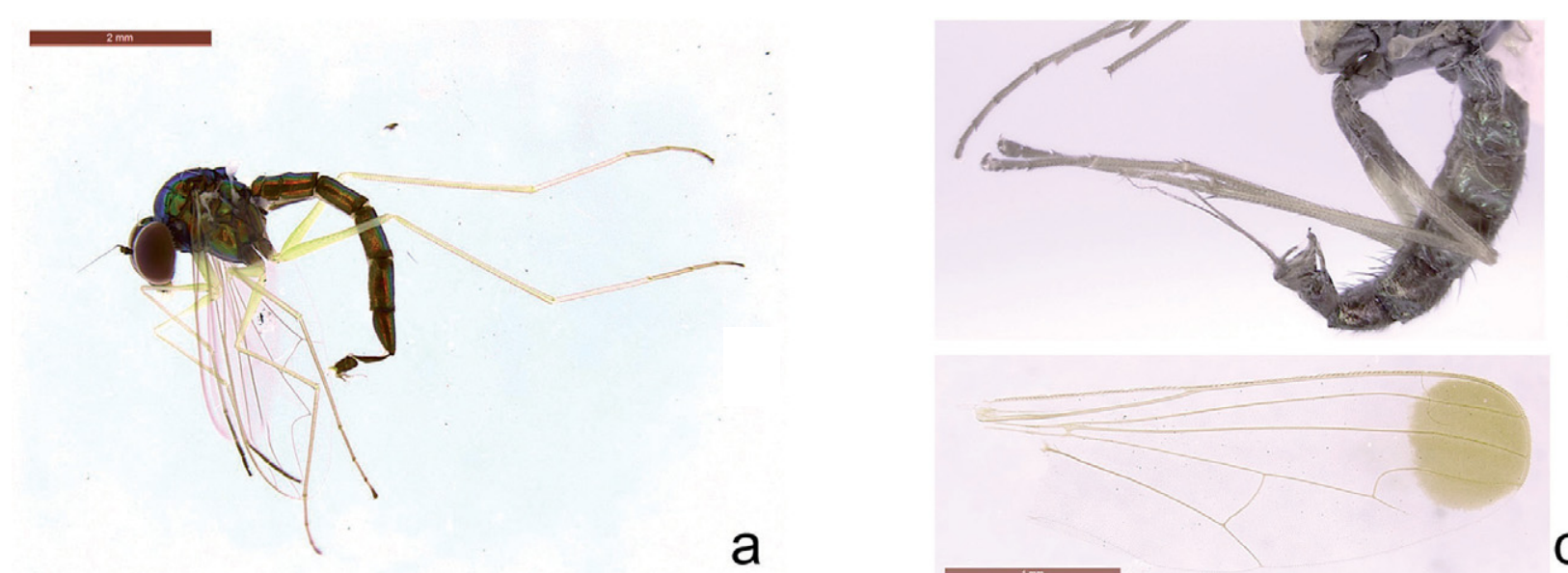

b

a
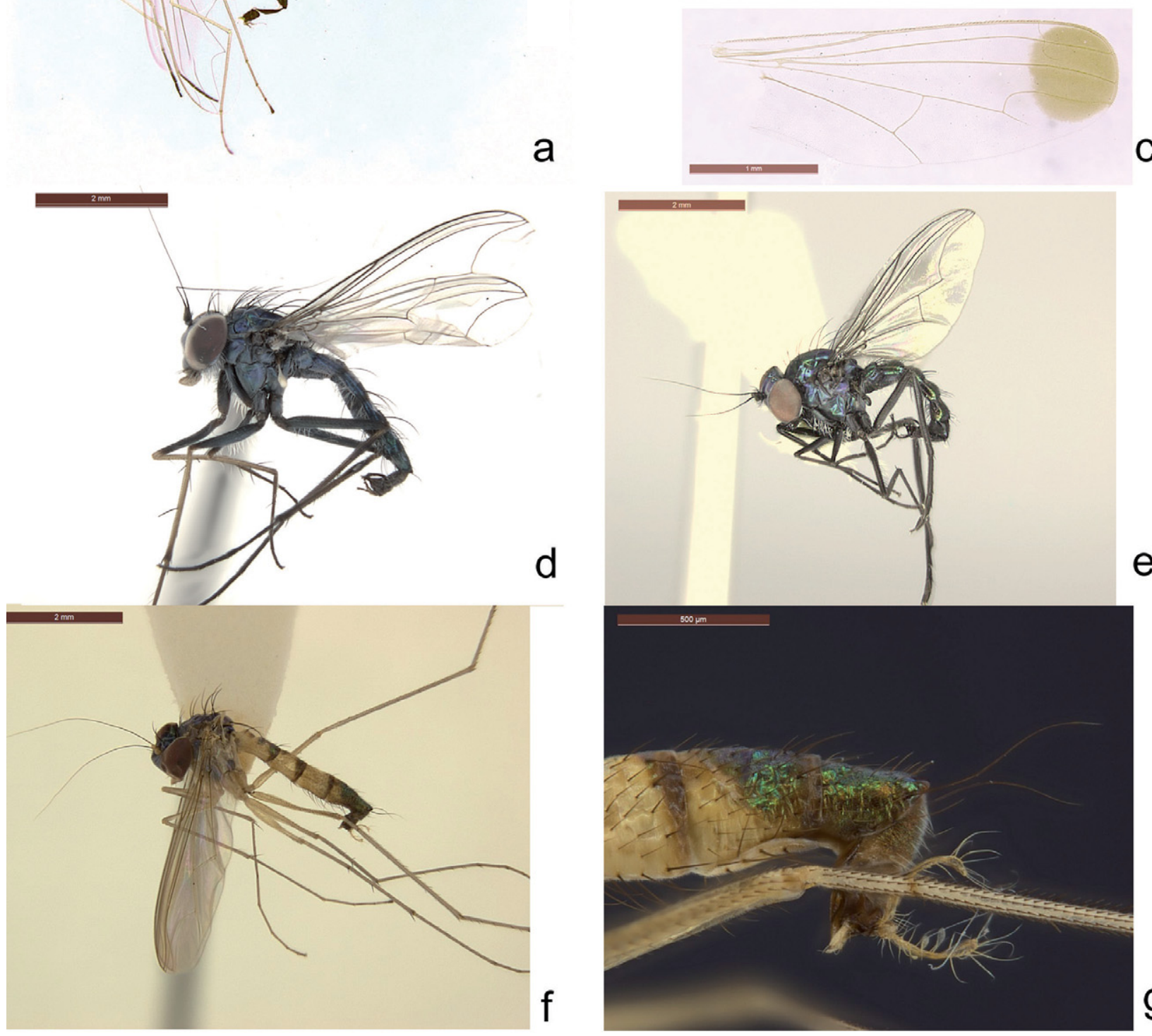

C

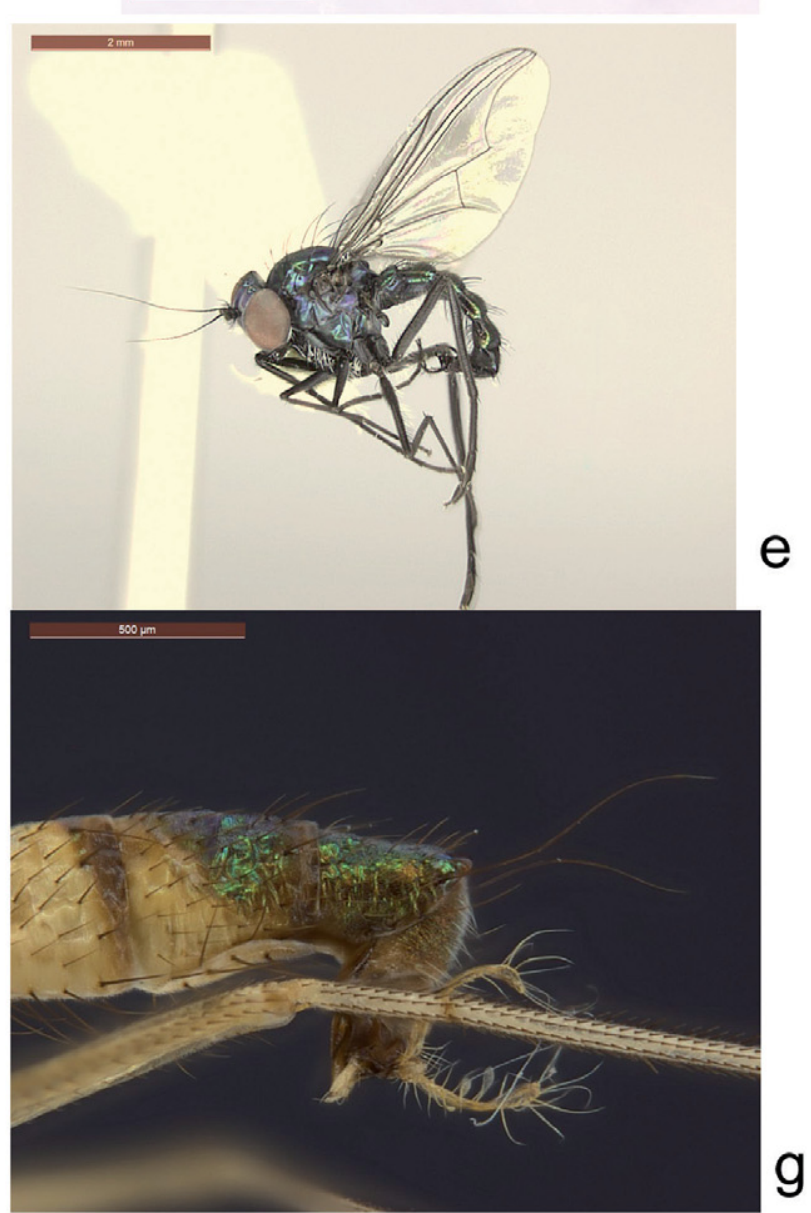
abdomen and hind legs, left lateral; c. male wing, dorsal. Chrysosoma nobile Parent: d. male habitus, left lateral. Parentia vulgaris Bickel: e. male habitus, left lateral. Amblypsilopus gressitti Bickel: a. male habitus, left lateral; b. male postabdomen, left lateral. 

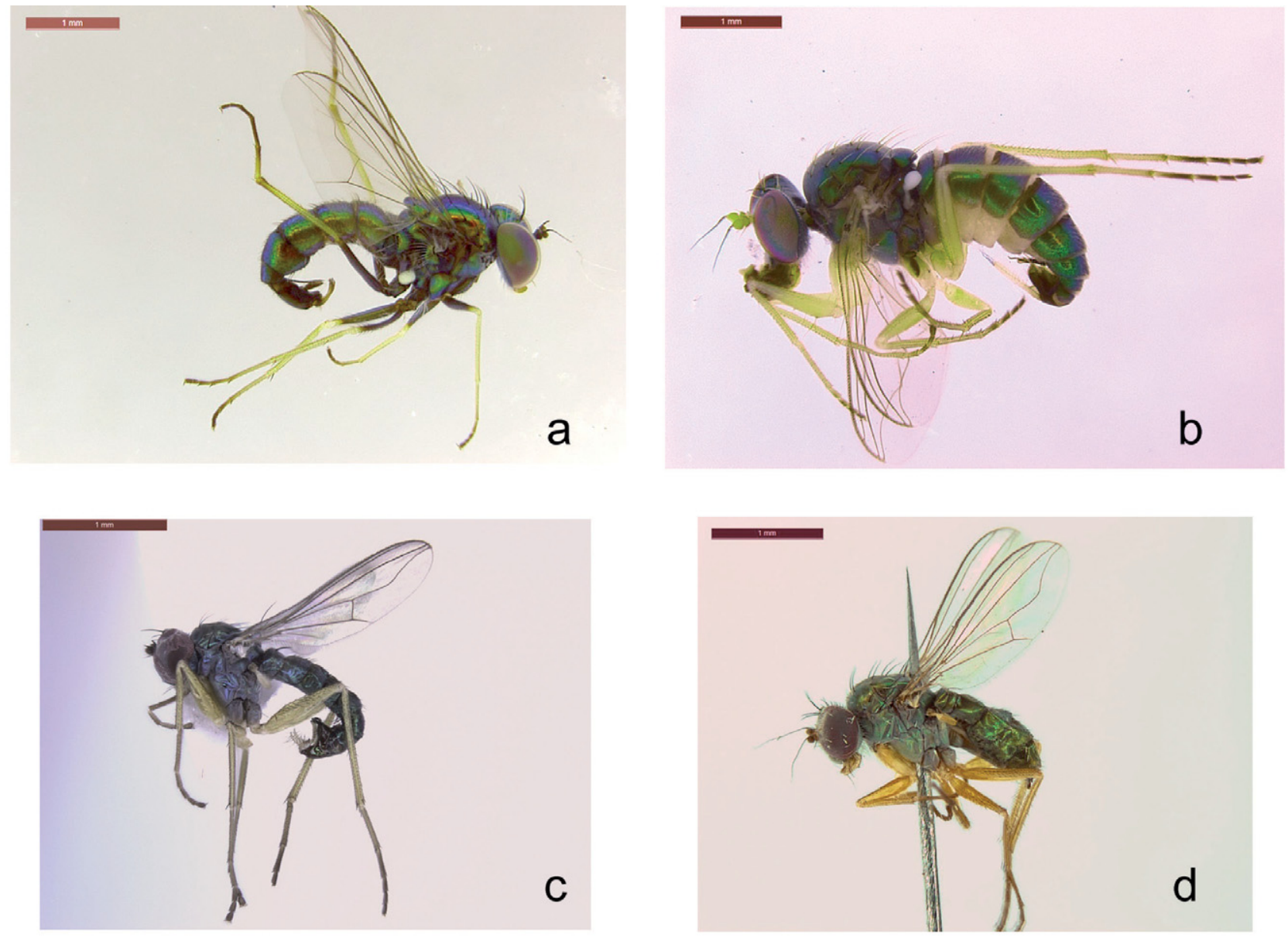
lateral. Pilbara octava Bickel: c. male habitus, left lateral. d. female habitus, left lateral. 


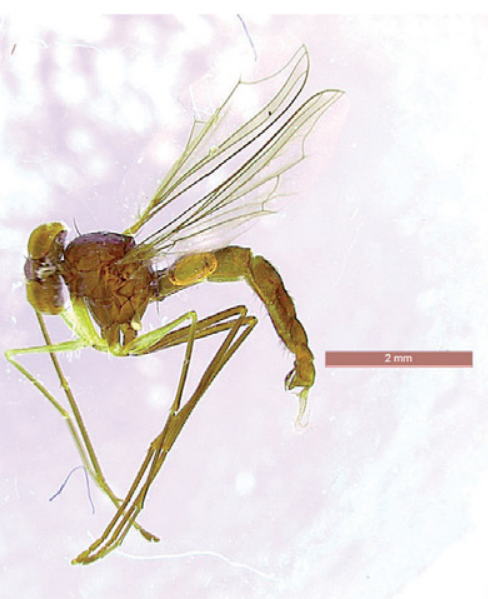

a
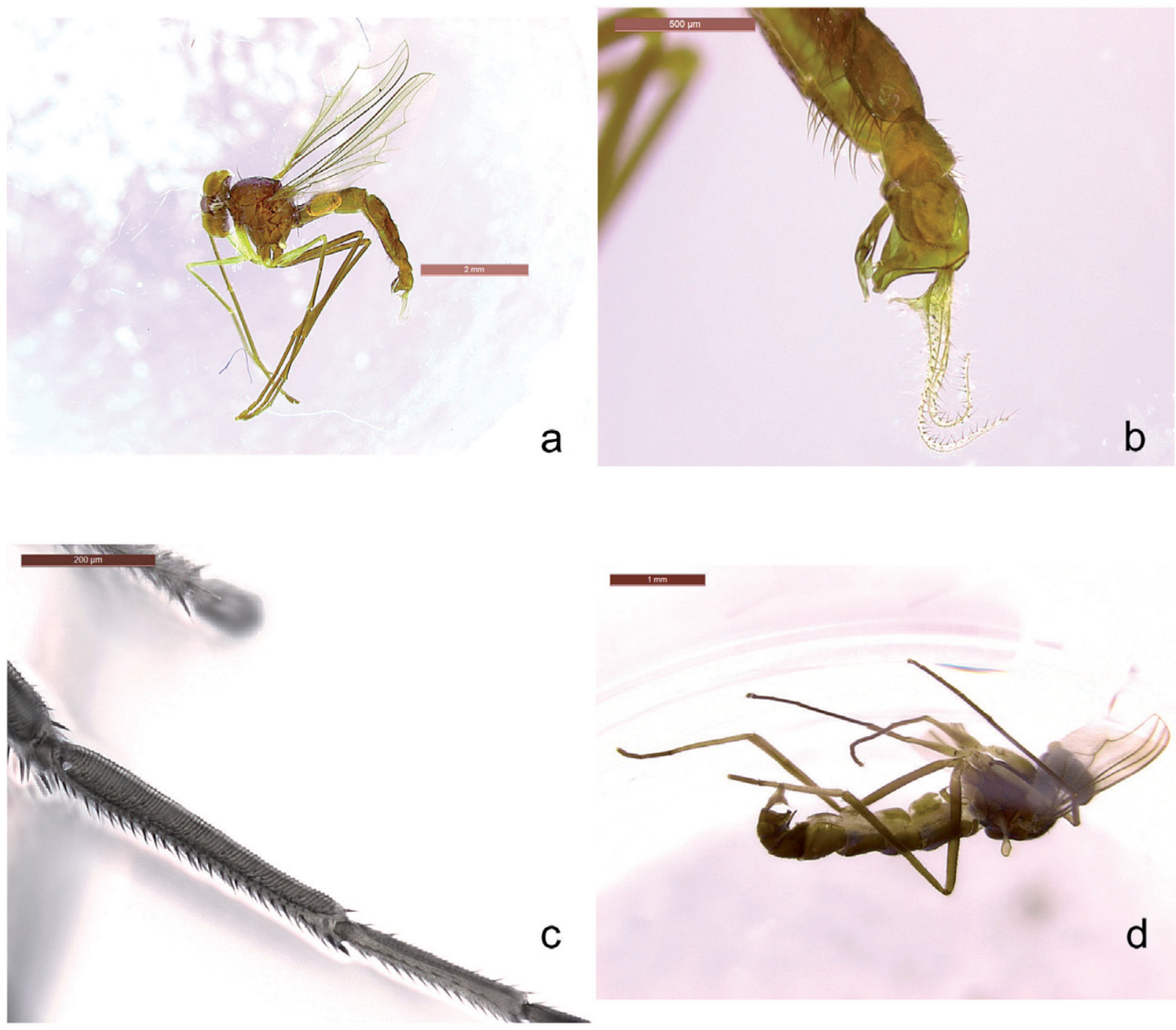

d

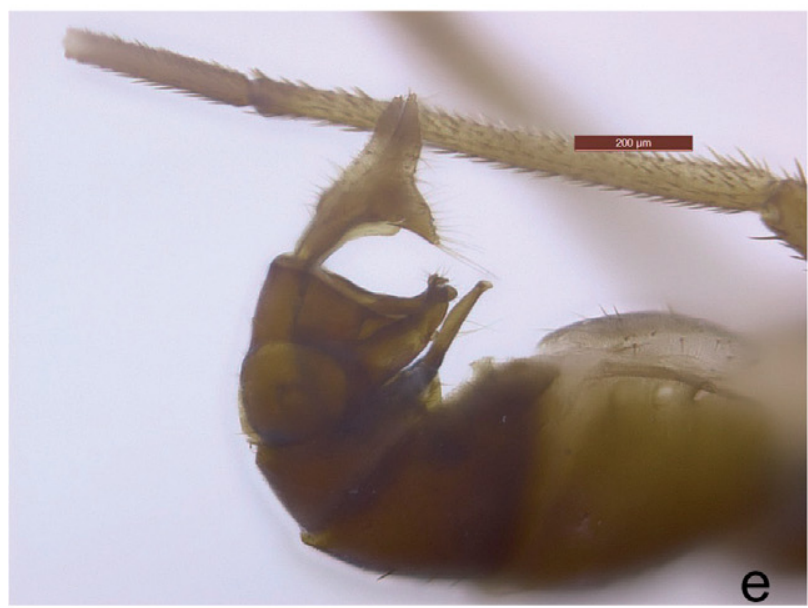

FIGURE 3

Pseudoparentia canalicula sp. nov.: a. male habitus, left lateral; b. male postabdomen, left lateral; c. male leg II tarsomeres 1-2, dorsal; Pseudoparentia niharae sp. nov.: d. male habitus, left lateral. e. male postabdomen, left lateral. 

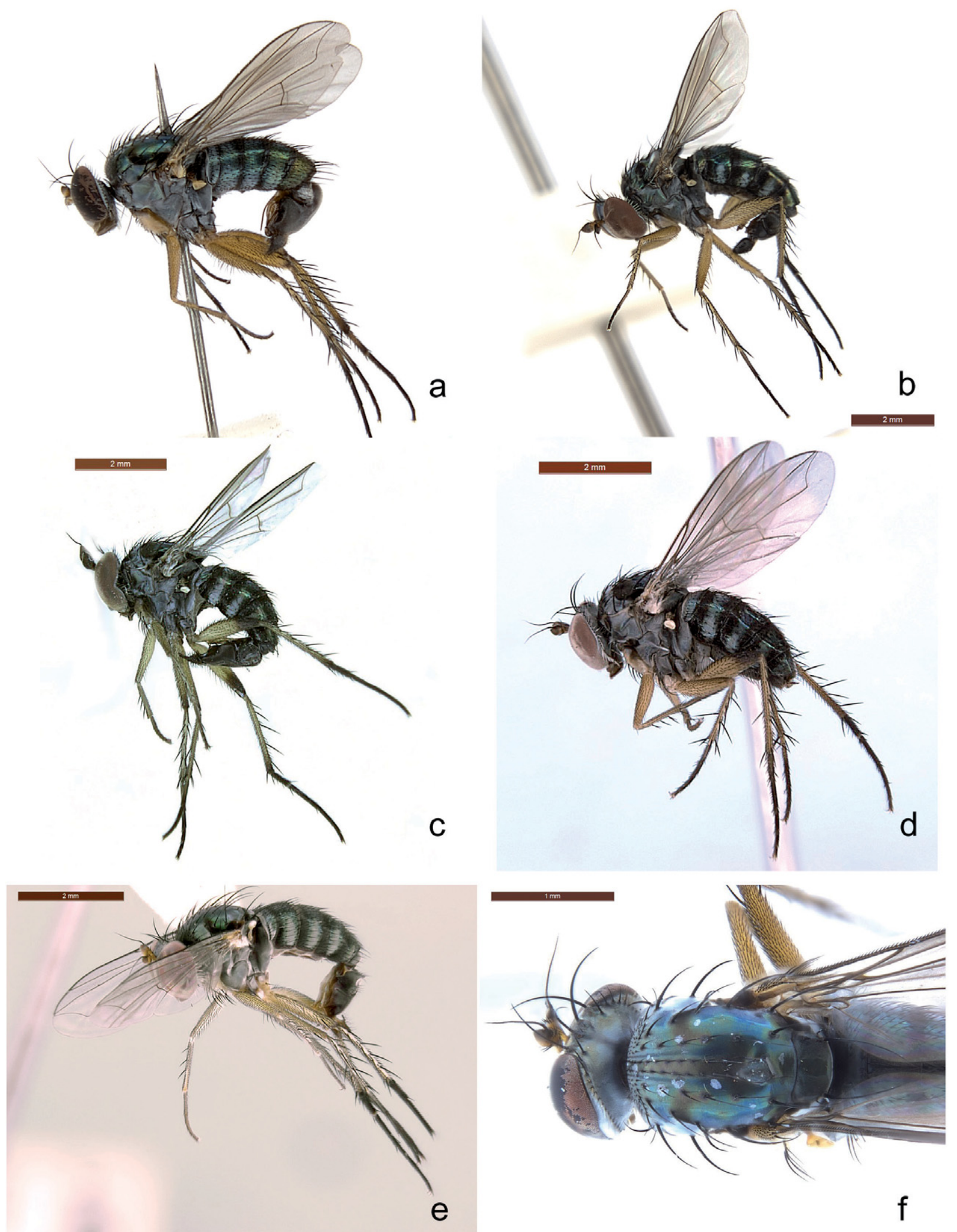

FIGURE 4

Paraclius trisetosus Parent: a. male habitus, left lateral; f. male thorax, dorsal. Paraclius obtusus Hardy: b. male habitus, left lateral. Paraclius manglar sp. nov.: c. male habitus, left lateral; d. female habitus, left lateral. Paraclius sexmaculatus Bezzi: e. habitus, left lateral. 


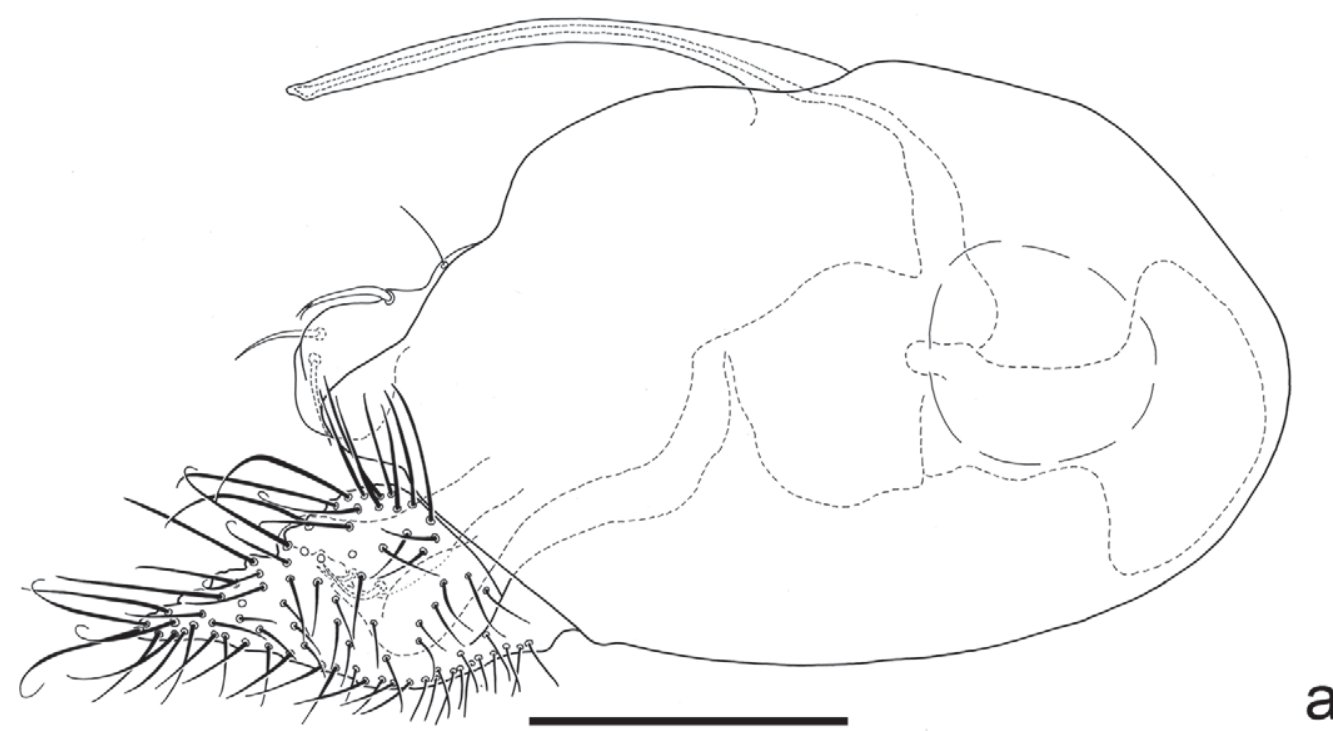

a

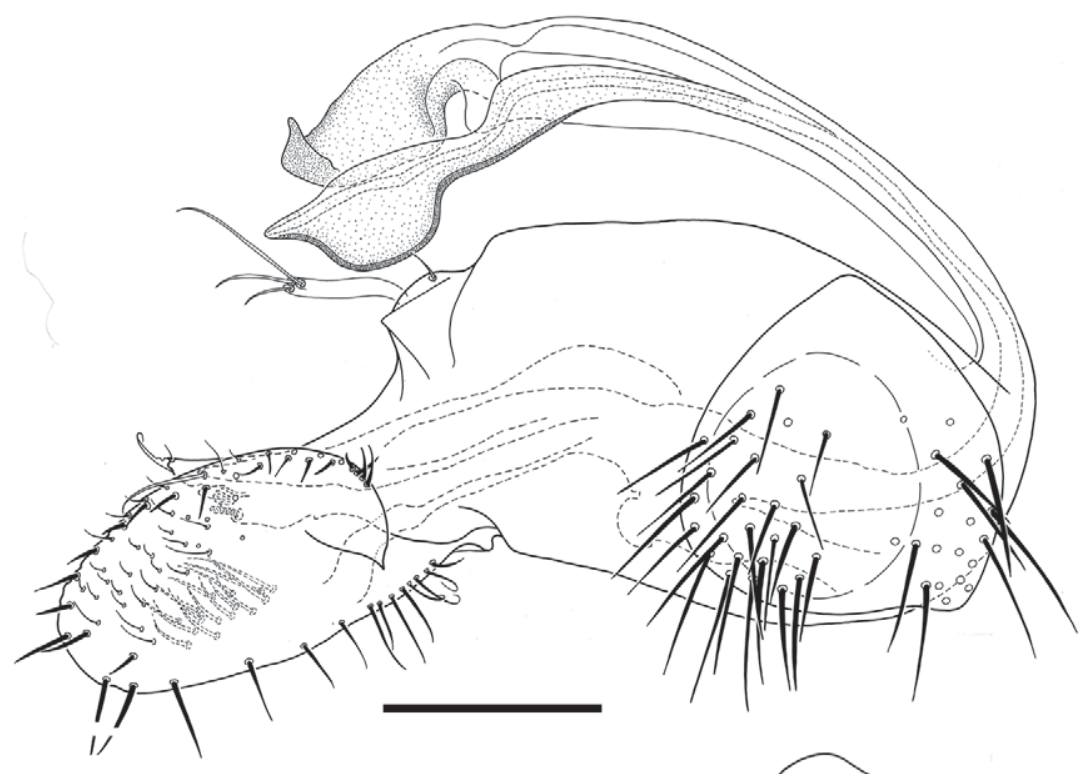

b

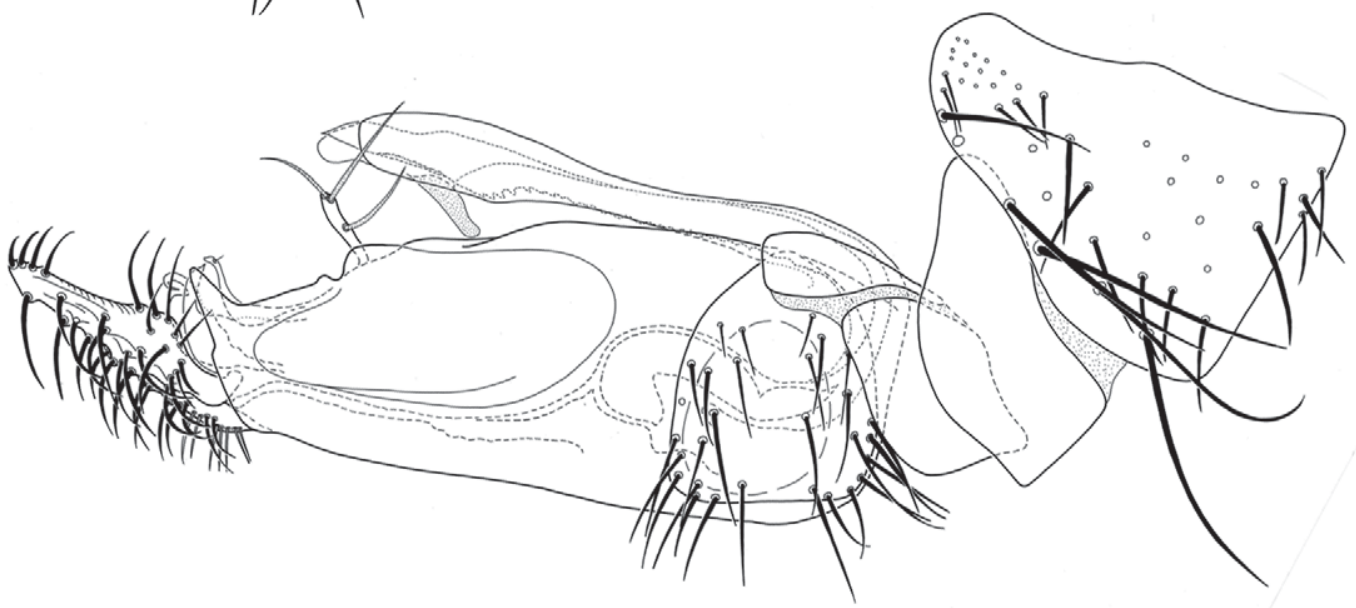

C hypopygium, left lateral. Paraclius manglar sp. nov.: c. male postabdomen, left lateral. Scale $=0.4 \mathrm{~mm}$ 


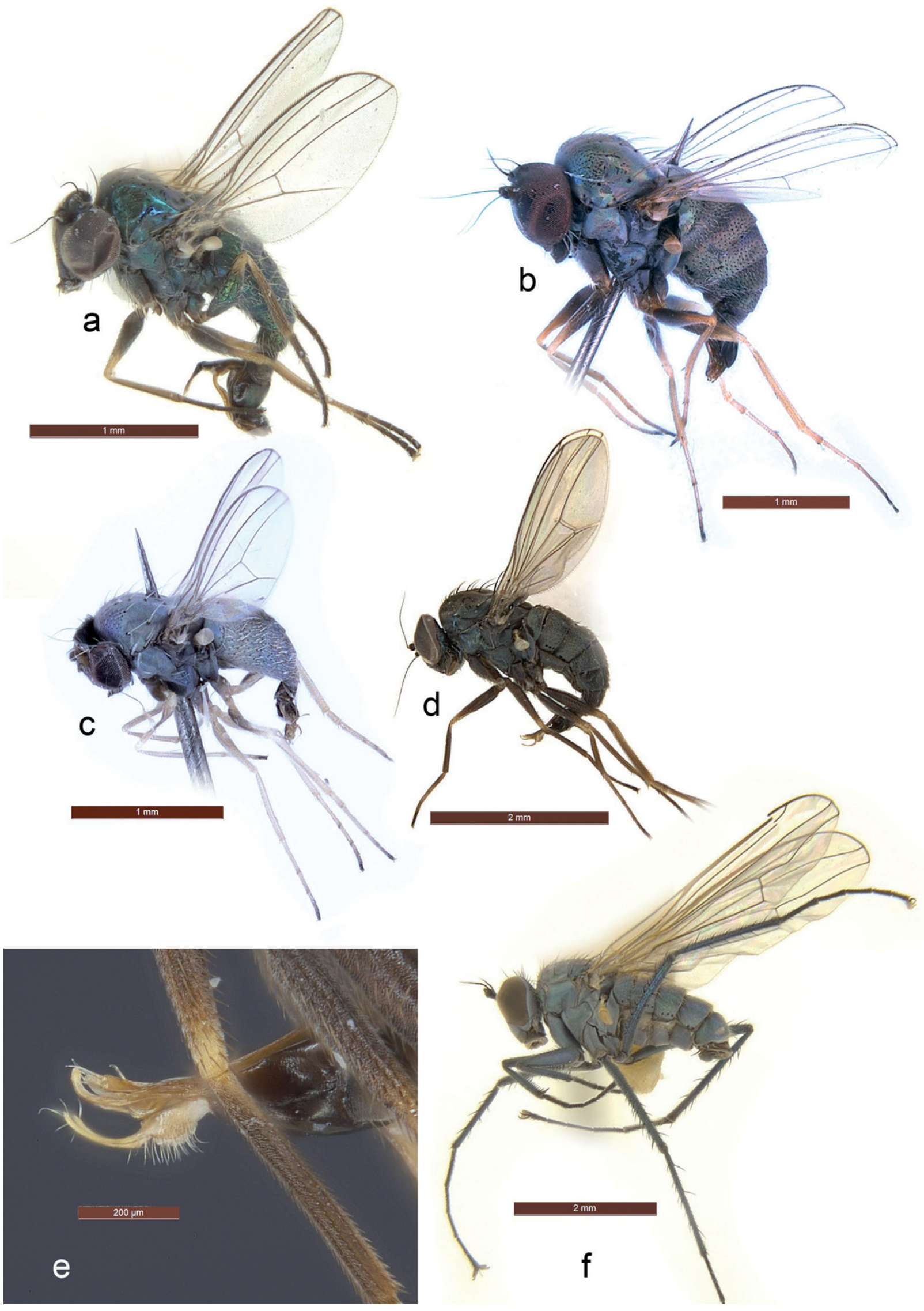

FIGURE 6

Thrypticus australis Bickel: a. male habitus, left lateral. Corindia collessi Bickel: b. male habitus, left lateral. Corindia capricornis Bickel: c. male habitus, left lateral. Corindia gascoynensis Bickel: d. male habitus, left lateral; e. male postabdomen, left lateral. Hydrophorus sp.: f. male habitus, left lateral. 

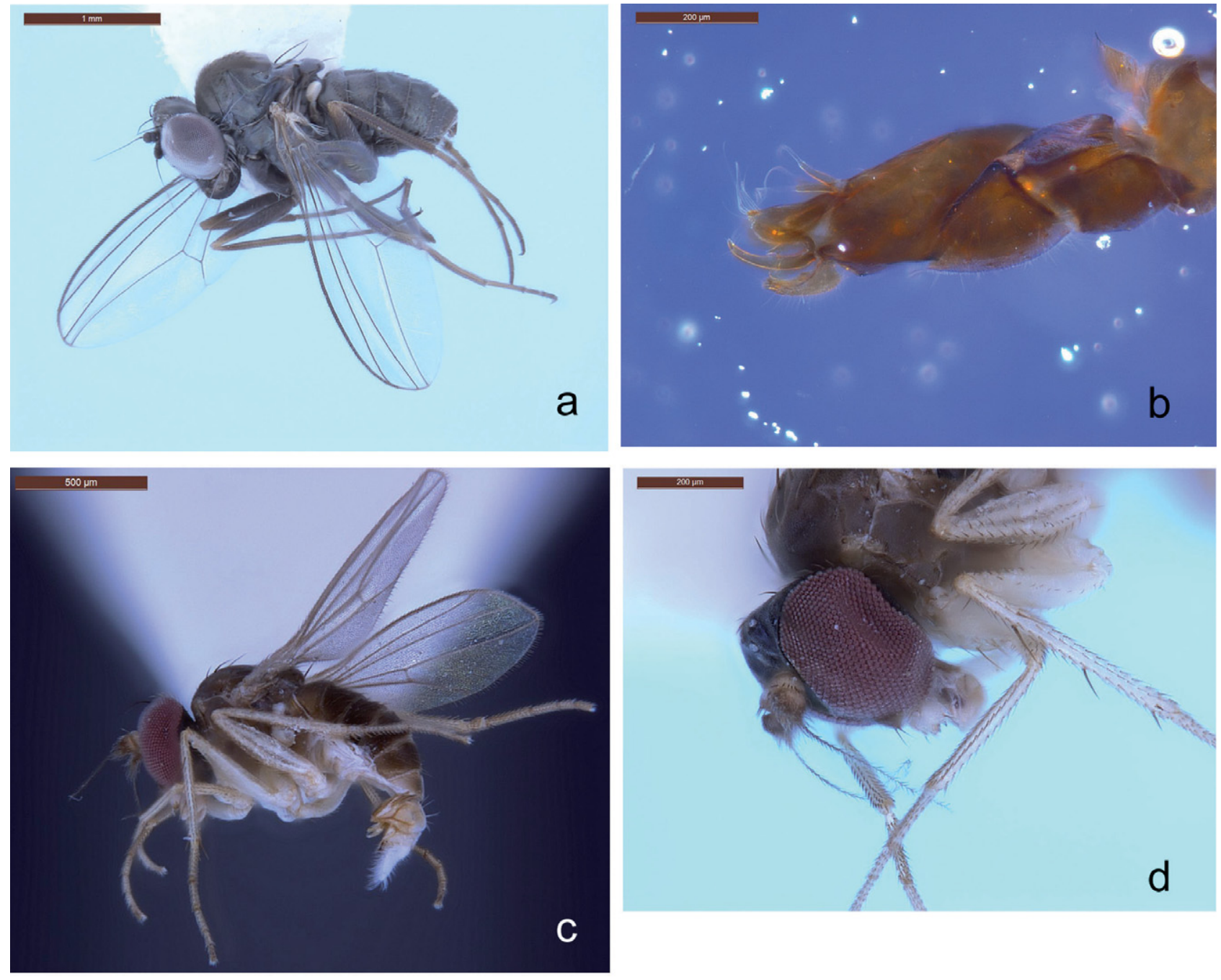

C 

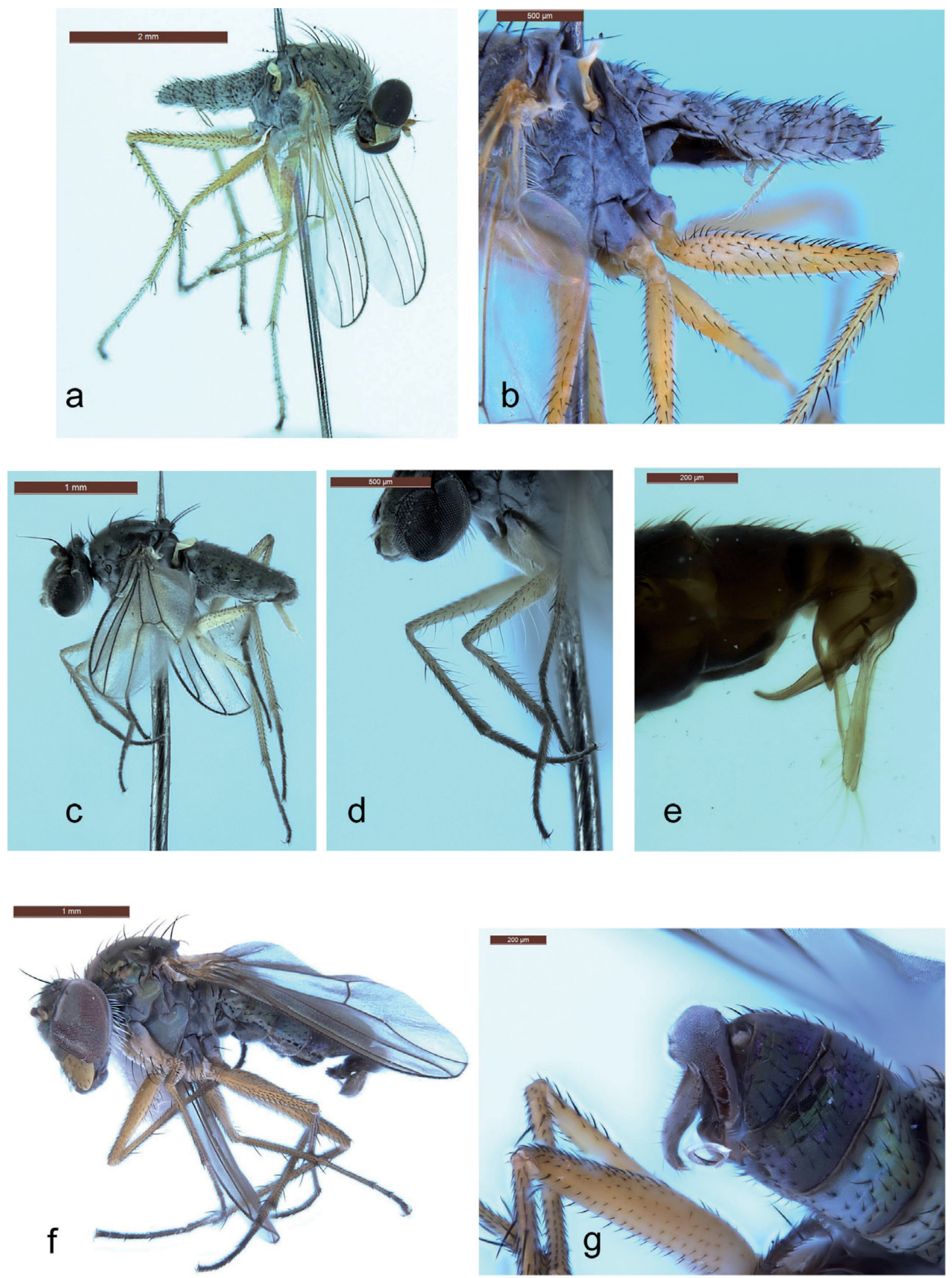

FIGURE 8

Thinophilus eboricoxa sp. nov:: a. male habitus, right lateral; b. male postabdomen, left lateral. Thinophilus splendens Grootaert and Meuffels: c. male habitus, left lateral; d. male forelegs and head, left lateral; e. male postabdomen, left lateral. Thinophilus yarraloola sp. nov.: f. male habitus, right lateral; g. male postabdomen, right lateral. 


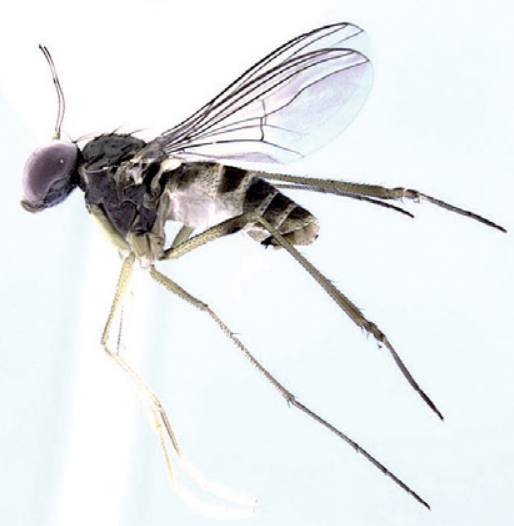

a
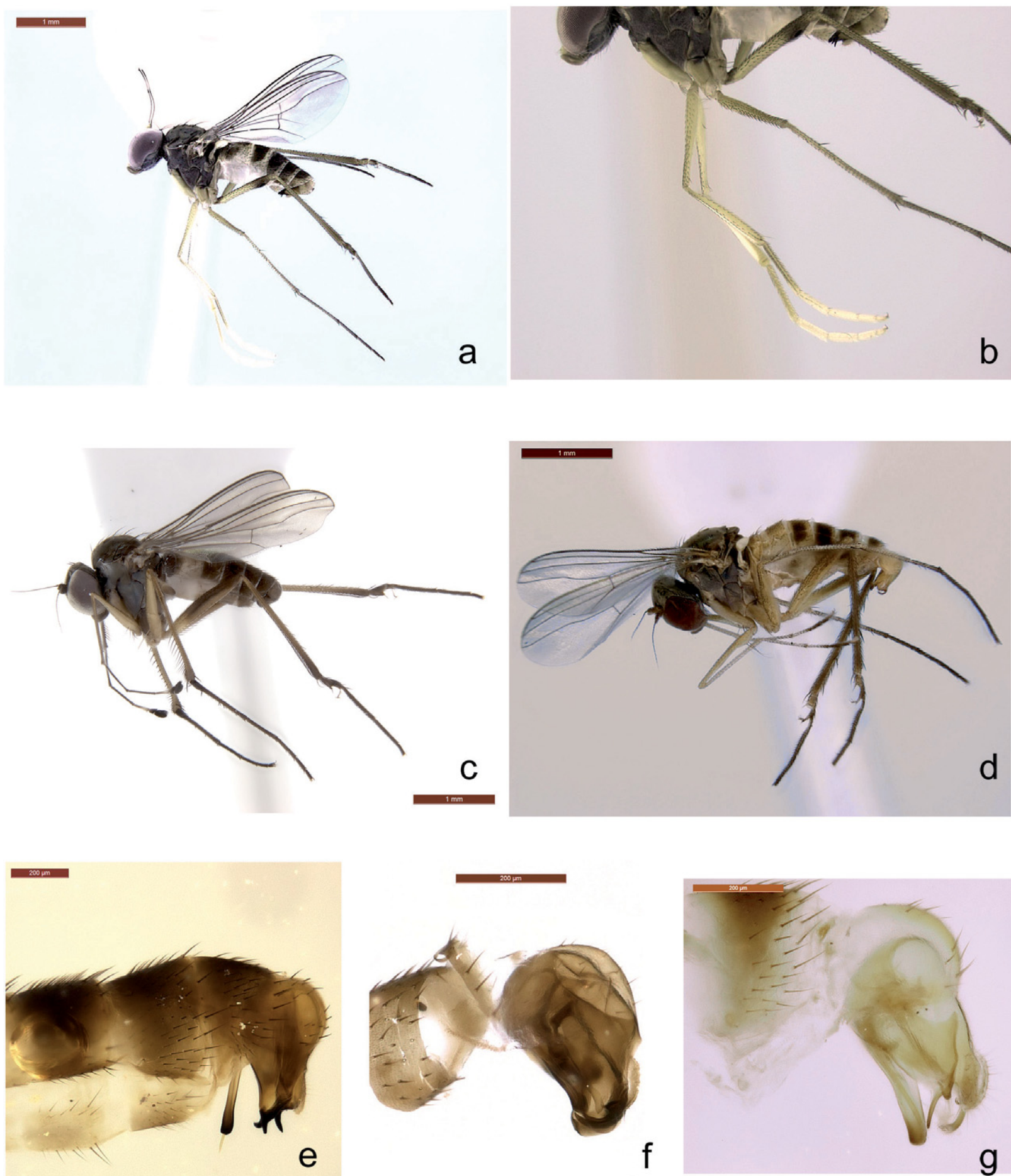

FIGURE 9

Chaetogonopteron bartaki Olejníček and Kubík: a. male habitus, left lateral; b. male legs, left lateral; e. male postabdomen, left lateral. Chaetogonopteron vexillum sp. nov.: c. male habitus, left lateral; f. male hypopygium, left lateral. Chaetogonopteron capricorne sp. nov.: d. male habitus, left lateral; g. male hypopygium, left lateral. 

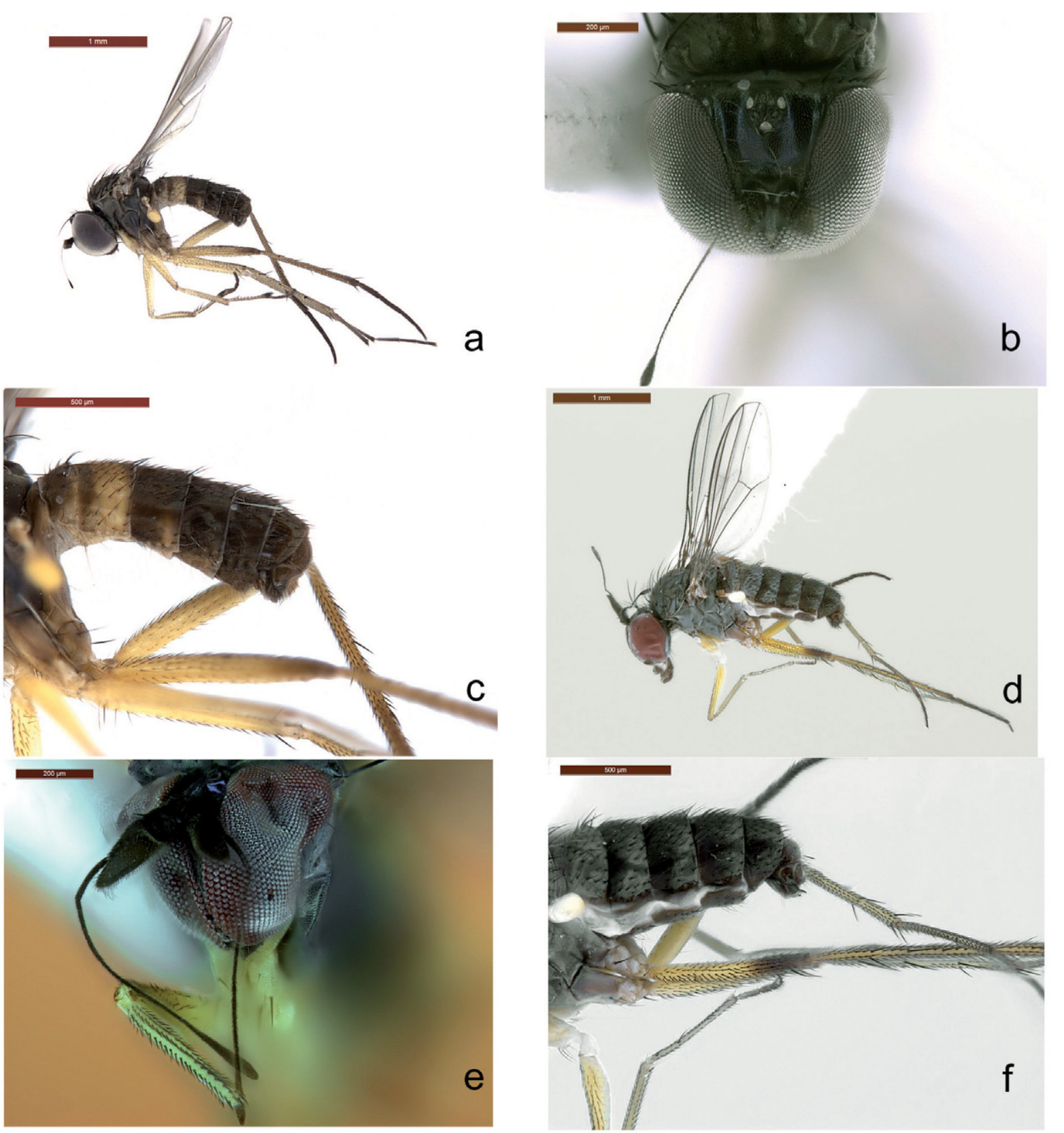

FIGURE 10

Sympycnus lacrimulus sp. nov.: a. male habitus, left lateral; b. male head and arista, anterodorsal; c. male postabdomen, left lateral. Sympycnus pistillus sp. nov.: d. male habitus, left; e. male head, anterodorsal; f. male postabdomen, left lateral. 

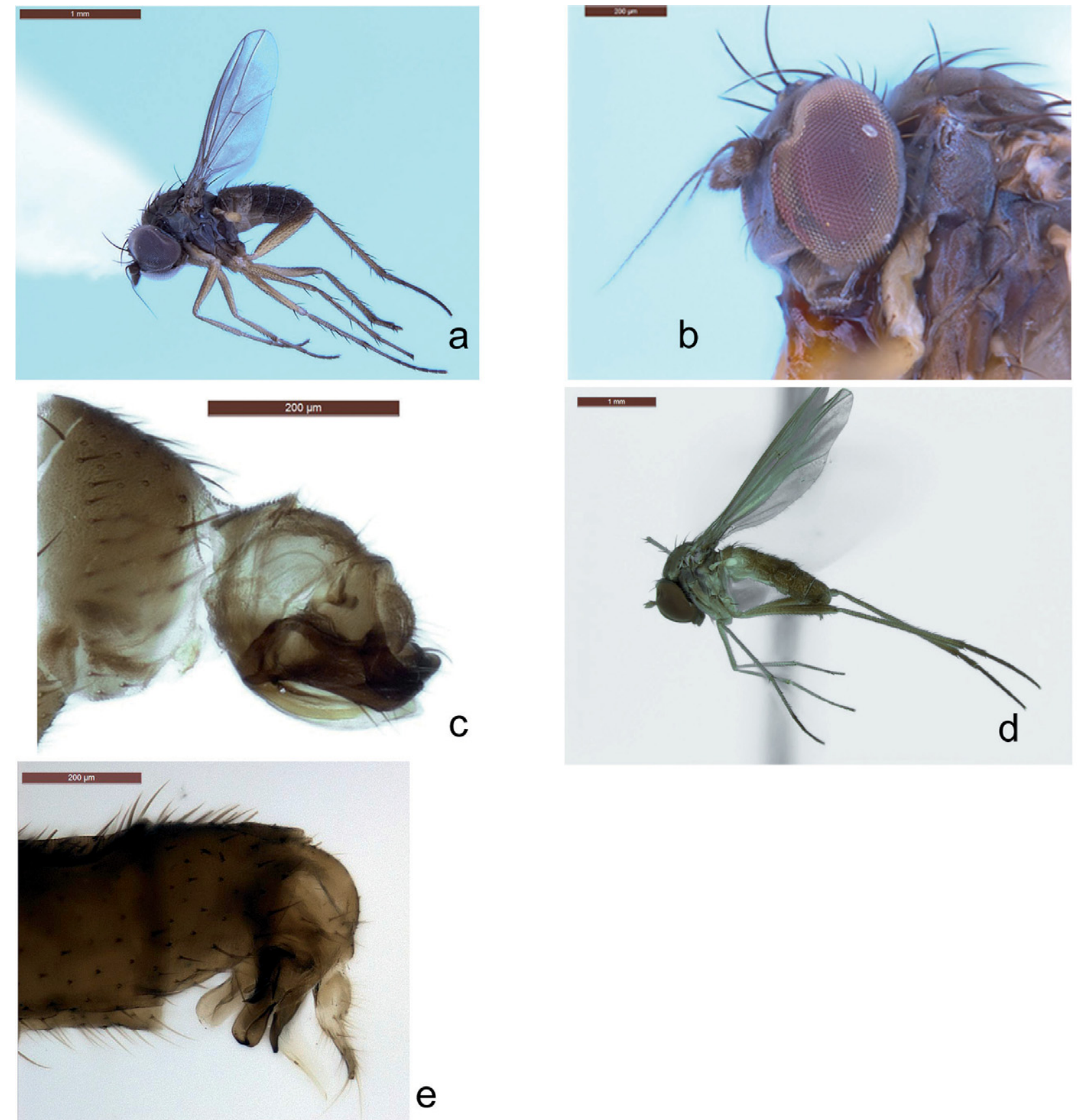

FIGURE 11

Sympycnus ephydroides sp. nov.: a. male habitus, left lateral; b. female head, left anterior; c. male hypopygium, left lateral. Sympycnus weano sp. nov.: d. male habitus, left lateral; e. male postabdomen, left lateral. 


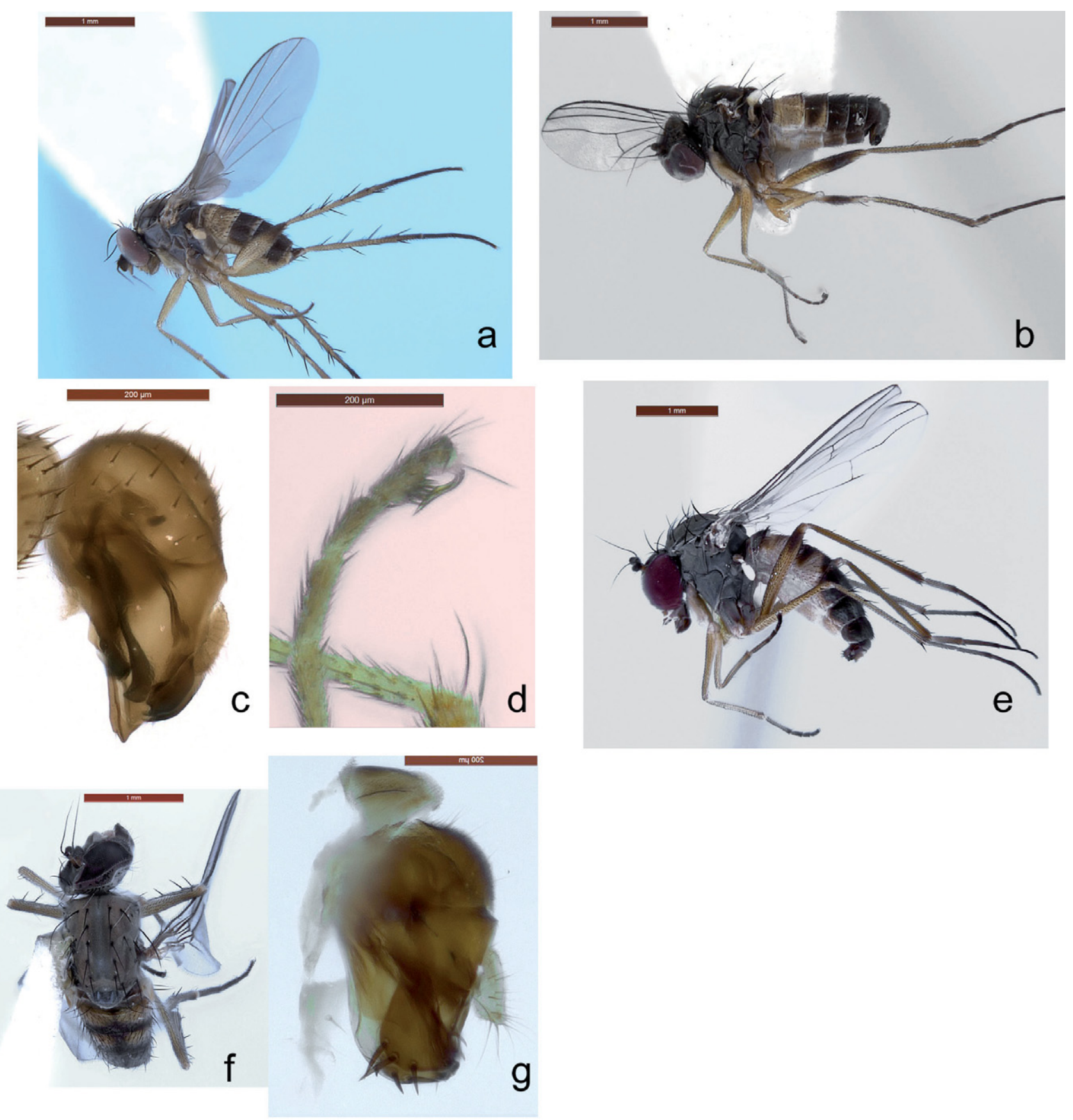
habitus, left lateral; c. male hypopygium, left lateral; d. male tarsus I, left lateral. Sympycnus colliepa sp. nov.: e. male habitus, left lateral; f. female thorax and head, dorsal; g. male hypopygium, left lateral. 

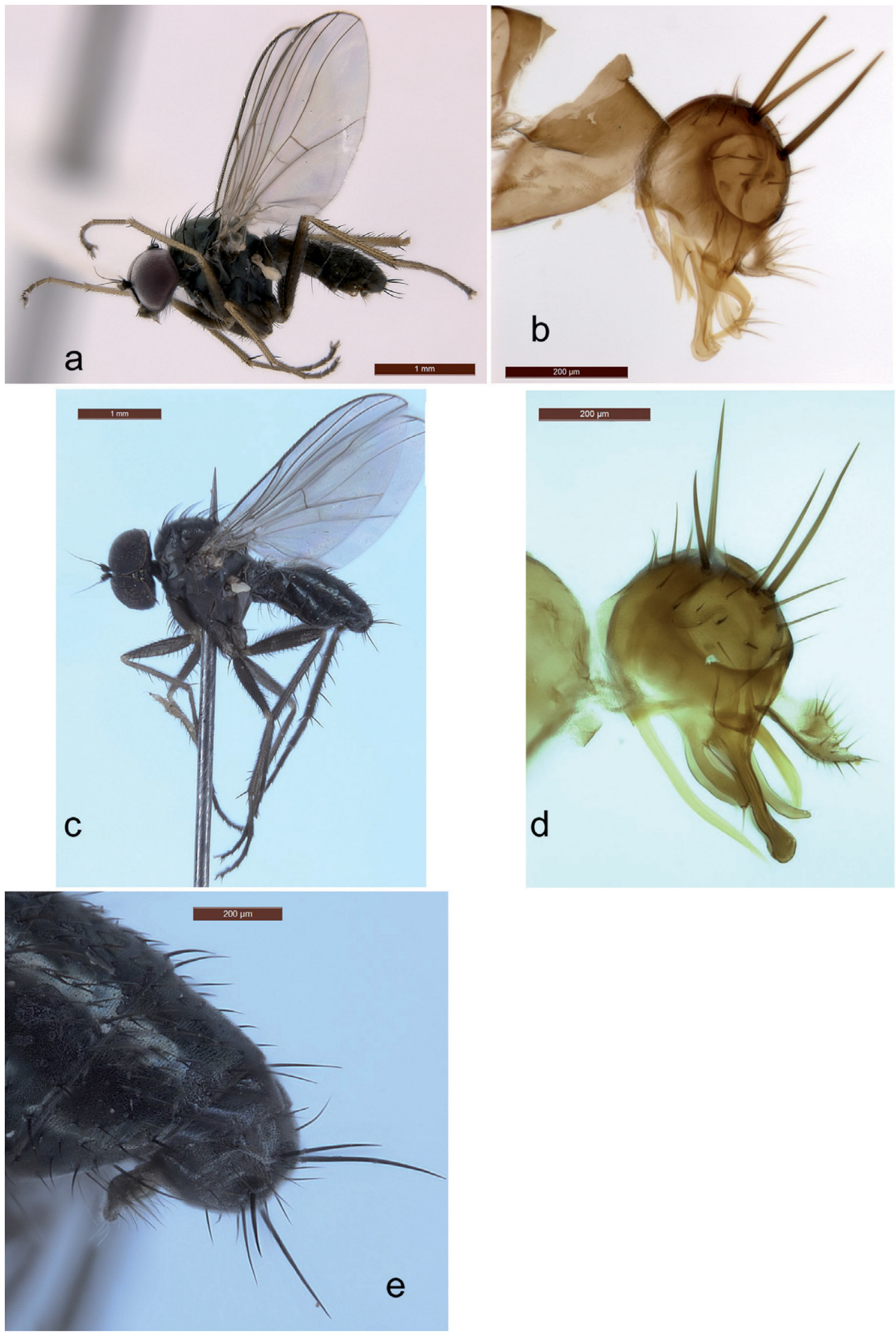

FIGURE 13

Diaphorus karijini sp. nov.: a. male habitus, left lateral; b. male hypopygium, left lateral; Diaphorus garnetensis sp. nov.: c. male habitus, left lateral; d. male postabdomen, left lateral; e. male hypopygium, left lateral. 

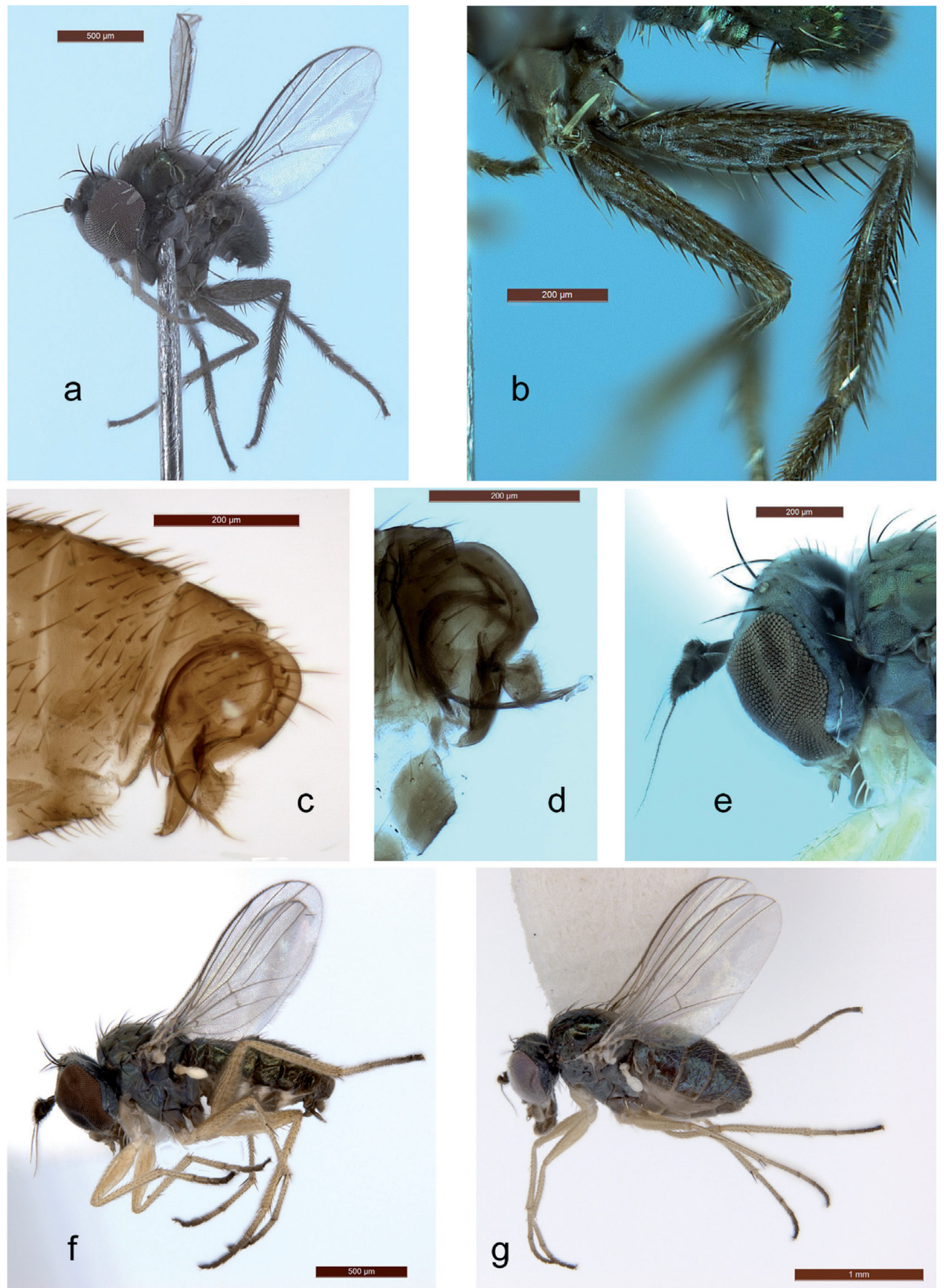

FIGURE 14

Chrysotus pilbarensis sp. nov.: a. male habitus, left anterior; b. male left femora II and III, anterior; c. male postabdomen, left lateral. Chrysotus austrotropicus sp. nov.: d. male hypopygium, left lateral; e. male head, left lateral; f. male habitus, left lateral; g. female habitus, left lateral. 


\section{TAXONOMY}

Family Dolichopodidae Latreille, 1809

Subfamily Sciapodinae Zeller, 1842

\section{REMARKS}

The Sciapodinae are one of the more cohesive dolichopodid subfamilies, often readily identified by the branched vein $\mathrm{M}$ and excavated vertex. These small, metallic green flies with their "swept-back" wings are frequently seen running on foliage in sunny moist habitats, making them familiar by sight even to casual observers. Sciapodines are often abundant and can form a conspicuous component of Malaise trap catches from warm mesic forests. The Australian fauna was treated in Bickel (1994).

\section{Genus Mesorhaga Schiner, 1868}

\section{REMARKS}

Mesorhaga is a near cosmopolitan genus recognized by a combination of distinctive venation and male postabdominal structure. The unbranched and curved vein $\mathrm{M}$ of Mesorhaga has been used as a key character for the genus, although some other sciapodines, such as the genus Pilbara, treated here, also have vein $\mathrm{M}$ unbranched. The Australian fauna comprises 31 species, and the genus is particularly rich in Western Australia, but most species are known only from their type localities. However, one of species treated here, M. flavicoma, is widely distributed across arid Australia.

\section{Mesorhaga flavicoma Bickel, 1984}

Figure 2a

Mesorhaga flavicoma Bickel 1984: 81.

MATERIAL EXAMINED

\section{Additional records}

Australia: Western Australia: MillstreamChichester National Park: 3 우 Roebourne Rd, $21^{\circ} 26^{\prime} 29^{\prime \prime} \mathrm{S}, 117^{\circ} 09^{\prime} 28^{\prime \prime} \mathrm{E}$, sandy creek: $337 \mathrm{~m}$, Eucalyptus/spinifex grassland 27 April-3 May 2003, Lambkin and Weir, Malaise trap; 10 , Yarraloola Rd, Fortescue River $21^{\circ} 37^{\prime} 38^{\prime \prime}$ S, $117^{\circ} 07^{\prime} 27^{\prime \prime}$ E, 28 April-3 May 2003, Malaise trap, creek with drying pools, Lambkin and Weir (ANIC).

\section{REMARKS}

Mesorhaga flavicoma is a distinctive species that occurs across much of arid interior Australia, including the Kimberley Ranges of Western Australia, South Australia, Northern Territory and
Queensland, as well as the large sandy islands off south-eastern Queensland. These are the first records from the Pilbara. The postvertical setae of both sexes are white.

\section{Mesorhaga longipenis Bickel, 1994}

Mesorhaga longipenis Bickel 1994: 68.

\section{MATERIAL EXAMINED}

\section{Additional records}

Australia: Western Australia: $1 \hat{\delta}$, MillstreamChichester National Park, McKenzie Spring, $21^{\circ} 20^{\prime} 18^{\prime \prime} \mathrm{S}, 117^{\circ} 12^{\prime} 38^{\prime \prime} \mathrm{E}$, Malaise over spring, rocky ravine, 299 m, 7-12 May 2003, Lambkin, Yeates and Recsei, (ANIC 2126); 1 đ̃, Karijini National Park, Juna Downs Rd, 22 $41^{\prime} 57^{\prime \prime} S, 118^{\circ} 25^{\prime} 06^{\prime \prime}$, Malaise trap between drying pools in rocky Turee Creek, 789 m, 19-25 April 2003, Lambkin and Weir (ANIC 2059).

\section{REMARKS}

Mesorhaga longipenis is known only from the Kimberleys and Pilbara area, Western Australia, and the holotype was described from Millstream. It has an elongate phallus which, when extended, projects well beyond the apex of the hypopygium (see Figures 19d-e, Bickel 1994).

\section{Genus Dytomyia Bickel, 1994}

\section{REMARKS}

Dytomyia is a small but distinctive genus from Australia and New Guinea adapted to monsoonal and semi-arid habitats, and is sometimes found on tree trunks.

\section{Dytomyia flaviseta Bickel, 1994}

Figure $2 b$

Dytomyia flaviseta Bickel 1994: 98.

\section{MATERIAL EXAMINED}

\section{Additional records}

Australia: Western Australia: 1 $\hat{\text {, }}$ Barrow Island, WGS84:338275, 7696313, 19-29 September 2011, ACZ1WIN1, N. Gunawardene and C. Taylor (WAM 83883).

\section{REMARKS}

Dytomyia flaviseta was known previously only from two separated localities, the Kimberley district and the Monte Bello Islands, both in tropical Western Australia, and this new Barrow Island record extends this species range further 
south. The pale yellow thoracic and head setae and overall whitish pruinosity (not evident in Figure $2 \mathrm{~b}$, photographed in alcohol) of this species are distinctive.

\section{Genus Pilbara Bickel, 1994}

\section{Pilbara octava Bickel, 1994}

Figures 2c-d

Pilbara octava Bickel 1994: 100.

\section{MATERIAL EXAMINED}

\section{Additional records}

Australia: Western Australia: MillstreamChichester National Park: 1 Oे, nr Crossing Pool,

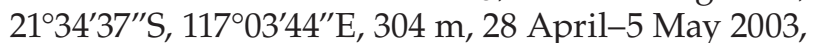
Malaise trap in Melaleuca riverine forest, Lambkin and Weir (ANIC 2007); 1 $\widehat{\lambda}$, Yarraloola Rd: Fortescue River, $2^{\circ} 37^{\prime} 38^{\prime \prime}$ S, $117^{\circ} 07^{\prime} 27^{\prime \prime} \mathrm{E}, 28$ April-3 May 2003, Malaise trap in creek with drying pools, Lambkin and Weir (ANIC 2119).

\section{REMARKS}

Pilbara is a monotypic genus known only from the Millstream site in the Pilbara region of Western Australia. It is morphologically isolated with respected to other Sciapodinae, and is characterized by a very shallowly excavated vertex, total loss of vein $\mathrm{M}_{2}$ (convergent with Mesorhaga, although of a different conformation), enlarged anteroventral eye facets in both sexes, absence of ac setae, 4 strong dc in both sexes, and females with two whitish basoventral setae on femur I (FSSC). The single known species, Pilbara octava, is rather short and compact, has a relatively low and spheroidal head, and has rather short legs, all features that are uncharacteristic of most Sciapodinae. However, the male hypopygium has a characteristic sciapodine structure. Without knowledge of the male genitalia, the inclusion of the species in the Sciapodinae might be questioned, especially since the genus lacks vein $\mathrm{M}_{2}$ and has a very shallowly excavated frons.

\section{Genus Parentia Hardy, 1935}

\section{REMARKS}

In Australia, the genus Parentia displays a classical Bassian distribution along the southern margin of the continent, and the genus is diverse in south-western Australia. Parentia is found in in wet eucalypt forests, dry sclerophyll woodland, and heaths, and in semiarid to arid habitats, often well away from permanent water. Parentia is the dominant sciapodine element in the New Zealand fauna and also occurs in New Caledonia (Bickel
2002), further attesting to its southern temperate affinities.

\section{Parentia vulgaris Bickel, 1994}

Figure 1e

Parentia vulgaris Bickel 1994: 127.

\section{MATERIAL EXAMINED}

\section{Additional records}

Australia. Western Australia: 1 + , Hamersley station, Railway Road just past Cooks Bore turnoff, Ridge paddock, UWA exclusion site, $22^{\circ} 18^{\prime} 6^{\prime \prime} \mathrm{S}$, 117\%41'35"E, 30 September-5 October 2004 (AMS); Karijini National Park: 1 , nr Johnson Gorge, $22^{\circ} 27^{\prime} 05^{\prime \prime}$ S, $118^{\circ} 27^{\prime} 14^{\prime \prime} \mathrm{E}, 684 \mathrm{~m}, 14-20$ May 2003, $684 \mathrm{~m}$, pool in rocky creek with Eucalyptus-Acacia, Malaise trap, Lambkin (ANIC).

\section{REMARKS}

Although most species of Australian Parentia are confined to southern temperate regions of the continent, the range $P$. vulgaris extends well into the tropics. It occus in Pilbara region, the coast and ranges of eastern Australia from northern Queensland to the southern New South Wales, the Murray River drainage, and Norfolk Island. The species is unknown from the Northern Territory. It was previously recorded from Millstream (April 1971 and October/November 1970, ANIC).

\section{Genus Pseudoparentia Bickel, 1994}

\section{REMARKS}

With the two new species described below, the genus Pseudoparentia now comprises seven species from semiarid and arid interior Australia, from the western slopes of New South Wales to desert regions of the Northern Territory and Western Australia. Pseudoparentia has only four strong dc in both sexes, strong vertical seta on both sexes, ac totally absent, femora mostly bare, antennal pedicel with only short setae, male face not expanded laterally, and lateral scutellar setae absent.

\section{Pseudoparentia canalicula Bickel sp. nov.}

Figures 3a-c

urn:Isid:zoobank.org:act:99E78F85-EA9F-4E10-8F17F62D1633DA16

\section{MATERIAL EXAMINED}

\section{Holotype}

Australia: Western Australia: 1 ô, Cape Range National Park, Mandu Mandu Creek, 50 m, 22 ${ }^{\circ} 08^{\prime} \mathrm{S}$, 
$113^{\circ} 50^{\prime} \mathrm{E}, 11-12$ August 2002, yellow pans, D. Bickel (WAM 8376).

\section{Paratypes}

Australia: Western Australia: $4 \hat{\partial}$, same data as holotype (AMS).

\section{DESCRIPTION}

\section{Male}

Length: $4.1-4.2 \mathrm{~mm}$; wing: $4.0 \times 1.3 \mathrm{~mm}$.

Head: vertex only shallowly excavated; head rather wide, and clypeus semicircular in anterior view; setae black; strong vertical seta present on lateral frons, with pair strong diverging ocellars and pair of tiny posterior setae on tubercle; face slightly bulging in male; clypeus separated from face by distinct frontoclypeal suture; frons, face and clypeus metallic green with dense grey pruinosity; palp yellow; proboscis yellowish; antennal scape and pedicel dark brown; pedicel with short dorsal and ventral setae; first flagellomere brown, rounded subrectangular, almost reniform; arista dorsal, as long as head width; ventral postcranium with abundant pale setae.

Thorax: dorsum bright metallic blue-green with dusting of brownish pruinosity; pleura with grey pruinosity; scutellum metallic blue; setae black; ac absent, but with tiny setulae on anterior slope of mesoscutum; 4 strong dc present; 1 pa, only 1 sa, only $1 \mathrm{sr}, 2$ National Parkl, $1 \mathrm{hm}$, and $1 \mathrm{pm}$ present; lateral scutellars absent.

Legs. CI entirely yellow, CII and CIII dark brown; leg III entirely brown; trochanter I yellow, trochanter II light brown, FI and FII yellow, but FI has some dorsal infuscation along basal half, TI yellow, TII yellowish; tarsi I and II yellowish except where noted; legs elongate and slender; CI with white weak anterolateral setae and white hairs, CIII with 2 white lateral setae; I: 5.0; 4.9; 3.0/ 1.3/ 0.8/ $0.6 / 0.4$; FI with $4-5$ white ventral setae from $1 / 10-$ $1 / 2$, otherwise legs I base of major setae; II: $6.0 ; 6.4$; 6.0/ 2.4/ 1.2/ 0.8/ 0.5; FII slightly swollen basally, tapering distally, without major setae; TII mostly bare but with apical corona of short setae, ad seta being stronger, and with dorsal surface flattened and bare of vestiture (MSSC); IIt 1 subequal to FII; IIt $_{1-2}$ with dorsal groove running length of these two tarsomeres, internally with fine transverse banding (MSSC) (Figure 3c); IIt dorsally from $1 / 5$ to apex with ad row of some 30-35 very short curved setae (MSSC); IIt $_{4-5}$ flattened and expanded as black flag, with $\mathrm{IIt}_{4}$ anteroventrally flattened and bearing curved dorsal crest, and IIt $_{5}$ less flattened and with shorter rounded crest (MSSC); III: 7.0; 8.9; 3.2/ 2.4/ 1.1/ 0.8/ 0.5; TIII near $1 / 2$ with posteroventral excavation with row of $4-5$ black posteroventral setae along excavation (MSSC); IIIt $_{3-5}$ weakly flattened and IIIt $t_{4-5}$ with dull yellow ventral pad-like surface (MSSC).
Wing: hyaline and elongate; $\mathrm{R}_{1}$ joins margin at $2 / 5 ; M_{1}$ in gentle arc to apex; $M_{2}$ present as distinct but faint vein; $\mathrm{CuAx}$ ratio: 2.0; anal angle present; lower calypter yellow with black rim and with fan of pale setae; halter yellow.

Abdomen: metallic green with bronze reflections; on segments 2-6, basal half of each tergum and narrow band on preceding adjacent matt brown; tergum 1 with posterior row of long marginal setae; postabdomen (Figure 3b); sternum 8 forming cap over left lateral hypopygial foramen; dark brown with yellow cerci; epandrium subtriangular; hypandrial arm arising beyond midlength of hypandrium and extending beyond hypandrial hood; phallus simple with expanded apex; epandrial lobe as short mound with 2 bristles; surstylus elongate subrectangular and slightly expanded, and with subequal digitiform dorsal arm; cercus yellow, elongate and flagelliform with triangular ventral mound near base which bears elongate setae, and flagelliform arm with spaced long yellow setae along length and with some long apical setae.

\section{Female}

Unknown.

\section{REMARKS}

Pseudoparentia canalicula was collected in yellow pans set along the gorge of Mandu Mandu Creek in the Cape Range Peninsula, to the west of the Pilbara region. The creek bed along the gorge was dry but with patches of damp earth. This species can be readily recognized by the distinct characters of the male legs (all MSSC): the remarkable dorsal groove that runs along leg II tarsomeres 1-2, leg II tarsomeres 4 and 5 flattened as a black apical flag, tibia III near $1 / 2$ with a posteroventral excavation and row of 4-5 black posteroventral setae along excavation, and the cercus with an elongate flagelliform arm.

\section{ETYMOLOGY}

The specific epithet canalicula is from the Latin canalus, referring to the channel or grove running along the basal two tarsomeres of male leg II.

\section{Pseudoparentia niharae Bickel sp. nov.}

Figures $3 d-e$

urn:Isid:zoobank.org:act:F0F528D1-EF37-4C69-80A7$284641751 \mathrm{E} 13$

\section{MATERIAL EXAMINED}

\section{Holotype}

Australia: Western Australia: 1 , Barrow Island, WGS84 (50): 334218, 7692088, 1 May 2007, NO5b PIT, S. Callan and K. Edwards (WAM 83877) 


\section{DESCRIPTION}

\section{Male}

Length: $3.6 \mathrm{~mm}$; wing: $4.0 \times 1.3 \mathrm{~mm}$.

Head: vertex only shallowly excavated; head rather wide, and clypeus semicircular in anterior view; setae black; strong vertical seta present on lateral frons, with pair strong diverging ocellars and pair of tiny posterior setae on tubercle; face slightly bulging in male; clypeus often separated from face by strong frontoclypeal suture; frons, face and clypeus metallic green with dense grey pruinosity; face slightly bulging; palp yellow with very strong apical seta, almost three times length of palp; proboscis yellow; antennal scape and pedicel brownish; pedicel with short dorsal and ventral setae; first flagellomere brown, short rounded subrectangular, almost reniform; arista dorsal, as long as head width; ventral postcranium with abundant pale setae.

Thorax: dorsum mostly dark brown with metallic reflections; ac absent, apparently 4 strong dc present; other major setae missing.

Legs. CI entirely yellow, CII and CIII dark brown; trochanter I yellow, trochanter II light brown, FI and FII yellow, but FI has some dorsal infuscation along basal half, FIII brown; TI yellow, TII and TIII yellowish; tarsi I and II yellowish; legs elongate and slender; CI with white weak anterolateral setae and white hairs, CIII with white lateral setae; femora, tibiae and tarsi without major setae; I: 3.7; 4.1; 3.0/ 1.3/ 1.0/ 0.7/ 0.4; II: 5.0; 3.8; 5.7/ 2.0/ 1.5/ 1.0/ 1.4; IIt ${ }_{1}$ much longer than TII, and ventrally with some short spaced setae; III: $6.0 ; 7.4 ; 4.1 / 1.7 /$ $1.0 / 0.6 /$ distal tarsomere missing; TIII near $1 / 2$ very slightly flattened and with small depression bare of vestiture just beyond $1 / 2$ (MSSC); IIIt $_{3-4}$ very slightly flattened.

Wing: hyaline; vein $M_{1}$ diverging from $R_{4+5}$ from base to halfway between crossvein $\mathrm{dm}-\mathrm{cu}$ and wing apex, where it bends in a gentle arch anteriorly to almost join $\mathrm{R}_{4+5}$ just anterior of wing apex; $\mathrm{M}_{2}$ as faint trace; $\mathrm{dm}-\mathrm{cu}$ straight; $\mathrm{CuAx}$ ratio: 1.5; anal angle weak; lower calypter yellow with black rim and with fan of pale setae; halter yellow.

Abdomen: mostly brown with metallic bluegreen reflections and short vestiture; abdomen elongate, with hypopygium hanging down; hypopygium dark brown with yellow cerci (Figure 3e); epandrium subtriangular; hypandrial arm arising beyond midlength of hypandrium and extending beyond hypandrial hood; phallus simple, extending beyond surstylus; epandrial lobe as short mound with 2 bristles; surstylus expanded, clubshaped, with narrow digitiform dorsal arm; cercus enlarged and triangular, and with pale yellow setae, especially well-developed at ventral apex.
REMARKS

Pseudoparentia niharae is known from a somewhat damaged male collected in a pitfall trap on Barrow Island, Western Australia. This species shares male characters with two other Pseudoparentia species, a triangular cercus with $P$. advena Bickel from Cape York Peninsula, Queensland, and having leg II tarsome 1 longer than tibia II, shared with $P$. centralis Bickel from the Alice Springs district, Northern Territory. This shows the variable expression of derived characters among closely related species.

\section{ETYMOLOGY}

This species is named in honor of Nihara Gunawardene, who involved me in the Barrow Island project.

\section{Genus Chrysosoma Guérin-Méneville, 1831}

\section{REMARKS}

Chrysosoma is a large and complex genus found across the humid Old World tropics. The Australian fauna shows close ties to the Papuan subregion. It is most diverse in the Queensland rainforests, but diminishes in species richness westward across the monsoonal zone where it is more or less confined to vine thicket vegetation. In Western Australia, although four species occur in the Kimberley District, only C. nobile is found in the Pilbara (Bickel 1994).

\section{Chrysosoma nobile Parent, 1933}

Figure 1d

Chrysosoma nobile Parent 1933: 175.

\section{MATERIAL EXAMINED}

\section{Additional records}

Australia: Western Australia: 15 ก, 4 , Millstream-Chichester National Park, nr Crossing Pool, Lambkin and Weir, 28 April-5 May 2003,

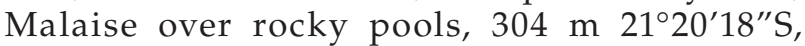
$117^{\circ} 12^{\prime} 38^{\prime \prime} \mathrm{E}$ (ANIC); 2 ふे, Karijini National Park: Weano Gorge Rd 25 April-15 May 2003; Malaise trap atdrying pool in rocky creek bed, $684 \mathrm{~m}$, $22^{\circ} 21^{\prime} 19^{\prime \prime} \mathrm{S}, 118^{\circ} 15^{\prime} 00^{\prime \prime} \mathrm{E}$, Lambkin and Weir (ANIC).

\section{REMARKS}

Chrysosoma nobile is known from tropical northern Australia, coastal Arnhem Land and the Torres Strait Islands. However, in Western Australia it is known only from the Fortescue River drainage, and has not been recorded from the Kimberley region. 


\section{Genus Amblypsilopus Bigot, 1888}

\section{REMARKS}

Amblypsilopus is a speciose pan-tropical genus which is probably polyphyletic.

In Australia, the 83 described species occur primarily in mesic forests along the eastern coast to the southern limit of subtropical rainforest in New South Wales, and across the tropical monsoonal, northern Australia. The three Pilbara species treated here also occur in Kimberley region and represent the southernmost occurrence of the genus in Western Australia.

They belong in the neoplatypus, zonatus, and pallidicornis species groups, respectively, all of which share a curved posterior seta in the distal quarter of male tibia I (MSSC) (see Bickel 1994 for further discussion).

\section{Amblypsilopus fortescuia Bickel, 1994}

Figure 1a

Amblypsilopus fortescuia Bickel 1994: 284.

\section{MATERIAL EXAMINED}

\section{Additional records}

Australia: Western Australia: MillstreamChichester National Park: 13 $\hat{0}, 3$ ㅇ, McKenzie

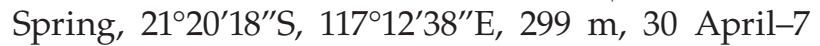
May 2003, Malaise trap in rocky ravine, Lambkin and Weir (ANIC 2126); 13 $\lambda, 14$ ㅇ, Crossing Pool, $21^{\circ} 20^{\prime} 18^{\prime \prime} \mathrm{S}, 117^{\circ} 12^{\prime} 38^{\prime \prime} \mathrm{E}, 304 \mathrm{~m}, 28$ April-5 May 2003, Melaleuca riverine forest, Lambkin and Weir (ANIC 2125); Karijini National Park: 1 , Hamersley-Mt Bruce Rd, $22^{\circ} 34^{\prime} 14^{\prime \prime} \mathrm{S}, 118^{\circ} 17^{\prime} 52^{\prime \prime} \mathrm{E}, 25$ April-14 May 2003, dry rocky creek bed, 757m, Malaise, Lambkin and Weir (ANIC 2056); 2 +, Juna Downs Rd, 19-25 April 2003, drying pool in rocky Turee Creek, 789 m, 22 $41^{\prime} 57^{\prime \prime} \mathrm{S}, 118^{\circ} 25^{\prime} 06^{\prime \prime} \mathrm{E}$, Lambkin and Weir, Malaise trap (ANIC 2059); 6 $\delta, 7$, nr Johnson Gorge, $22^{\circ} 27^{\prime} 05^{\prime \prime} \mathrm{S}, 118^{\circ} 27^{\prime} 14^{\prime \prime} \mathrm{E}, 684 \mathrm{~m}$, 14-20 May 2003, $684 \mathrm{~m}$, drying pool in rocky creek with Eucalyptus-Acacia, Malaise trap, Lambkin (ANIC 2143); 1 , Hamersley Range, Yampire Gorge, seepage in canyon, 20 September 1983, Schlinger and Irwin (CAS).

\section{REMARKS}

Amblypsilopus fortescuia is a member of the neoplatypus species group, defined by having a modified male postabdomen, with strong size reduction in the hypopygium and accompanying loss of both the left hypandrial arm and dorsal angle of the phallus. Indeed, the tiny male genital capsules of some species appear almost aberrant. There are ten described Australian species, but many species await description from the Oriental and the Papuan regions.

Amblypsilopus fortescuia is known from the Pilbara and Kimberley districts in northern Western Australia and is common in the Fortescue River drainage. This species is close to A. commoni Bickel, known from the Kimberley Ranges across tropical Australia to the Gulf of Carpentaria. The male tarsus I of A. commoni is strongly flattened, but only slightly flattened in A. fortescuia.

\section{Amblypsilopus putealis Bickel, 1994}

Figures $1 \mathrm{~b}-\mathrm{c}$

Amblypsilopus putealis Bickel 1994: 317.

\section{MATERIAL EXAMINED}

\section{Additional records}

Australia: Western Australia: 1 Oे, Cape Range National Park, Mangrove Bay, 0-10 m, 22 09'31'S, $113^{\circ} 55^{\prime} 13^{\prime \prime} \mathrm{E}, 12-13$ August 2002, yellow pans, D. Bickel (AMS).

\section{REMARKS}

Amblypsilopus putealis is a member of the zonatus species group, whose male wings are usually modified with an apical maculation and a tendency for $M_{1}$ to become parallel with $R_{4+5}$, and $M_{2}$ to become reduced or lost. The zonatus Group is found primarily in coastal eastern Australia (including Lord Howe and Norfolk Islands), but A. putealis occurs disjunctly in north-western Australia (see Bickel 1994 for further discussion).

Amblypsilopus putealis was originally described from a pair taken in the Kimberley region, Western Australia, and the Cape Range record is a significant southward extension. This species is readily recognized by the large brown spot on the distal quarter of the male wing. The association of this species with mangoves is characteristic of coastal/ littoral habitats found in most species in the zonatus group.

\section{Amblypsilopus gressitti Bickel, 1994}

Figures $1 f-g$

Amblypsilopus gressitti Bickel 1994: 311.

\section{MATERIAL EXAMINED}

\section{Additional records}

Australia: Western Australia: 1 त, Derby, 12 March 1999, J. Kerr (AQIS, Broome); 1 đ , 1 q , 100m east of Fortescue Falls, $22^{\circ} 28^{\prime} 37^{\prime \prime} \mathrm{S}, 118^{\circ} 33^{\prime} 9^{\prime \prime}$ E, 16 April 005 (AMS, K.252264). 


\section{REMARKS}

Amblypsilopus gressitti is a member of the pallidicornis species group, characterised in both sexes by an elongate apical arista which is more than twice the head height. In most other Amblypsilopus species, the aristal length is rarely more than the head height, and the arista is usually dorsally positioned on the first flagellomere. The group has a broad range throughout the Oriental and Australasian regions.

Amblypsilopus gressitti was described from Arnhem Land, Northern Territory, and the above records extend its range to the Pilbara and Kimberley districts, Western Australia.

\section{Subfamily Dolichopodinae Latreille, 1809}

\section{REMARKS}

The subfamily Dolichopodinae has its greatest diversity across the Holarctic region. The Australian fauna is small and primarily northern in distribution, suggesting it is a rather recent arrival from the Australasian tropics. Indeed, a number of Australian species have distributions that include Melanesia.

Species that might occur in the Pilbara region but are not recorded there include the widespread Old World tramp species, Tachytrechus tessellatus (Macquart), and members of the Dolichopus ziczac group of species. Both are known from the Kimberley District, Western Australia (see Bickel 2008 for further discussion). They are keyed but not considered in the text below.

\section{Genus Paraclius Loew, 1864}

\section{REMARKS}

Paraclius occurs in all zoogeographical regions, but is most diverse in the Neotropics. In the Australasian region, some 22 species have been described (Bickel and Dyte 1990), mostly from northern and eastern Australia and western Melanesia, although there are many undescribed species in collections, especially from New Guinea. Brooks (2005) regards Paraclius as a polyphyletic assemblage, essentially a provisional "holding genus."

\section{Paraclius sexmaculatus Bezzi, 1928}

Figure $4 \mathrm{e}$

Paraclius sexmaculatus Bezzi 1928: 55.

\section{MATERIAL EXAMINED}

\section{Additional records}

Australia: Western Australia: Kimberley Research Station, Wyndham, $15^{\circ} 28^{\prime} \mathrm{S}, 128^{\circ} 06^{\prime} \mathrm{E}, 4$
December 1953, Lurins (ANIC); 1 ภ, Millstream, $21^{\circ} 35^{\prime} \mathrm{S}, 117^{\circ} 05^{\prime} \mathrm{E}, 8$ April 1970, Colless (ANIC).

\section{REMARKS}

Paraclius sexmaculatus is a widespread Australasian lowland species known from northern Australia (Qld, NT, WA), New Guinea, Belau, Kiribati, Vanuatu, Fiji and New Caledonia (see redescription, synonymies and distribution records in Bickel, 2008). This species occurs in the Millstream area of the Pilbara region. Paraclius sexmaculatus is part of a large, mostly undescribed Australian-Melanesian group of species, characterized by a metallic green thorax with diagnostic dark band on the anterior mesonotum.

\section{Paraclius trisetosus Parent, 1933}

Figures $4 \mathrm{a}, 4 \mathrm{f}, 5 \mathrm{a}$

Paraclius trisetosus Parent 1933: 185.

\section{MATERIAL EXAMINED}

\section{Holotype}

Parent described Paraclius trisetosus from a single female taken at Kuranda, Queensland (BMNH, examined). The female is distinctive enough to be associated with males, and the species is redescribed below.

\section{Additional records}

Australia: New South Wales: 2 ô, 4 , Boonanghi $\mathrm{SF}$, "The Blowhole" $24 \mathrm{~km} \mathrm{~W}$ of Kempsey, 8 October 1993, G and A Williams (AMS). Northern Territory: 1 ô, 1 o, Caranbirini Water Hole, $33 \mathrm{~km}$ SW of Borroloola, 22 April 1976, Colless; 7 , Surprise Creek, 45 km SSW of Borroloola, 15 April 1976, Colless; 6 9, Baroalba Creek Gorge, $19 \mathrm{~km} \mathrm{NE}$ of Mt Cahill, 1248'S, 132 $49^{\circ} \mathrm{E}$, 17 November 1972 (ANIC). Queensland: 1 + , Iron Range, 14 June 1971, Feehan;

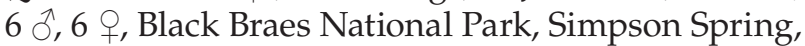
$9.7 \mathrm{~km}$ NNE of homestead, $19^{\circ} 28^{\prime} 01^{\prime \prime} \mathrm{S}, 144^{\circ} 15^{\prime} 29^{\prime \prime} \mathrm{E}$, $820 \mathrm{~m}$, sandy dry creek, $820 \mathrm{~m}$, Malaise trap, 2-4 November 2001, Yeates; 4 $\hat{0}, 3$ \&, Desailly Creek, $10 \mathrm{~km} \mathrm{NW}$ of Mt Carbine, 16 $6^{\circ} 30^{\prime} \mathrm{S}, 144^{\circ} 55^{\prime} \mathrm{E}, 19$ May 1981, Colless; 1 ग, Moses Creek, 4 km NE of Mt Finnigan, $15^{\circ} 46^{\prime} \mathrm{S}, 145^{\circ} 17^{\prime} \mathrm{E}, 16$ October 1980 , Malaise trap, Colless; 1 §, 1 , Annan River, $3 \mathrm{~km}$ SW of Black Mountain, 28 September 1980, Malaise, Colless; 1 गे, 2 , $15 \mathrm{~km} \mathrm{~W}$ of Irvinebank, $17^{\circ} 26^{\prime} \mathrm{S}$, $145^{\circ} 10^{\prime} \mathrm{E}, 28$ November 1981, Malaise, Colless; 1 गे, 2 ㅇ, 30 mi. SE Ayr, 4 September 1950, Riek; 1 ठ, Mt Spec, 6 May 1968, Ferrar; 1 ठ, Bin Bin Range, 10 km SW of Biggenden, 19 December 1975, Frauca; 1 , $2 \mathrm{~km} \mathrm{~N}$ of Rokeby, $13^{\circ} 39^{\prime} \mathrm{S}, 142^{\circ} 40^{\prime} \mathrm{E}, 17$ December 1993-17 January 1994, Malaise trap, Zborowski and Shaw; 1 '․, Coen, $13^{\circ} 57^{\prime} \mathrm{S}, 143^{\circ} 12^{\prime} \mathrm{E}, 16$ August-13 September 1993, Zborowski, Malaise (ANIC); Highvale, 07 January 1977, Schneider (AMS); 2 , 
Upper Cedar Creek, via Dayboro, 25 September 1987, Daniels; 1 đ̋, Eungella National Park, Crediton Creek, Eungella National Park, 30 November 1992, yellow pans, Bickel; 1 d̂, Carnarvon National Park, Carnarvon Creek, 28 November 1992, riverine forest, yellow pans, Bickel (AMS). Western Australia: 1 กิ, 1 , Carson Escarpment, Drysdale River, 14\%49'S, 126 $49^{\circ}$ E, 227, 9-15 August 1975, Malaise trap, Common and Upton; MillstreamChichester National Park: (a) 1 0, 7 , , Narrina Pool, rocky Creek bed, Eucalyptus 27-30 April 2003, $159 \mathrm{~m} 21^{\circ} 20^{\prime} 43^{\prime \prime} \mathrm{S}, 117^{\circ} 16^{\prime} 08^{\prime \prime} \mathrm{E}$, Malaise, Lambkin and Yeates; (b) 5 ऽ, 2 ㅇ, Yarraloola Rd, Fortescue River, 28 April-3 May 2003, Malaise trap in broken creek with drying pools $21^{\circ} 37^{\prime} 38^{\prime \prime} \mathrm{S}, 117^{\circ} 07^{\prime} 27^{\prime \prime} \mathrm{E}$, Lambkin and Weir; (c) $10 \hat{\delta}, 5$, Snappy Gum Drive, $21^{\circ} 34^{\prime} 50^{\prime \prime}$ S, $117^{\circ} 05^{\prime} 42^{\prime \prime} \mathrm{E}, 249 \mathrm{~m}, 28$ April-11 May 2003, Malaise, sandy creek with Acacia/Eucalyptus, Lambkin and Weir; (d) 2 , nr Crossing Pool, $21^{\circ} 34^{\prime} 37^{\prime \prime} \mathrm{S}, 117^{\circ} 03^{\prime} 44^{\prime \prime} \mathrm{E}, 304 \mathrm{~m}, 28$ April-11 May 2003, Malaise, Melaleuca riverine forest, Lambkin and Weir; 4 Oे, 5 ㅇ, Millstream, 22-25 October 1970, Colless; Karijini National Park: (a) 6 ô, 3 ㅇ, Weano Gorge Rd 25 April -15 May 2003, dry Creek, $695 \mathrm{~m} 22^{\circ} 21^{\prime} 19^{\prime \prime} \mathrm{S}, 118^{\circ} 15^{\prime} 00^{\prime \prime} \mathrm{E}$, Lambkin and Weir:

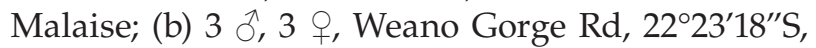
$118^{\circ} 15^{\prime} 23^{\prime \prime} \mathrm{E}, 20-25$ April 2003, beside drying pool grassy bank, $711 \mathrm{~m}$, Malaise, Lambkin and Weir; (c) $4 \hat{O}, 3$, Johnson Gorge, 23 April-14 May 2003, drying pool in rocky Creek, Eucalyptus-Acacia scrub, $684 \mathrm{~m}, 22^{\circ} 21^{\prime} 19^{\prime \prime} \mathrm{S}, 118^{\circ} 15^{\prime} 00^{\prime \prime} \mathrm{E}$, Lambkin and Weir, Malaise trap; (d) 1 o, Kalamina Gorge, $22^{\circ} 24^{\prime} 59^{\prime \prime} \mathrm{S}$, $118^{\circ} 24^{\prime} 11^{\prime \prime} \mathrm{E}$, creek with Melaleuca, Malaise trap, 24 April-14 May 2003, Lambkin (ANIC). 1 , Pilbara Region, Parabardoo, Tom Price Rd, approx. $11 \mathrm{~km}$ $S$ of Tom Price, $\left(22^{\circ} 44^{\prime} 58^{\prime \prime}\right.$ S, $117^{\circ} 53^{\prime} 48^{\prime \prime}$ E), 5 June 2004 (AMS, K.248813).

\section{REDESCRIPTION}

\section{Male}

Body length: 4.2-4.4 mm; wing: $3.8 \times 1.5 \mathrm{~mm}$.

Head: postorbitals strong, in single row, and all white except dorsal three on each side black; vertex and frons dark brown with dusting of grey pruinosity; major setae black; pairs of strong postvertical, vertical, and diverging ocellar setae present; face wide ventrad of antennae, but parallel sided, and with dense silvery pruinosity; slight flexion present at fronto-clypeal suture; ventral margin of clypeus straight; palp yellow with black apical seta; proboscis yellowish; scape and pedicel yellowish; scape with short dorsal setae; pedicel with strong dorsal seta; first flagellomere basally yellow, but distally infuscated, and subtriangular; arista dorsal, about as long as head height; lower postcranium with some scattered pale setae.

Thorax: mesonotum mostly metallic blue green, but with metallic bronze over ac band, over humeral area, and on lateral mesonotum posteriad of mesonotal suture area, extending laterally on pleura posteriad of notopleuron, scutellum metallic green; pruinose band extending from anterior notopleuron to edge of ac band appearing silvery in posterior view; pleura and metepimeron dark brown with metallic green reflections, and covered with dusting of grey pruinosity; major setae black, and sockets dark brown/ bronze; notopleuron with some grey pruinosity in dorsal view; some 10 pairs of short ac present; anterior slope of mesonotum covered by field of short setulae; 6 strong dc present, with short dc anteriormost; strong black setae: $1 \mathrm{pa}, 2 \mathrm{sa}, 1 \mathrm{sr}, 1 \mathrm{hm}, 1$ presutural intra-alar, $1 \mathrm{pm}, 2 \mathrm{npl}$; propleuron with long curved seta just above base of CI, and with 2 short setae and white hairs anteriad of anterior spiracle; lateral scutellar seta as short side hair, about one fifth length of median scutellars.

Legs: CI yellow; CII and CIII brown but distally yellow; trochanters, femora, tibiae and tarsi yellow, but distal tarsomeres slightly infuscated; vestiture black; CI short black anterior setae and with 4 strong distolateral setae; CII with short anterior setae and 3 strong lateral setae; CIII with strong lateral seta at $1 / 2$; I: 4.8; 4.3; 2.0/ 0.8/ 0.6/ 0.4/ 0.4; FI with short subapical pv seta; TI with strong ad seta at $1 / 5,3 / 10,1 / 2$ and $3 / 5$ (strong), pd seta at $1 / 6$ (short), $1 / 3$, and $3 / 5$, strong posterior seta near $1 / 2$, and short apical ad and pd seta; II: 5.2; 5.9; $2.6 /$ 1.5/ 1.2/ 0.7/ 0.6; FII with 2 strong anterior setae, at $7 / 10$ and $7 / 8$, with shorter posterior seta at $4 / 5$, and adjacent short subapical pv seta, and with a field of some 25-30 long anteroventral hairs from base to $3 / 5$; TII with 3 strong dorsal setae from $1 / 5$ to $2 / 3$, strong ad at $1 / 8,4$ strong pd setae from $1 / 8$ to $7 / 10,2$ strong ventral setae positioned near $2 / 5$ and $2 / 3$, and with subapical circle of strong dorsal, ad, av, pd, pv, and av seta; III: 5.8; 6.9; 2.0/ 2.6/ 1.7/ 1.0/ 0.7; FIII with strong anterior seta at $4 / 5$, subtended dorsobasally by second slightly shorter anterodorsal seta, but without subapical posterior seta; TIII with strong dorsals at $1 / 8$ and $1 / 6,5$ strong ad setae from $1 / 8$ to $3 / 4$, and 4 strong pd setae from $1 / 8$ to $2 / 3$, with strong subapical ad and ventral setae TIII, and with some 7-8 short almost erect ventral setae from $1 / 4$ to $4 / 5$; on both TII and TIII, each strong seta pair is followed distally by an area bare of vestiture; IIIt ${ }_{1}$ with weak ventral setae.

Wing: hyaline; anal lobe reduced; vein $R_{2+3}$ joins margin at $4 / 5$; from base vein $M$ gradually diverging from $\mathrm{R}_{4+5}$, but bends two thirds distance distad of $\mathrm{dm}-\mathrm{cu}$ crossvein, to almost join $\mathrm{R}_{4+5}$ at margin at 9/10 well before wing apex; $\mathrm{CuA}_{1}$ not extending to wing margin; cross vein $\mathrm{dm}-\mathrm{cu}$ with slight flexion; CuAx ratio: 1.0; lower calypter pale yellow with fan of black setae; halter yellow.

Abdomen: each tergum 1-6 mostly dark metallic green with black posterior border, and covered with dusting of grey pruinosity; sternum 8 dark brown; hypopygium (Figure 5a) mostly dark brown but 
with brownish hypandrium and ventral epandrial margin; cercus black; epandrium subrectangular; hypandrium as elongate narrow trough enclosing narrow phallus; epandrial lobe expanded and rounded, with basal seta, modified forked seta at $1 / 3$, and two distal setae; surstylus as short rounded prominence laterad of epandrial lobe; cercus rounded and expanded basally and tapering cone-like distally, and with abundant black setae.

\section{Female}

Similar to male except as noted: face and clypeus slightly wider; first flagellomere slightly smaller; leg colouration and setation similar.

\section{REMARKS}

Paraclius trisetosus has a wide distribution, from northern New South Wales, along the Queensland ranges to Cape York Peninsula, and across the monsoonal north into the Kimberley and Pilbara districts of Western Australia. In the Pilbara district it appears to be common in the Fortescue River drainage.

\section{Paraclius obtusus Hardy, 1939}

Figures $4 b, 5 b$

Paraclius obtusus Hardy 1939: 347.

Paraclius albodivisus Parent 1941: 223. Syn. nov.

\section{MATERIAL EXAMINED}

\section{Holotypes}

Hardy described Paraclius obtusus from a series of 3 males and 5 females collected in Brisbane. No depository was named and the types could not be found in any major collection. However, his description is complete enough to establish the species described below. Parent described Paraclius albodivisus from a single female (BMNH, examined) collected in south-eastern Queensland and it matches Hardy's description, especially the leg setation and overall colour pattern, and I regard the two species as synonyms.

\section{Additional records}

Australia: New South Wales: 1 ô, Williams River and Salisbury Road, N of Tillegra, cattle grazed creek, yellow pans, 19 December 1993, yellow pans, Bickel (AMS); $1 \hat{\jmath}$, Ku-ring-gai Chase National Park, Cicada Creek nr Church Point, tidal creek, 22-23 September 2001, 3339' $151^{\circ} 17^{\prime} \mathrm{E}$, yellow pans, Bickel (AMS). Northern Territory: $2 \hat{\jmath}$, Gregory National Park, $8.3 \mathrm{~km} \mathrm{~N}$ of Humbert Jct., 6-12 June 2001, Malaise in Creek bed, $16^{\circ} 02^{\prime} 26^{\prime \prime} 130^{\circ} 27^{\prime} 8^{\prime \prime} \mathrm{E}$, Irwin et al. (ANIC); 1 万े, W of Bukalara Plateau, 46 km SSW Borroloola, 23 April 1976, Colless (ANIC); 1 우 , Kakadu National Park, Baroalba Creek Gorge, $19 \mathrm{~km} \mathrm{NE}$ of Mt Cahill, 12 $48^{\prime} \mathrm{S}, 132^{\circ} 49^{\prime} \mathrm{E}, 17$
November 1972, Colless (ANIC); 1 ภ, Jabiru, 5-9 June 1984, pan traps, Naumann (ANIC); 1 +, Bessie Spring, 8 Km ESE of Cape Crawford, 12 April 1976, Colless (ANIC); 1 + , Berry Springs, 30 October-4 December 1991, monsoonal vine thicket, Malaise trap, Wells and Webber (AMS). Queensland: 19 $\lambda, 8$ 을 Brisbane, Indooroopilly, QDPI campus, 6-12 December 1983, 5-12 December 1984, 21-28 February 1983, 11-18 March 1980, Malaise trap, Galloway (QDPI); 2 ô, Stradbroke I., Dunwich, 24-26 September 1985, yellow pans (QDPI); 2 के, 1 ㅇ, Brisbane, 15 September 1940, Ashby (ANIC); 1 d, 1 , Moses Creek, $4 \mathrm{~km}$ NE of Mt Finnigan, $15^{\circ} 46^{\prime} \mathrm{S}$, $145^{\circ} 17^{\prime} \mathrm{E}$, 16 October 1980, Malaise trap, Colless (ANIC); Black Braes National Park, 2 ô, Log Spring, $17.5 \mathrm{~km}$ WSW of homestead, $19^{\circ} 34^{\prime} 01^{\prime \prime} \mathrm{S}, 144^{\circ} 02^{\prime} 24^{\prime \prime} \mathrm{E}$, sandy dry creek bed, $980 \mathrm{~m}$, Malaise trap, 5-11 November 2001; 3 ㅇ, Simpson Spring, 9.7 km NNE of homestead, $19^{\circ} 28^{\prime} 01^{\prime \prime} \mathrm{S}, 144^{\circ} 15^{\prime} 29^{\prime \prime} \mathrm{E}$, sandy dry creek bed, $820 \mathrm{~m}$, Malaise trap, 2-4 November 2001, Yeates, et al. (ANIC). Western Australia: 1 त, Millstream-Chichester National Park, Snappy Gum Drive, $21^{\circ} 34^{\prime} 50^{\prime \prime} \mathrm{S}, 117^{\circ} 05^{\prime} 42^{\prime \prime} \mathrm{E}, 249 \mathrm{~m}, 28$ April-11 May 2003, Malaise, sandy creek with Acacia / Eucalyptus, Lambkin and Weir (ANIC).

\section{REDESCRIPTION}

\section{Male}

Body length: $4.8-5.1 \mathrm{~mm}$; wing: $4.3 \times 1.7 \mathrm{~mm}$; similar to $P$. trisetosus except as noted:

Head: ventral margin of clypeus straight; palp yellow with black apical seta; proboscis yellowish; scape and pedicel orange yellow; pedicel with strong dorsal setae; first flagellomere yellow at very base along segmental join with pedicel, but mostly brown, and rounded subtriangular, almost ovate, and with subapical dorsal arista, about as long as head height.

Thorax: similar in all respects.

Legs: CI brown at very base, but distally yellow; CII and CIII brown; trochanters, femora, tibiae and tarsi mostly yellow, but FIII dorsoapically with brown infuscation, tarsus III totally black, and distal tarsomeres I and II infuscated; vestiture black; CI short black anterior setae and with 4 strong distolateral setae; CII with short anterior setae and 3 strong lateral setae; CIII with strong lateral seta at $1 / 2$; I: $6.0 ; 4.8 ; 2.4 / 0.8 / 0.6 / 0.4 / 0.4$; FI with $2-3$ subapical av and $2-3$ subapical pv setae; TI with equally strong ad seta at $1 / 4,2 / 5$, and $3 / 5$, shorter dorsal seta at $1 / 5,2 / 5$, and $3 / 5$, and strong pd seta at $1 / 4,2 / 5$ and $2 / 3$; II: 7.6; 7.0; 3.0/ 2.0/ 1.4/ 1.0/ 0.8; FII with single strong anterior seta at $4 / 5$, with 2 subapical pv seta, and with an irregular ventral row of 7-8 longer setae from base to 3/5; TII with strong ad seta at $1 / 10,1 / 8,1 / 4$, and $1 / 2$, and strong pd seta at $1 / 10,1 / 8$ and $3 / 5$, strong av seta near $1 / 2$, and with circle of strong subapical dorsal, ad, av, pd, pv, and av seta; III: 7.5; 8.3; 2.2/ 3.7/ 2.3/ 1.4/ 0.8; FIII with single strong anterior seta positioned near dorsal margin at $4 / 5$, and with ventral row of $7-8$ setae 
from base to $4 / 5$; TIII with strong dorsal at $3 / 4$, with subequal ad setal pairs at $1 / 10$ (short), $1 / 5,1 / 3$ and $1 / 2$, with strong subapical ad seta; on both TII and TIII, each strong seta pair is followed distally area bare of vestiture; IIIt ${ }_{1}$ with weak ventral setae.

Wing: hyaline; anal lobe reduced; vein $\mathrm{R}_{2+3}$ joins margin at $4 / 5$; from base vein $M$ gradually diverging from $R_{4+5^{\prime}}$ but bends two thirds distance distad of $\mathrm{dm}-\mathrm{cu}$ crossvein, to almost join $\mathrm{R}_{4+5}$ at margin at 9/10 well before wing apex; $\mathrm{CuA}_{1}$ not extending to wing margin; cross vein $\mathrm{dm}-\mathrm{cu}$ with slight flexion; $\mathrm{CuAx}$ ratio: 0.8; wing margin with slight indentation where $\mathrm{CuA}$ joins; lower calypter pale yellow with fan of black setae; halter yellow.

Abdomen: each tergum 1-6 mostly dark metallic green with black posterior border, and covered with dusting of grey pruinosity; lateral terga 2-6 each with orientated silvery pruinose spot, visible in posterior view; sternum 8 dark brown and with setae as Figured (Figure 5b); hypopygium mostly dark brown with yellowish hypandrium; cercus black; epandrium subrectangular; hypandrium as narrow trough which is distally sinuate, and enclosing phallus that is distally expanded and hood like; epandrial lobe as elongate peduncle with 3 apical setae and with basal seta; surstylus prolonged and tapering with apical modified setae; distal surstylus enclosed by large shining lobate cercus, covered with short external setae as Figured.

\section{Female}

Similar to male except as noted: face and clypeus slightly wider; first flagellomere slightly smaller; leg colouration and setation similar; ventral setae along base of FII somewhat shorter, FIII bare of ventral setae.

\section{REMARKS}

Paraclius obtusus has a wide distribution, from the Sydney district and north along the coast and ranges of New SouthWales and Queensland to Cape York Peninsula, across the monsoonal tropics of the Northern Territory and into the Pilbara district of Western Australia. Males from the Moses Creek site in Queensland have a yellowish epandrium but are otherwise similar to specimens with dark brown epandria.

\section{Paraclius manglar Bickel sp. nov.}

Figures $4 c-d, 5 c$

urn:Isid:zoobank.org:act:5D81D770-FC38-4C64-A265EE55838D5147

\section{MATERIAL EXAMINED}

\section{Holotype}

Australia: New South Wales: 1 त, Botany Bay, Towra Point, yellow pans in mangroves, 29 March 1986, D. Bickel (AMS, K.364388).

\section{Paratypes}

Australia: New South Wales: $5 \hat{\rho}, 4$, same data as holotype (AMS).

\section{Additional records}

Australia: New South Wales: 1 , Brunswick Heads National Park, $28^{\circ} 32^{\prime} \mathrm{S}, 1^{\circ} 3^{\circ} 33^{\prime} \mathrm{E}, 13-16$ September 2001, mangroves, 0-5 m, yellow pans, Bickel (AMS). Queensland: 4 , Redland Bay, 22 May 1999, mangrove edge, yellow pans, Bickel (AMS). Western Australia: 12 ก, 37 , Cape Range National Park, Mangrove Bay, 21 $57^{\prime} 04^{\prime \prime} S$, $113^{\circ} 57^{\prime} 01^{\prime \prime} \mathrm{E}$, mangroves, yellow pans, Bickel (AMS; specimens to ANIC and WAM 83880).

\section{DESCRIPTION}

\section{Male}

Body length: 4.3-4.5 mm; wing: 4.0 x $1.7 \mathrm{~mm}$.

Head: postorbitals strong, in single row, and all white except dorsal three on each side black; vertex and frons dark brown with dusting of grey pruinosity; major setae black; pairs of strong postvertical, vertical, and diverging ocellar setae present; face narrow ventrad of antennae, but parallel sided, and with dense silvery pruinosity; slight flexion present at fronto-clypeal suture; ventral margin of clypeus straight; palp yellowish with black apical seta; proboscis yellowish; scape and pedicel yellowish; scape with short dorsal setae; pedicel with strong dorsal seta; first flagellomere brown and distinctly enlarged rounded subtriangular, bladelike (MSSC); arista apical (MSSC), and short, about one third head height; lower postcranium with scattered pale setae.

Thorax: mesonotum and scutellum shining metallic green, with matt brown band across the anterior thoracic slope, above occiput, and including humeral area, with pruinose band extending from anterior notopleuron to edge of ac band appearing silvery in posterior view, and with narrow matt brown band extending from posterior notopleuron to dc row, also not joined across dorsum; scutellum, pleura and metepimeron dark brown with metallic green reflections; setae black and rather thin, not robust; 6-7 pairs of long ac present; 6 dc present, with posterior dc much stronger; $1 \mathrm{pa}, 2 \mathrm{sa}, 1 \mathrm{sr}, 1$ $\mathrm{hm}, 1$ presutural intra-alar, $1 \mathrm{pm}, 2$ National Parkl; propleuron with long curved seta just above base of CI, with fine pale hairs mediad towards occiput; lateral scutellar seta about one quarter length of median scutellars.

Legs: CI yellow except brown at very base; CII and CIII brown; trochanters, femora, tibiae and tarsi mostly yellow, but FII brown along distal fifth, FIII dark brown along distal third, tarsus III totally black, and distal tarsomeres I and II infuscated; vestiture black; CI short black anterior setae and with 4 long distolateral setae; CII with short 
anterior setae and 3 strong lateral setae; CIII with strong lateral seta at 2/3; all tarsomeres 5 with pair distinct claws and pair short rounded pulvilli; I: 5.0; 4.6; 1.9/ 0.8/ 0.7/ 0.3/ 0.4; FI with 3 weak subapical pv setae; TI with 3-4 strong ad setae between $1 / 4$ and $3 / 5$, and 2 strong pd seta near $1 / 4$ and $3 / 5$, and short subapical ad and pd seta; II: 6.5; 6.3; 2.8/ 1.6/ 1.1/ 0.8/ 0.5; FII with single strong anterior setae positioned dorsally at $7 / 8$, with shorter pv seta also at 7/8; TII with strong ad seta at $1 / 8,1 / 4,1 / 2$, and $7 / 10$, strong pd seta at $1 / 8$ and $7 / 10$, strong av seta at $2 / 3$, and with subapical circle of strong dorsal, ad, av, pd, pv, and av seta; III: 7.0; 8.0; 2.0/ 2.9/ 1.9/ 1.0/ 0.7 ; FIII with strong dorsally positioned anterior seta at $3 / 4$, and with 6-7 long setae along basal twothirds; TIII with strong dorsal at $4 / 5$, with subequal ad setal pairs at $1 / 10$ (short), $1 / 5,1 / 3$ and $1 / 2$, with strong subapical ad and ventral seta; on both TII and TIII, each strong seta pair is followed distally area bare of vestiture; IIIt $t_{1}$ with weak ventral setae.

Wing: hyaline; anal lobe reduced; vein $R_{2+3}$ joins margin at $4 / 5$; from base vein $M$ gradually diverging from $\mathrm{R}_{4+5}$, but bends two thirds distance distad of $\mathrm{dm}-\mathrm{cu}$ crossvein, to almost join $\mathrm{R}_{4+5}$ at margin at 9/10, before wing apex; $\mathrm{CuA}_{1}$ not extending to wing margin; $\mathrm{CuAx}$ ratio: 0.6; lower calypter pale yellow with fan of brownish and black setae; halter yellow.

Abdomen: each tergum 1-6 mostly dark metallic green with black posterior border and black band on adjacent tergum, and with black median stripe; metallic green tergal areas covered with dusting of orientated silvery pruinosity which in posterior view appears like lateral row of silvery patches; sternum 8 dark brown; hypopygium (Figure 5c) mostly black but with yellowish epandrial lobes and hypandrium; cercus black; epandrium subrectangular; hypandrium as elongate narrow trough enclosing narrow phallus, and phallus with serrated dorsal margin; epandrial lobe elongate with 3 strong setae, one midlength and two apical; surstylus as short rounded prominence; cercus thick digitiform with abundant strong setae as Figured.

\section{Female}

Similar to male except as noted: face and clypeus slightly wider; first flagellomere distinctly smaller, almost cordate in shape, basally yellow with wide brown rim; arista at about $3 / 4$ along dorsal surface; leg colouration and setation similar.

\section{REMARKS}

Paraclius manglar is known from coastal New South Wales, south-eastern Queensland, and a disjunct population at Cape Range in north-western Australia. All specimens were collected with yellow pans at the edge of coastal mangroves. I suspect this species will be found in additional mangrove habitats along the tropical Australian coast using this simple collecting method.

\section{ETYMOLOGY}

The specific epithet "manglar" is the Spanish word for "mangroves." It should be regarded as a noun in apposition.

\section{Subfamily Medeterinae Fischer von Waldheim, 1819}

\section{Genus Medetera Fischer von Waldheim, 1819}

\section{REMARKS}

Adults of this diverse and cosmopolitan genus are commonly found resting on vertical surfaces such as tree trunks. The larvae of some Holarctic species are predators of scolytid bark beetles within their galleries, and are therefore of forestry interest for biocontrol (also see Bickel 1985).

\section{Medetera junensis Bickel sp. nov.}

Figures $7 a-b$

urn:Isid:zoobank.org:act:7991F14A-69E3-4B1B-ADCCFC53615B145A

\section{MATERIAL EXAMINED}

\section{Holotype}

Australia: Western Australia: 1 , Karijini National Park, Juna Downs Road, 19-25 April 2003, drying pool in rocky Turee Creek, 789 m, 22041'57"S, $118^{\circ} 25^{\prime} 06^{\prime \prime} \mathrm{E}$, Malaise trap, Lambkin and Weir (ANIC).

\section{Paratype}

Australia: Western Australia: 19 , same data as holotype except 25 April-14 May 2003 (ANIC).

\section{Additional records}

Australia: Western Australia: 1 ô, Hamersley Station, Nanutarra-Wittenoom Road, approx. $13 \mathrm{~km}$ NE of Railway Road crossing, $22^{\circ} 26^{\prime} 8^{\prime \prime} \mathrm{S}$, $117^{\circ} 49^{\prime} 56^{\prime \prime}$ E, 13-18 April 2005, Bulbert, et al. (AMS, K.252272); 1 , , Hamersley Station, Horseshoe Bore, $300 \mathrm{~m}$ north of windmill, $22^{\circ} 29^{\prime} 11^{\prime \prime} \mathrm{S}, 117^{\circ} 41^{\prime} 29^{\prime \prime} \mathrm{E}, 30$ September 2004 (AMS, K.248811).

\section{DESCRIPTION}

\section{Male}

Length: $2.2 \mathrm{~mm}$; wing dimensions: $2.3 \times 0.7 \mathrm{~mm}$.

Head: vertex, frons metallic green-black with bronze reflections and covered with some brown pruinosity; face, clypeus bright satiny metallic blue-green with some pruinosity laterally and on 
frontoclypeal suture; proboscis black, proboscis keel-like and projecting anteriorly; antenna entirely black; arista about as long as head height.

Thorax: dorsum dark metallic green with bronze reflections, with brown pruinosity dorsally and grey pruinosity on pleura; setae black; $8-10$ pairs ac about as long as width of ac band; two strong dc bordering mesoscutal depression, anterior dc; reduced to short setae; lateral scutellars about three quarters length of medians.

Legs: coxae and basal two-third of femora dark brown to black; with remainder of legs yellow; CI and CII with white anterior hairs and setae; CIII with lateral seta at $2 / 5$; legs bare of major setae; I: $2.6 ; 2.5 ; 1.0 / 0.8 /$ distal tarsomeres missing; II: $2.8 ; 2.7 ; 1.5 / 1.2 / 0.8 / 0.5 / 0.4$; TII with short white apical av and pv seta; III: $2.7 ; 3.2 ; 0.7 ; 1.4 ; 0.8 ; 0.4 ; 0.4$; TIII with some short white dorsal seta along distal third.

Wing: $\mathrm{M}$ in gentle curve towards $\mathrm{R}_{4+5} ; \mathrm{CuAx}$ ratio: 1.0; lower calypter yellow with brown rim and fan of pale setae; halter yellow.

Abdomen: metallic black-bronze with short black setulae; hypopygium, cylindrical, and

somewhat dorsoventrally flattened, and black with brownish cerci (Figure 7b); hypandrium elongate, forming an inverted trough over phallus; two epandrial lobes as elongate peduncules, each bearing elongate apical seta; and distalmost lobe adjacent to membranous join of surstylus with epandrium; surstylus deeply cleft into dorsal and ventral arms; dorsal surstylar arm elongate with ventral subapical seta; ventral surstylar arm more lobate with elongate curved distal setae; cercus relatively simple, slightly tapering, with only short external setae and apically blunt.

Female

See Figure 7a; similar to male but with wider face.

\section{REMARKS}

Medetera junensis is known only from the Hamersley/ Karijini area in the Pilbara, Western Australia. Based on setation, colouration, and genitalic structure, it is clearly part of the australiana species group, which otherwise comprises four species from coast and ranges of New South Wales and Queensland (see discussion in Bickel 1985).

\section{ETYMOLOGY}

The specific epithet "junensis" is from the type locality place name, Juna Downs.

\section{Genus Corindia Bickel, 1986}

\section{REMARKS}

Corindia species are often found on the trunks of smooth-barked eucalypt trees. Here they display a stance similar to that of Medetera, a vertical upright posture, with the body leaning outwards, such that the abdomen makes an angle with the surface. Corindia is widespread in Australia with nine previously described species, and a number awaiting description (see Bickel 1986 for details of described species).

\section{Corindia collessi Bickel, 1986}

Figure $6 b$

Corindia collessi Bickel 1986: 140.

\section{REMARKS}

Corindia collessi occurs across northern tropical Australia, and is known from the Millstream site and the Kimberley Ranges in Western Australia. It is broadly symptric with C. capricornis.

\section{Corindia capricornis Bickel, 1986}

Figure $6 \mathrm{c}$

Corindia capricornis Bickel 1986: 141.

\section{REMARKS}

Corindia capricornis is known from tropical Queensland at the base of the Cape York Peninsula, and from the Kimberleys and Millstream site in Western Australia.

\section{Corindia gascoynensis Bickel sp. nov.}

Figures $6 \mathrm{~d}-\mathrm{e}$

urn:Isid:zoobank.org:act:184158C5-E962-4619-B7D5777FE4D9162A

\section{MATERIAL EXAMINED}

\section{Holotype}

Australia: Western Australia: 1 oे, Gascoyne River and Highway 1, ENE of Carnarvon, 24 $50^{\circ}$ 'S, $113^{\circ} 46^{\prime} \mathrm{E}, 20 \mathrm{~m}$, 11-14 August 2002, sticky traps on Eucalyptus sp. trunks, D.J. Bickel (WAM 83878).

\section{Paratypes}

Australia: Western Australia: 22 0,8 क, same data as holotype; (WAM 83879); 4 $\delta, 2$ ㅇ (ANIC); 16 ô, 6 우 (AMS).

\section{DESCRIPTION}

\section{Male}

Length $2.5-2.7 \mathrm{~mm}$; wing: $2.6 \times 0.8 \mathrm{~mm}$.

Head: major setae black; vertex blue violet; pair of strong vertical and ocellar setae present; face violet and with longitudinal striae; distinct fronto-clypeal suture present; eyes well-separated; 
eyes facets uniform; palp dark brown with black short setulae and apical seta; proboscis brownish; antenna entirely black; scape and pedicel short; first flagellomere rounded subrectangular; arista apical, almost $11 / 2$ head height; lower postorbitals whitish, upper postoribitals black.

Thorax: mesonotum and scutellum dark metallic blue with violet reflections; setae black with brownish reflections; ac short biseriate, approximately 10 pairs; five dc setae present, decreasing in size anteriorly; strong pa, sa, sr, $\mathrm{hm}$ and $2 \mathrm{npl}$ setae present; anterior slope of mesonotum with field of some short brownish setulae, on each side extending anteriad of mesonotal suture and across from humeral callus to dc row; scutellum with pair of strong median setae and pair short weak lateral hairs.

Legs: all coxae, trochanters and femora brown almost to apices; femoral "knees", tibiae and tarsi yellow; coxal vestiture whitish although stronger setae appear yellowish; CI with short anterior setae and some stronger distolateral setae; CII with short anterior setae and 2 stronger anterolateral seta; CIII with strong lateral seta at $1 / 3$ and 2 shorter lateral setae ventrad; I: 3.1; 2.6; $1.4 / 0.7 / 0.5 / 0.3 / 0.3$; leg bare of major setae; II: 3.2; 3.2; 1.3/ 0.9/ 0.5/ 0.4/ 0.3; FII with subapical pv seta; TII bare except for short anterior and ventral apicoventral seta; III: 3.4; 3.4; 0.8/ 1.4/ 0.7/ 0.4/ 0.3; leg III bare of major setae.

Wing: $\mathrm{R}_{1}$ joins the costa near $1 / 3 ; \mathrm{R}_{4+5}$ and $\mathrm{M}$ subparallel to apex; CuAx ratio: 0.8; lower calypter pale yellow with white hairs, halter pale yellow.

Abdomen: tergum mostly brown with metallic blue green reflections; vestiture brown with yellowish reflections; terga with longer seta near margins and otherwise covered with short setae; sterna brownish; sternum 8 brown; epandrium mostly dark brown, but with hypandrium, cercus and surstylus yellow; hypopygium (Figure 6e); epandrium subrectangular; epandrial lobe with two strong seta arising from short basal collar; hypandrium elongate, with angular flexion near 7/8; surstylus elongate and cleft distally, with curved dorsal outer arm and shorter ventral arm with apical setae; cercus comprising rounded setose basal mound from which projects distolateral arm bearing apical setae.

\section{Female}

Similar to male except as noted: face slightly wider; abdominal terga 2 and 3 variably yellow laterally, and dark brown dorsally with some yellow areas near dorsal midline, although some specimens with terga mostly dark brown; sterna 3-5 mostly yellow.

\section{REMARKS}

Corindia gascoynensis is known only from the type locality near the Gascoyne River, east of Carnarvon, Western Australia and just south of the Tropic of
Capricorn. Although not strictly in the Pilbara, it is nevertheless described here. It was collected with sticky traps placed on smooth-barked eucalypt trees. In genitalic structure it is most similar to $C$. robensis Bickel from South Australia and C. cooloola Bickel from Queensland.

\section{ETYMOLOGY}

The specific epithet "gascoynensis" refers to the types series of this species collected near the Gascoyne River, Western Australia.

\section{Corindia sp.}

\section{REMARKS}

Bickel (1986) cited the possible occurrence of the predominately eastern Australian Corindia major Bickel at the Millstream, Western Australia site based on the similar yellow abdominal terga 1-3 of isolated female specimens (ANIC). I have not seen males that confirm the presence of this species at Millstream, and now prefer to regard these females as unidentified. Although C. gascoynensis sp. nov. has yellow female abdominal terga, it has the antenna entirely black, in contrast to the yellow scape and pedicel of $C$. major.

\section{Genus Thrypticus Gerstäcker, 1864}

\section{REMARKS}

Thrypticus is unique among the Dolichopodidae in that all known larvae are phytophagous stemminers in the monocot families Cyperaceae, Poaceae, Juncaceae, and Pontideriaceae. Females have a sclerotized, laterally flattened blade-like oviscapt designed for piercing and ovipositing within stems. The relatively small adults are generally taken by sweeping wet grassland or marsh habitat.

\section{Thrypticus australis Bickel, 1986}

Figure 6a

Thrypticus australis Bickel 1986: 145.

\section{MATERIAL EXAMINED}

\section{Additional records}

Western Australia: 2 ô, 3 , Millstream, 25 October 1970, 10 April 1971, Colless; 1 गे, Millstream-Chichester National Park, Yarraloola Road, Fortescue River, 6-11 May 2003, Malaise in broken creek bank with drying pools, $21^{\circ} 37^{\prime} 38^{\prime \prime} \mathrm{S}$, $117^{\circ} 07^{\prime} 27^{\prime \prime} \mathrm{E}$, Lambkin and Weir (ANIC).

\section{REMARKS}

Thrypticus australis occupies a broad zone across much of Australia and is also on isolated Norfolk 
Island. It has been taken from such diverse habitats as coastal swamps, subalpine woodland and interior desert. It is one of the few dolichopodids found throughout much of the semiarid and arid interior, in association with riverine habitats. Here it is able to utilize its larval stem-mining habit and exploit the temporary abundance of grasses and sedges after rainfall.

\section{Thrypticus fortescuensis Bickel, 1986}

Thrypticus fortescuensis Bickel 1986: 147.

\section{REMARKS}

Thrypticus fortescuensis is known only from the type series taken along the Fortescue River at Millstream, Western Australia.

\section{Subfamily Hydrophorinae Fallén, 1823}

Genus Hydrophorus Fallén, 1823

Hydrophorus praecox (Lehmann, 1822)

Figure $6 f$

Dolichopus praecox Lehmann, 1822: 42.

\section{MATERIAL EXAMINED}

\section{Additional records}

Australia: Western Australia: 1 ก, 4 \&, $1 \mathrm{~km} \mathrm{NE}$ of Millstream, 2 November 1970, Upton and Feehan (ANIC); 1 ㅇ, Barrow Island, WGS84 (50): 337551, 7699293, 15 March 2006, S. Callan and R. Graham (WAM 83884); 1 ㅇ, Hamersley Station, Railway Road past Cooks Bore turnoff, Ridge paddock, UWA exclusion site, $22^{\circ} 18^{\prime} 6^{\prime \prime} \mathrm{S}, 117^{\circ} 41^{\prime} 35^{\prime \prime} \mathrm{E}$, Malaise trap, 15-19 May 2006, K.248815 (AMS).

\section{REMARKS}

The near cosmopolitan genus Hydrophorus is characteristically found in association with saline, brackish and freshwater littoral habitats. Only one species is known from Australia, Hydrophorus praecox, a widespread tramp species recorded from many Old World localities - Europe, Africa, Arabia, Central Asia, India, China, Australian, New Zealand, and French Polynesia (also see discussion of Afrotropical fauna in Grichanov 1997).

The species is common in Australia, and often occurs in large numbers in various coastal habitats and along the shores of interior playa lakes. Collections indicate that $H$. praecox occurs throughout the continent in a wide range of habitats, from arid desert to montane streams near Nothofagus forest in northern New South Wales. It maintains a constant facies throughout its Australian range, with only minor variation in size or colouration.

\section{Genus Thinophilus Wahlberg, 1844}

\section{REMARKS}

Thinophilus is a diverse and almost cosmopolitan genus that occurs in a variety of littoral habitats, characteristically the marine tidal zone and mangroves, but also in various riverine and lacustrine habitats. The Australian fauna is rich and many species await description.

\section{Thinophilus splendens Grootaert and Meuffels, 1984}

Figures 8c-e

Thinophilus splendens Grootaert and Meuffels 1984: 217.

\section{MATERIAL EXAMINED}

\section{Additional records}

Australia: Northern Territory: 1 त, Surprise Creek, $45 \mathrm{~km}$ SW by S of Borroloola, 15 April 1976, Colless; 5 O , 2 ㅇ, Birraduk Creek, 17 km WSW of Nimbuwah Rock, 4 June 1975, Colless; 1 o, 1 ㅇ, McArthur River, 2 km SSE of Borroloola, 30 April 1976, Colless; 2 d, 2 +, McArthur River, $14 \mathrm{~km} \mathrm{~S}$ by W of Cape Crawford, 12 April 1976, 1 o, 6 ㅇ, Kakadu National Park, South Alligator River, Coronation Hill, 4-5 June 1988, Cranston; 1 ô, Nourlangie Creek, $6 \mathrm{~km}$. E. of Mt Cahill, 18 November 1972, Colless (ANIC). Queensland: 1 त, 4 ㅇ, Pimpama, 14 December 1964, Norris (ANIC); 1 त, $3 \mathrm{~km} \mathrm{~W}$ of Batavia Downs, $12^{\circ} 40^{\prime} \mathrm{S} 142^{\circ} 39^{\prime} \mathrm{E}$, 16 June -22 July 1992, Zborowski (ANIC); 1 ô, 1 ㅇ, Bowling Green Bay, $19^{\circ} 24^{\prime}$ S $147^{\circ} 13^{\prime}$ E, 0-5 m, tidal mud flats, 9-10 April 1994, yellow pans, Bickel (AMS). Western Australia: 1 o, 6 우, Drysdale River, Site A1, $15^{\circ} 02^{\prime}$ S $126^{\circ} 55^{\prime} \mathrm{E}, 3-8$ August 1975, Common and Upton; 1 , Carson Escarpment, Site B1, 14\%49'S, 126 $49^{\prime} \mathrm{E}$, 9-15 August 1975, Common and Upton; 6 +, Millstream, 9-11 April 1971, Colless (ANIC).

\section{DESCRIPTION}

\section{Male}

Body length: 1.9-2.2 mm; wing: 2.2 x 0.8 .

Head: postocular setae long and white in ventral two-thirds, but short and black on the upper third; postvertical setae positioned on the dorsal postcranium; vertex and frons dull blue-green with bronze reflections; pairs of strong diverging ocellars, short verticals; eyes widely separated; face and clypeus covered with dense grey pruinosity; frontoclypeal suture distinct; clypeus short, and terminating about quarter eye height from base of eyes; palpi large and not projecting but appressed to head above proboscis, ivory coloured, and each with 
two vertical median rows of short brown setulae; proboscis grey with white setulae; scape, ventral half of pedicel and basal half of first flagellomere yellow, with dorsalmost pedicel and distal first flagellomere dark brown; first flagellomere rounded with short dorsal arista, about two-thirds head height in length.

Thorax: dorsum metallic green, with some bronze reflections; pleura with grey pruinosity; setae black; ac absent; 4 pairs dc present; $1 \mathrm{pa}, 2 \mathrm{sa}, 1 \mathrm{sr}, 1 \mathrm{hm}, 1$ presutural intraalar, $1 \mathrm{pm}$, only $1 \mathrm{npl}$; propleuron with fine white hairs near occiput; median scutellar setae strong, laterals absent.

Legs: CI yellow; CII and CIII dark brown; remainder of legs yellow, with distal tarsomeres infuscated; CI and CIII with whitish anterior hairs; CIII with weak white lateral seta at $1 / 2$; I: 3.0; 2.7; 1.0/ 0.5/ 0.4/ 0.3/ 0.4; FI with short subapical pv seta, and with av and pv rows, each with 7-8 long white setae, and with some additional weak brownish anterior setae (MSSC); TI with strong black pd seta at $1 / 4$, and with some $18-20$ weak white ventral setae along length; II: 3.6; 3.5; 1.6/ 0.7/ 0.5/ 0.4/ 0.3; FII with short subapical av and pv seta; TII with ad-pd setal pair at $1 / 4$ and with apical circle of short setae; III: 4.2; 3.9; 0.7/ 0.8/ 0.5/ 0.4/ 0.4; FIII dorsal seta at $4 / 5$, with subapical av and pv setae and in distal half with irregular row of 5-6 dark brown ventral setae; TIII with dorsal seta at $2 / 5$ and subapically.

Wing: hyaline; $\mathrm{R}_{4+5}$ and $\mathrm{M}$ gradually diverging near base, but becoming subparallel beyond crossvein $\mathrm{dm}-\mathrm{cu}$, and $\mathrm{M}$ ends at wing apex; $\mathrm{dm}-\mathrm{cu}$ straight; $\mathrm{CuAx}$ ratio: 0.7; lower calypter yellow with fan of pale yellow setae; halter pale yellow.

Abdomen: metallic blue-green with bronze reflections, with grey pruinosity laterally, and with short black vestiture; hypopygium at rest enclosed by ventral areas of segments $5-7$ so only cerci visible externally (Figure 8c); hypopygium (Figure 8e) dark brown with ivory coloured cerci; epandrium elongate; hypandrium as elongate hood; phallus elongate and tapering; surstylus elongate and tapering and subapically curved; cercus elongate and slightly clavate distally, and with white marginal and apical setae.

\section{Female}

Similar to male, except as noted: slightly larger, wing length: 2.3; face-clypeus slightly wider; palpus with distinctly yellow apex; leg I unmodified, FI and TI bare.

\section{REMARKS}

Grootaert and Meuffels described Thinophilus splendens from one male and five females (IRSN, not seen) collected near Bogia, coastal Madang Province, Papua New Guinea. They noted that the specimens had little pruinosity, which is correct except for the thoracic pleura which have grey pruinosity. The Australian specimens considered here match their detailed description, and I consider them conspecific.

Thinophilus splendens also occurs in Australia, in both coastal and some interior habitats, from southeastern Queensland to Cape York Peninsula, across northern tropical Australia to the Kimberley and Pilbara districts, Western Australia. The long white ventral setae on male femur I and tibia I (MSSC) are diagnostic for this species.

\section{Thinophilus eboricoxa Bickel sp. nov.}

Figures 8a-b

urn:Isid:zoobank.org:act:E0771F80-5B0D-40F4-97614258487D0867

\section{MATERIAL EXAMINED}

Holotype

Australia: Western Australia: 1 ô, $6 \mathrm{~km} \mathrm{~W}$ of Martins Well, West Kimberley, 26 April 1977, Malaise trap, D.H. Colless (ANIC).

\section{Paratypes}

Australia: Western Australia: 2 ภ, 12 ㅇ, same data as holotype (ANIC).

\section{Additional records}

Australia: Western Australia: 1 , Barrow Island, 4 February 1977, at light, H. Heatwole and W.H. Butler (AMS).

\section{DESCRIPTION}

\section{Male}

Length: $3.5 \mathrm{~mm}$; wing: $3.1 \times 1.0 \mathrm{~mm}$.

Head: postocular setae long and white in ventral two-thirds, but shorter and black on the upper third; postvertical setae positioned on the dorsal postcranium; pairs of strong diverging ocellars and incurved verticals, vertex, frons, face and clypeus covered by dense silvery pruinosity; eyes widely separated; frontoclypeal suture distinct; clypeus short, and terminating about one fifth eye height from base of eyes; eyes with anteroventral facets enlarged; palpi large and projecting over proboscis, and ivory coloured with a few short dark setulae near median and ventral margin; proboscis grey with white setulae; antenna entirely orange-yellow; first flagellomere rounded with short yellow dorsal arista, about two-thirds head height in length.

Thorax: dorsum metallic green, with some bronze reflections and covered with grey pruinosity, except for bronze stripe over middle of ac band, over dc row and bronze areas on scutellum; pleura with grey pruinosity; setae black; ac absent; 6 pairs dc 
present; 1 pa, $2 \mathrm{sa}, 1 \mathrm{sr}, 1 \mathrm{hm}, 1$ presutural intraalar, $1 \mathrm{pm}$, only $1 \mathrm{npl}$; propleuron with fine white hairs near occiput; median scutellar setae strong, lateral as weak seta about one-third length.

Legs: CI yellow with ivory-coloured pruinosity; CII and CIII basally metallic green with grey pruinosity, becoming yellow distally; remainder of legs yellow, with distalmost tarsomeres infuscated; CI with tuft of white anterior hairs near base and with some short white anterior hairs distally; CII with some white anterior setae and black anterolateral seta at $1 / 2$; CIII with black lateral seta at $1 / 2$; legs appear bare with short erect black vestiture; I: $4.2 ; 3.5 ; 1.4$; $0.6 / 0.5 / 0.3 / 0.4$; FI with row 4 short subapical pv setae; TI with ad-pd setal pair at 2/5, and with strong subapical ventral seta; It1 with ventral row of 8 short erect peg-like black setae (MSSC); II: 5.5; 5.0; 2.6/ 1.0/ $0.8 / 0.4$ / 0.5; FII with distinct av seta at $1 / 8$; TII with ad seta at $1 / 8$, ad-pd setal pair at $1 / 2$ and with apical circle of strong av and pv setae and shorter ad and anterior seta; III: 6.4 ; 6.3; 1.4 / 1.2/ 0.5/ 0.4/ 0.4; FIII without distinctive setation; TIII with offset ad-pd pair at $1 / 5$, ad at 2/5, distinct ad-pd setal pair at $1 / 2$, and with strong subapical ad, pd and av setae.

Wing: hyaline; $\mathrm{R}_{4+5}$ and $\mathrm{M}$ gradually diverging near base; $\mathrm{M}$ with bosse alaire or flexion about twofifths distance beyond crossvein $\mathrm{dm}-\mathrm{Cu}$, and beyond which $\mathrm{M}$ becomes subparallel with $\mathrm{R}_{4+5^{\prime}}$ and ends at wing apex; $\mathrm{R}_{4+5}$ and $\mathrm{M}$ subparallel to apex, and $M$ with slight flexion towards $R_{4+5}$ about one third distance beyond crossvein $\mathrm{dm}-\mathrm{cu}$; crossvein $\mathrm{dm}-\mathrm{cu}$ straight; CuAx ratio: 0.8; lower calypter yellow with fan of pale yellow setae; halter pale yellow.

Abdomen: metallic green with bronze reflections, covered with brownish pruinosity, with dense grey pruinosity laterally, and covered with short black vestiture; hypopygium elongate and at rest enclosed by ventral areas of segments 5-7 (Figure 7b); hypopygium dark brown with yellow cerci; phallus subapically with elongate ribbon-like projection; cercus narrow digitiform, white with pale white hairs.

\section{Female}

Similar to male, except as noted: slightly larger, wing length: 3.5 ; $\mathrm{It}_{1}$ ventrally bare, without short erect setae.

\section{REMARKS}

Thinophilus eboricoxa is known only from the Kimberley coast and Barrow Island, Western Australia. The ivory coloured palps and coxa I, as well as the elongate thin cercus are diagnostic.

\section{ETYMOLOGY}

The specific epithet eboricoxa is derived from the Latin, eboris meaning "ivory" and coxa meaning "hip."
Thinophilus yarraloola Bickel sp. nov.

Figures $8 \mathrm{f}-\mathrm{g}$

urn:Isid:zoobank.org:act:668CF81C-DA10-4F33-8472B9DA48AE0CD3

\section{MATERIAL EXAMINED}

\section{Holotype}

Australia: Western Australia: 1 $\hat{\jmath}$, MillstreamChichester National Park, Yarraloola Rd, Fortescue River, 28 April-3 May 2003, Malaise trap in rocky creek bank: drying pools, $21^{\circ} 37^{\prime} 38^{\prime \prime} \mathrm{S}, 117^{\circ} 07^{\prime} 27^{\prime \prime} \mathrm{E}$, Lambkin and Weir (ANIC).

\section{Paratype}

Australia: Western Australia: 1 त, Karijini National Park: Weano Gorge Rd 15-20 May 2003, grassy dry creek, 695m, 22 $21^{\prime} 19^{\prime \prime} \mathrm{S}, 118^{\circ} 15^{\prime} 00^{\prime \prime} \mathrm{E}$, Malaise trap, C. Lambkin and T. Weir (ANIC).

\section{DESCRIPTION}

\section{Male}

Length: 3.2-3.3 mm; wing: $3.2 \times 1.1 \mathrm{~mm}$.

Head: postocular setae long and white in ventral two-thirds, but shorter and black on the upper third; vertex, frons, face and clypeus dull metallic blue-green with bronze reflections and dusting of brownish pruinosity; postvertical setae positioned on the dorsal postcranium; pairs of strong diverging ocellars and incurved verticals, eyes widely separated; frontoclypeal suture distinct; clypeus short, and terminating about one fifth eye height from base of eyes; eyes with anteroventral facets enlarged; palpi large and projecting over proboscis, and ivory coloured with 7-12 short on external surface; proboscis brown with white setae; antennal scape and pedicel brown (first flagellomere missing on both specimens).

Thorax: brown with metallic green and bronze reflections and mesonotum and scutellum covered with brown pruinosity, pleura with grey pruinosity; setae black; ac absent; 5 strong posterior dc, with anterior most dc short; 1 pa, 2 sa, $1 \mathrm{sr}, 1 \mathrm{hm}, 1$ presutural intraalar, $1 \mathrm{pm}$, only $1 \mathrm{npl}$; propleuron with fine pale hairs near occiput; median scutellar setae strong, lateral as weak seta about one-third length.

Legs. CI yellow with but with some metallic green cuticle near very base; $\mathrm{CII}$ and CIII basally metallic green with grey pruinosity, becoming yellow distally; remainder of legs yellow, with distalmost tarsomeres infuscated; CI with scattered short black anterior hairs and with lateral two setae stronger; CII with some short black anterior and black anterolateral seta at $1 \frac{1}{2}$; CIII with black lateral seta at $1 / 2$; I: $4.5 ; 3.5 ; 1.3 ; 0.7 / 0.5 / 0.3 / 0.4$; FI with row $4-5$ short black setae along basal half, and with $3-4$ 
short subapical pv setae; TI with offset ad-pd setal pair with ad strong than pd at $1 / 5$ and $1 / 2$, and with short subapical ventral seta; II: 4.4; 4.8; 2.7/ 1.0/ 0.5/ 0.4/ 0.4; FII with $4-5$ pd setae along distal third; TII with ad-pd setal pairs at $1 / 5$ and $1 / 2$, and with apical circle of strong av and pv seta and shorter ad and anterior seta; III: 5.7; 6.1; 1.5/ 1.3/ 0.8/ 0.5/ 0.4; FIII with $2-4$ strong ad setae, positioned between $1 / 2$ and $4 / 5$, otherwise without distinctive setation; TIII with offset ad-pd setal pair at $1 / 5$, ad at $2 / 5$, strong offset ad-pd setal pair near $1 / 2$, pd seta near $3 / 4$, and with strong subapical ad, pd and av seta.

Wing: hyaline; $\mathrm{R}_{4+5}$ and $\mathrm{M}$ gradually diverging near base; $\mathrm{M}$ with bosse alaire or flexion about one third distance beyond crossvein $\mathrm{dm}-\mathrm{cu}$, and beyond which $\mathrm{M}$ becomes subparallel with $\mathrm{R}_{4+5}$ and ends at wing apex; crossvein $\mathrm{dm}$-cu slightly bowed; CuAx ratio: 0.8; lower calypter yellow with fan of pale yellow setae; halter pale yellow.

Abdomen: terga 1-4 metallic blue-green with bronze reflections, with dense grey pruinosity laterally, and with short black vestiture; terga 5-6 shining metallic blue/violet postabdomen (in striking contrast to the anterior four terga); hypopygium (Figure 8g) elongate, dark brown; surstylus narrow tapering and apically curved; phallus white curled; cerci dark brown, large and bladelike with upcurved apex.

\section{Female}

Unknown.

\section{REMARKS}

Thinophilus yarraloola_is known from Millstream and Karijini areas along the Fortescue River drainage of the Pilbara district. This species is part of a larger Australasian/ Oriental group whose males have a shining metallic blue/violet postabdomen (in striking contrast to the anterior four abdominal terga), and large blade-like cerci. I have seen additional undescribed species (ANIC, AMS) from across Australia in both coastal and interior habitats (including species from the Kimberley district, Western Australia), and from Kalimantan, Borneo (AMS). As well, Thinophilus flagellatus Grootaert and Meuffels from Papua New Guinea belongs to this group.

\section{ETYMOLOGY}

The specific epithet yarraloola is a place name of indigenous origin, and refers to the species type locale in Millstream-Chichester National Park. It is a noun in apposition.

\section{Thinophilus sp.}

\section{REMARKS}

I have seen a female Thinophilus species from Barrow Island which cannot confidently be associated with males from elsewhere in Australia (ㅇ, Barrow I., WGS84 (50): 341230 7707278, 2 May 2007, S. Callan and K. Edwards).

\section{Subfamily Sympycninae Loew, 1857}

\section{Genus Chaetogonopteron de Meijere, 1914}

\section{REMARKS}

Chaetogonopteron is a diverse genus found in the Afrotropical, Oriental, and Australasian regions. Although most species occur in the moist tropics, species are known from higher latitudes, such as central Algeria and southern Australia. Some 69 species have been referred to the genus (Yang et al. 2006), but the genus is much larger, and most species are undescribed. Samples from montane tropical forests of New Guinea, the Philippines and Borneo indicate very rich Chaetogonopteron faunas. I have seen some 25 undescribed recent Australian species, and a fossil species has been described from Cape York amber (Bickel, 2009b).

Chaetogonopteron is separated from other members of the subfamily Sympycninae by two synapomorphies found on male leg III (see Meuffels and Grootaert 1997):

a) leg III tarsomere 1 is shorter than tarsomere 2 (both sexes); in other genera of the Sympycninae, leg III tarsomere 1 is usually longer than tarsomere 2.

b) Male leg III tarsomere 2 has an elongate projection, known as a clidium or vermiform appendage. The clidium is a male secondary sexual character and often has diagnostic species characters, its length, shape (if bent, branched, etc.) and setation (modified setae are often present).

The three species described below comprise a species group, all of which have laterally asymmetrical male hypopygia. This group is unusual in that many species are adapted to arid habitats, unusual in Chaetogonopteron, a genus more characteristic of mesic forests. I have included a description of the widespread C. capricorne for completeness, and although it is not recorded from the Pilbara region, I suspect it eventually might be found there.

\section{Chaetogonopteron bartaki Olejnicek and Kubik}

$$
\text { Figures } 9 a-b \text {, e }
$$

Chaetogonopteron bartaki Olejníček and Kubík 2007: 183.

\section{MATERIAL EXAMINED}

\section{Holotype}

Olejníček and Kubík based their description on specimens collected in Brisbane, Queensland by M. Barták (to be deposited AMS). 


\section{Additional records}

Australia: Australian Capital Territory: Black Mtn., Malaise site 2, 15-17 February 1980 (ANIC). New South Wales: Wallaroi Creek, $15 \mathrm{~km} \mathrm{~S} \mathrm{of}$ Condoblin, 27 December 1976; Pond's Creek, E of Armidale, 13 October 1962; Fowler's Gap, N of Broken Hill, $31.05^{\circ} \mathrm{S} 141.47^{\circ} \mathrm{E}, 29$ November to 2 December 1981 (ANIC); Hay, 5 December 1978; Bogan River, nr Nyngan, 29 November 1984; Pilliga Scrub, Timmallallie Creek and Newell Hwy., 15 November 1990, yellow pans; S of Mendooran, 3 October 1970, at light; Old Mootwingee Gorge, 5-8 November 1984 (AMS). Northern Territory: 32 km WNW of Alice Springs, 9 October 1978, Malaise trap, D.H. Colless (ANIC); $14 \mathrm{mi}$. W of Humpty Doo, 10 June 1964 (BPBM); Todd River, 9 km N by E of Alice Springs, 11 October 1978, Malaise trap; MacArthur River, 48 km SW by S of Borroloola, 14 April 1978; Surprise Creek, $45 \mathrm{~km}$ SW by S of Borroloola, 14-20 April 1978; Batten Point, $32 \mathrm{~km} \mathrm{NE}$ by E of Borroloola, 18 April 1978 (ANIC). Queensland: Dart River, $31 \mathrm{~km} \mathrm{NW}$ by $\mathrm{N}$ of Longreach, 7 April 1976; 7-14 miles W of Herberton, via Watsonville, 1 May 1967; 15 km S of Charleville, 6 April 1976 (ANIC); Escot Stn., W of Burketown, 17.44S 139.25E 19 December 1991; Carnarvon Creek, 16 km NE of Park, yellow pans at pools in creek bed, 28 November 1992 (AMS); Emerald, 6 to 18 September 1981; Wallumbilla, 9-11 April 1977 (QDPI); Lake Broadwater, nr. Dalby, 25-26 November 1986; Mt. Moffat National Park, Top Moffat, 13 December 1987, at light; Rocky Creek, Chinchilla, 26 July-17 August 1987. Scawfell Is., NE of Mackay, $20.5^{\circ} \mathrm{S}$ $147.37^{\circ} \mathrm{E}, 17$ to 26 November 1986 (QMB); Kholo, 28 December 1972 (CNC); Normanton, 7 May 1963, at light (SAM). Victoria: Laverton, shallow saline lake, 27 November 1981 (AMS). Western Australia: $10 \mathrm{mi}$. E of Northam, 14 November 1962 (CAS); Crawley, 5 May 1934; $60 \mathrm{~km} \mathrm{NE}$ of Wubin, $29.43^{\circ} \mathrm{S}, 117.04^{\circ} \mathrm{E}$, 27 September 1981 (ANIC); “The Humps," 19 km N of Hyden, 32.19S 118.57E, 10 January 1986, at light (UQIC); Karijini National Park: 7 , 10 , Weano Gorge Rd 15-20 May 2003, grassy dry creek, 695m, $22^{\circ} 21^{\prime} 19^{\prime \prime} \mathrm{S}, 118^{\circ} 15^{\prime} 00^{\prime \prime} \mathrm{E}$, Malaise trap, C. Lambkin and T. Weir; 3 ก̃, 1 , Johnson Gorge, 23 April-14 May 2003, drying pool in rocky creek, EucalyptusAcacia scrub, $684 \mathrm{~m}, 2^{\circ} 21^{\prime} 19^{\prime \prime} \mathrm{S}, 118^{\circ} 15^{\prime} 00^{\prime \prime} \mathrm{E}$, Lambkin and Weir, Malaise trap (ANIC) [128 $\hat{\jmath}, 65$ q examined].

\section{DESCRIPTION}

\section{Male}

Length: $3.0 \mathrm{~mm}$; wing: 2.4 x $0.9 \mathrm{~mm}$.

Head: frons metallic blue-green with dense grey pruinosity; head setae black; strong verticals, strong diverging ocellars present; postverticals represented by 4-5 short black setae, continuation of postorbitals; male face narrowed to small silvery triangle beneath antennae and eyes joined along face; anterior facets enlarged; palp yellow; proboscis brown; ventral postcranium with pale hairs, lower postorbitals pale yellow, dorsally black; antenna mostly yellow, but first flagellomere sometimes infuscated; first flagellomere short subtriangular; arista dorsal, black, with distinctly flattened nodes at 2/3 and apex (MSSC); postorbitals whitish ventrally and black dorsally.

Thorax: metallic blue-green and covered with grey pruinosity; metepimeron yellow; disc of scutellum blue-green, but margin near lateral setae distinctly brownish; mesoscutum slightly flattened anteriad of scutellum; setae black; ac short, uniseriate; 5 strong dc present; 1 pa, 2 sa (anterior weak), 2 sr, 1 strong upcurved hm, 1 weak pm and 2 npl; strong median scutellars present, laterals reduced to tiny weak hairs or absent; propleuron with pale seta near CI.

Legs: CI yellow: CII and CIII dark metallic green; trochanters and remainder of legs yellow (except where noted), and distalmost tarsomeres II and III infuscated; CI with 3-4 pale distolateral setae and CIII with black lateral seta; I: 12.0; 11.0; 7.5/ 4.0/ 3.0/ 2.0/ 1.2; FI with slightly swollen base (MSSC), and with 2 short pale basoventral setae (MSSC); TI laterally flattened and with elongate anterior grove which bears bright silvery pruinosity (MSSC), and with 2 dark posterior subapical setae (MSSC); It 1 yellow basally, becoming white-silvery distad (MSSC); It ${ }_{2-4}$ flattened and totally white-silvery, and each tarsomere with dorsal crest of silvery hairs (MSSC); It 5 pale yellow (MSSC); II: 6.5; 8.0; 5.0/ 2.5/ 1.8/ 1.0/ 0.8; TII with ad setae at $1 / 6$ and $2 / 5$, pd seta at $1 / 4$ and ad at $2 / 5$; III: $7.5 ; 9.5 ; 0.8 ; 1.0 ; 3.8$ / 2.0/ 0.7; FIII with anterior swollen black subapical callus, circularly excavated with attendant short black hairs (MSSC, and lacking anterior preapical seta; TIII expanded distally (MSSC), with strong posterior seta at $3 / 5$, and TIII with curved apicoventral setae (MSSC); IIIt ${ }_{1}$ with strong ventral bladelike seta, and IIIt $_{2}$ with bent clidium bearing apical seta (MSSC).

Wing: hyaline; $\mathrm{M}$ bowed towards $\mathrm{R}_{4+5}$ in distal $1 / 3$ of wing; $\mathrm{CuAx}$ ratio from 0.5; lower calypter pale with fan of yellow setae; halter yellow

Abdomen: tergum 1 dark brown; tergum 2 yellow with dorsal infuscation; terga 3 to 6 dark brown with distal margins yellowish; tergum 1 with some long lateral setae; distal abdomen expanded with sternum 6 forming hood over hypopygium; hypopygium mostly yellow with dark brown surstyli (Figure 9e); hypopygial foramen left lateral; surstyli asymmetrical, with left surstylus porrect and digitiform, and right surstylus with diverging curved dorsal and ventral projections; cercus short and setose. 


\section{Female}

Similar to male, except lacks MSSC and as noted: eyes separated, with silvery pruinosity on face; arista about equal to head height, and unmodified; scutellum dorsally with wide yellow margin; I: 6.0; 5.0; 3.3/ 1.8/ 1.2/ 1.0/ 0.8; FI not swollen and without basoventral setae; TI and It unmodified; II: 7.5; 8.5; 4.8/ 2.5/ 1.5/ 1.0/ 0.8; TII with stronger setae, with ad at $1 / 6$ and $1 / 3$, pd at $1 / 5$, strong ventral at $1 / 3$, and weaker ventral at $2 / 3$; III: 8.0 ; 9.5; 1.2; 2.5; 2.0/ 1.0/ 0.8; FIII and TIII unmodified, but also lacking anterior preapical seta; TIII with row of dorsal setae, ad at $1 / 3$ and also with strong posterior seta at $3 / 5$; IIIt unmodified; abdominal colouration similar.

\section{REMARKS}

Chaetogonopteron bartaki is widely distributed across mainland Australia, primarily in interior semiarid and arid habitats, including Karijini National Park in the Pilbara. However, it was also collected in a Malaise trap on Black Mountain, A.C.T., a cold montane woodland, and in tropical coastal habitats, such as Cumberland Group of the Great Barrier Reef. In arid interior sites, it is often collected in large numbers, especially in the winter and early spring.

The binodate male arista, the silvery male leg I, and the callus on FIII (all MSSC) are striking and diagnostic. Minor intraspecific variation in the position of leg setae and colouration is evident among specimens.

\section{Chaetogonopteron vexillum Bickel sp. nov.}

Figures $9 c, f$

urn:Isid:zoobank.org:act:A6563A79-AD91-4050-BB582763E3DF358C

\section{MATERIAL EXAMINED}

\section{Holotype}

Australia: Western Australia: 1 ô, Millstream, Crossing Pool, 21 October 1970, D.H. Colless (ANIC).

\section{Paratypes}

Australia: Western Australia: 4 के, 3 ㅇ, Millstream, 20-25 October 1970, D.H. Colless (ANIC).

\section{Additional records}

Australia: Northern Territory: 1 , Todd River, $9 \mathrm{~km} \mathrm{~N}$ by E of Alice Springs, 11 October 1978, Malaise trap, Colless. Queensland: 1 त, Eidsvold, 6 April 1924, Bancroft; possible $\bigcirc$ : $3 \mathrm{~km} \mathrm{NE}$ of Mt Webb, 15.03S 145.09E, 2 October 1980, Colless; Annan River, $3 \mathrm{~km} \mathrm{~W}$ by S of Black Mtn, 28 September 1980, Colless; $3.5 \mathrm{~km} \mathrm{SW}$ by S of Mt Baird, 17.26S 145.04E, 28 November 1981, Colless. (ANIC). Western
Australia: Karijini National Park: (a) 8 万, 4 , Weano Gorge Rd, 25 April-20 May 2003, grassy dry creek, $695 \mathrm{~m}, 22^{\circ} 21^{\prime} 19^{\prime \prime} \mathrm{S}, 118^{\circ} 15^{\prime} 00^{\prime \prime} \mathrm{E}$, Malaise trap, Lambkin and Weir; (b) 2 , Juna Downs Road, 19-25 April 2003, drying pool in rocky Turee Creek, 789 $\mathrm{m}, 22^{\circ} 41^{\prime} 57^{\prime \prime} \mathrm{S}, 118^{\circ} 25^{\prime} 06^{\prime \prime} \mathrm{E}$, Malaise trap, Lambkin and Weir; (c) 1 त̂, Johnson Gorge, 23 April-14 May 2003, drying pool in rocky creek, Eucalyptus-Acacia scrub, $684 \mathrm{~m}, 22^{\circ} 21^{\prime} 19^{\prime \prime} \mathrm{S}, 118^{\circ} 15^{\prime} 00^{\prime \prime} \mathrm{E}$, Malaise trap, Lambkin and Weir; Millstream-Chichester National Park: (a) 8 त̂, Yarraloola Rd, Fortescue River, 28 April-3 May 2003, Malaise trap in rocky creek bank with drying pools $21^{\circ} 37^{\prime} 38^{\prime \prime} \mathrm{S}, 117^{\circ} 07^{\prime} 27^{\prime \prime} \mathrm{E}$, Lambkin

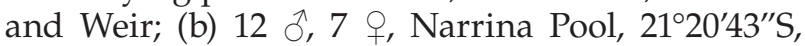
$117^{\circ} 16^{\prime} 08^{\prime \prime} \mathrm{E}, 150 \mathrm{~m}, 27$ April-7 May 2003, Malaise over spring in rocky ravine, Lambkin and Weir (ANIC).

\section{DESCRIPTION}

\section{Male}

Length: $2.6-2.7 \mathrm{~mm}$; wing: $2.4 \times 0.8 \mathrm{~mm}$.

Head: frons metallic green-bronze; head setae black; strong verticals, strong diverging ocellars present; postverticals represented by $4-5$ short black setae, continuation of postorbitals; male face narrowed to small silvery triangle beneath antennae and eyes joined along face; palp silvery; proboscis brown; antenna brown; 1st flagellomere not strongly produced ventrally; arista dorsal; postorbitals whitish ventrally and black dorsally.

Thorax: metallic bronze-green with blue-green bands between ac and dc rows; pleura dull metallic blue-green with grey pruinosity; mesoscutum slightly flattened anteriad of scutellum; setae black; ac short, uniseriate; 5 strong dc present; 1 pa, 2 sa (anterior weak), $2 \mathrm{sr}, 1$ strong upcurved hm, 1 weak $\mathrm{pm}$ and $2 \mathrm{npl}$; strong median scutellars present, laterals reduced to tiny weak hairs or absent; propleuron with weak pale seta just above CI.

Legs: CI yellow; CII and CIII mostly brown; FI, FII, and tibiae mostly yellow; FIII basally yellow, brown on distal half; tarsi mostly brownish, except where noted; CI with black distolateral setae and CIII with black lateral seta; I: 5.5; 5.0; 2.5/ 2.0/ 1.2/ 0.5/ 1.0; FI with 3 black ventral setae in basal fifth (MSSC); TI from $3 / 5$ to $7 / 8$ with 5-6 distally increasing ventral setae (MSSC); $\mathrm{It}_{3}$ white, $\mathrm{It}_{4-5}$ black and both expanded as black apical flag (MSSC); II: 6.0; 8.0; 4.5/ 2.5/ 2.0/ 1.2/ 0.8; FII with weak anterior posterior subapical setae; TII with ad-pd setal pair only at $1 / 5$; TII with av to ventral row of 15-18 long curved setae from $1 / 5$ to apex (MSSC), and apically swollen with strong curved black apicoventral setae (MSSC) (Figure 9c); IIt ${ }_{1}$ slightly swollen at base (MSSC); III: 6.5; 9.0; 0.8; 0.5; 3.5/ 1.5/ 1.0; FIII with weak anterior preapical seta; TIII with long posterior seta at 1/2 (MSSC) and in distal half with ventral row of curved overlapping yellowish setae (MSSC), and with 2 curved apicoventral setae; IIIt $_{1}$ 
with strong curved ventral seta (MSSC); IIIt ${ }_{2}$ with 3 strong black anterior setae; clidium with apical bladelike apical seta.

Wing: hyaline; anal angle reduced in male; $\mathrm{M}$ bowed towards $R_{4+5}$ in distal $1 / 3$ of wing; $\mathrm{CuAx}$ ratio 0.6; lower calypter yellow with fan of pale setae; halter yellow but club slightly infuscated on some specimens.

Abdomen: tergum 1 dark brown; tergum 2 mostly translucent yellow, and remainder of preabdomen dark brown; male tergum 1 with some longer lateral setae; hypopygium dark brown with yellow cerci (Figure 9f); phallus projecting outward from hypandrium; surstyli broad, bilaterally asymmetrical, and bearing strong subapical seta; cercus elongate and setose.

\section{Female}

Similar to male except lacking MSSC and as noted: eyes separated, with silvery pruinosity on face; thorax also with blue-green bands between ac and dc rows; pleura dull metallic blue-green with grey pruinosity; CI yellow, CII and CIII mostly metallic coloured, becoming yellow ventrally; TII with more complete component of setae: ad at $1 / 8$, $1 / 4$, and $1 / 2$, pd at $1 / 4$, and ventrals at $1 / 3$ and $2 / 3$; TIII with dorsals at $2 / 5$ and $2 / 3$; halters distinctly yellow; abdominal terga 1 and 2 dorsally yellowish, with remaining terga brown.

\section{REMARKS}

Chaetogonopteron vexillum is common along the Fortescue River drainage in the Pilbara district, Western Australia. It is also known from the Alice Springs district, Northern Terriotroy and central Queensland, and possibly from the base of the Cape York Peninsula (females only). It probably occurs in suitable relictual habitats across arid central Australia apparently south of the monsoonal belt. It is not known from the Kimberleys or Arnhem Land.

\section{ETYMOLOGY}

The name "vexillum" is from the Latin meaning flag, and refers to the expanded black flag-like tarsomeres 4-5 on male leg I.

\section{Chaetogonopteron capricorne Bickel sp. nov.}

Figures $9 \mathrm{~d}, \mathrm{~g}$

urn:Isid:zoobank.org:act:5A1BC46F-28ED-420C-A780B16401B6E09E

\section{MATERIAL EXAMINED}

\section{Holotype}

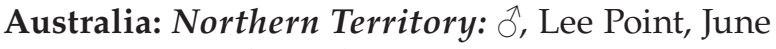
1964, K.R. Norris (ANIC).

\section{Paratypes}

Australia: Northern Territory: $1 \hat{0}, 3$, same data as holotype (ANIC).

\section{Additional records}

Australia: Northern Territory: Howard Springs, June 1964; Jabiluka W.H., 22 August 1978; 20 km W of Humpty Doo, 10 June 1964; MacArthur River, 2 km SSE of Borroloola, 20 April 1978; Surprise Creek, 45 km SW by S of Borroloola, 15 April 1978; Caranbirini W.H., $33 \mathrm{~km}$ SW of Borroloola, 22 April 1978; Batten Creek, $31 \mathrm{~km}$ WSW of Borroloola, 23 April 1978, at light; W of Bukalara Plateau, 46 km SSW of Borroloola, 23 April 1978; Bessie Springs, $16.40^{\circ} \mathrm{S} 135.31^{\circ} \mathrm{E}$, ESE of Cape Crawford, 26 October 1975; Lelia Creek, $16.34^{\circ} \mathrm{S} 135.41^{\circ} \mathrm{E}$, ESE of Cape Crawford, 6 November 1975; $8 \mathrm{~km} \mathrm{SW} \mathrm{by} \mathrm{S} \mathrm{of}$ Oenpelli Mission, 7 June 1973; $16 \mathrm{~km}$ E by N of Mt Cahill, 13 June 1973; $9 \mathrm{~km} \mathrm{~N}$ by E of Mudginberry H.S., at light, 10 June 1973 (ANIC). Queensland: Batavia Downs, $12.40^{\circ} \mathrm{S} 142.39^{\circ} \mathrm{E}, 18$ June-22 July, 22 July 23-August, and 16 September-24 October 1992; Iron Range, $9 \mathrm{~km} \mathrm{~W}$ by $\mathrm{N}$ of Mt Tozer, 28 June- 16 July 1986; Mt Webb National Park, 27 April-1 May 1981; Big Mitchell Creek, Mareeba-Molloy Rd, 4 May 1967; Annan River, 3 km W by S of Black Mtn, 28 September 1980, 26 April 1981; Mt Cook National Park, 12 May 1981; $1 \mathrm{~km} \mathrm{~W}$ of Cooktown, 13 May $1981 ; 15 \mathrm{~km} \mathrm{~W}$ of Irvinebank, $17.26^{\circ} \mathrm{S} 145.04^{\circ} \mathrm{E}, 28$ November 1981 (ANIC); Archer River crossing, $13.25^{\circ} \mathrm{S} 142.56^{\circ} \mathrm{E}, 7$ April 1989, at light (UQIC); 5 km N of Rutland Plains, 25 May 1983 (QDPI); 7 km W of Ravenshoe, 6 November 1962, 780 m (CAS). Western Australia: Carson Escarpment, Drysdale River, 9-15 August 1975; $14.52^{\circ} \mathrm{S}, 125.50^{\circ} \mathrm{E}$, "The Crusher", CALM site $8 / 1,4 \mathrm{~km} \mathrm{~S}$ by W of Mining Camp, Mitchell Plateau, 2-6 June 1988 (49 Ô, 41 †, all ANIC except where noted).

\section{DESCRIPTION}

\section{Male}

Length: $2.3-2.5 \mathrm{~mm}$; wing: $2.1 \times 0.9 \mathrm{~mm}$.

Head: frons metallic covered with dense grey pruinosity; setae black; strong verticals, strong diverging ocellars present; postverticals represented by $4-5$ short black setae, continuation of postorbitals; male face narrowed to small silvery triangle beneath antennae and eyes joined along face; palp yellow; proboscis brown; antenna yellowish with distal first flagellomere dark brown; postorbitals whitish ventrally and black dorsally.

Thorax: metallic blue-green and covered with dense grey pruinosity, but metepimeron yellow; dorsal setae black; scutellum entirely metallic bluegreen dorsally, but yellow ventrally; mesoscutum slightly flattened anteriad of scutellum; setae black; ac short, uniseriate; 5 strong dc present; 1 pa, 2 sa (anterior weak), $2 \mathrm{sr}, 1$ strong upcurved $\mathrm{hm}, 1$ weak 
pm and 2 npl; strong median scutellars present, laterals reduced to tiny weak hairs or absent; propleuron with seta just above coxa I.

Legs: CI and CIII yellow: CII yellow but darkened laterally with grey pruinosity; remainder of legs mostly yellow, except distal quarter FIII; distalmost tarsomeres infuscated except as noted; CI with black distolateral setae and CIII with black lateral seta; I: 5.5; 5.0; 2.8/ 1.5/ 1.0/ 0.6/ 0.5; FI with swollen base (MSSC), and with 2 long black ventral setae with some adjacent hairs at 1/10; each about onethird femoral length (MSSC); TI bare; It $_{3-4}$ black and It $t_{5}$ whitish (MSSC); II: 6.0; 8.0; 5.0/ 2.5/ 1.8/ 1.2/ 0.8; FII distinct but rather weak anterior subapical setae, and without posterior subapical setae; TII with ad setae at $1 / 8,1 / 3,2 / 3$, and apically, and pd setae at $1 / 5$ and apically; III: $7.2 ; 8.5 ; 0.7 ; 1.0 ; 3.0 / 2.0 / 0.7$; TIII with ad at $1 / 5$ and $3 / 4$, with $4-5$ dorsal setae, and pd at 3/4 and subapically with curved apicoventral setae (MSSC); IIIt ${ }_{1}$ with strong ventral seta (MSSC), and IIIt $_{2}$ with bent clidium bearing expanded apical seta (MSSC).

Wing: anal angle reduced in male; stronger in female; $\mathrm{M}$ bowed towards $\mathrm{R}_{4+5}$ in distal $1 / 3$ of wing, $\mathrm{CuAx}$ ratio 0.5 ; lower calypter yellow with fan of black setae; halter yellow.

Abdomen: dorsal terga 1-2, posterior margins of terga 3-6 and all segments 7 and 8 yellow, with remainder of abdomen dark brown; tergum 1 with some long lateral setae; sterna $4-5$ ventrally expanded to form hood for hypopygium; hypopygium (Figure 9g) yellow except surstyli dark brown hypopygial foramen left lateral; surstyli bilaterally asymmetrical, with left side porrect and digitiform, and right side strongly recurved, and each bearing distinctive setae as Figured; cercus short and setose.

\section{Female}

Similar to male except lacks MSSC and as noted: eyes separated, with silvery pruinosity on face; scutellum with wide yellow margin; FI without long ventral setae and not basally swollen; IIIt unmodified and $\mathrm{IIIt}_{2}>\mathrm{IIIt}_{3}$; anal angle stronger; abdominal tergum 2 with only faint yellow band, otherwise mostly metallic green.

\section{REMARKS}

Chaetogonopteron capricorne is found across northern tropical Australia, from the Cape York Peninsula to the Kimberley Ranges, Western Australia. It is not known from the Pilbara region but is described here for completeness, as it is close to the other two new Chaetogonopteron species. The two long ventral setae on male femur I are diagnostic. Females have a yellow scutellar margin, in contrast to the entirely dark green scutellum of males. Chaetogonopteron capricorne is closely related to the more widespread $C$. bartaki and the two species share similar overall colouration and some MSSC. As well, females of both species have a yellow margin on the scutellum.

\section{ETYMOLOGY}

This species is found mostly north of the Tropic of Capricorn, hence the specific epithet capricorne.

\section{Genus Sympycnus Loew, 1857}

\section{REMARKS}

This cosmopolitan genus is one of the most difficult in the family and lacks strong definition. The Australian fauna is rich and often abundant in trap samples, but it remains largely undescribed.

\section{Sympycnus lacrimulus Bickel sp. nov.}

Figures $10 a-c$

urn:Isid:zoobank.org:act:C49960FF-4486-4992909B-6FC097ACB6BE

\section{MATERIAL EXAMINED}

Holotype

Australia: Northern Territory: 1 dै, Batten Creek, $31 \mathrm{~km}$ WSW of Borroloola, 16 April 1976, Malaise trap, Colless (ANIC).

\section{Paratypes}

Australia: Northern Territory: 1 o, 1 , McArthur River, $2 \mathrm{~km}$ SSE of Borroloola, 19-20 April 1976, Malaise trap; 2 , McArthur River, 48 km SW by S of Borroloola, 14 April 1976, Malaise trap, Colless (ANIC).

\section{Additional records}

Australia: Western Australia: $1 \hat{\sigma}, 1$, Millstream, 25 October 1970, 7 April 1971 (at light); $1 \hat{\jmath}$, Karijini National Park, Weano Gorge Rd: $22^{\circ} 21^{\prime} 16^{\prime \prime} \mathrm{S}, 118^{\circ} 15^{\prime} 11^{\prime \prime} \mathrm{E}$, Malaise trap over running creek above Hancock Gorge, 699 m, 15-20 May 2003, C. Lambkin and T. Weir (ANIC).

\section{DESCRIPTION}

\section{Male}

Length: $1.6 \mathrm{~mm}$; wing: 1.7 x $0.5 \mathrm{~mm}$.

Head: frons shining metallic blue-violet; setae black; strong verticals, strong diverging ocellars present; postverticals represented by $4-5$ short black setae, continuation of postorbitals; face narrowed beneath antennae and covered with silvery pruinosity; eyes meeting at centre of face (MSSC); eyes with tiny hairs between facets; anterior facets enlarged; palp and proboscis brown; antenna black; 1st flagellomere subtriangular; arista with distinctive tear-shaped apical flag (MSSC) (Figure 10b). 
Thorax: metallic blue-green with bronze reflections, with some brown pruinosity; pleura metallic blue with grey pruinosity; metepimeron yellow; postscutellum with distinct median longitudinal mound; setae black; ac uniseriate, with 6-8 short but distinct setae; 6 strong de present; $1 \mathrm{pa}, 2 \mathrm{sa}, 2 \mathrm{sr}, 2 \mathrm{npl}, 1 \mathrm{hm}, 1 \mathrm{pm}$ present; median scutellar seta strong, lateral present as fine short hair; proepisternum bare.

Legs: CI yellow; CII and CIII mostly yellow with some basal infuscation; trochanters and remainder of legs mostly yellow, except distal tarsomeres infuscated; CI with pale anterior hairs and black distolateral setae; CII with short black anterior setae; CIII with black lateral seta at $1 / 3$; I: 4.5 ; 3.5 ; 3.0/ 1.0/ 0.3/ 0.3/ 0.5;FI bare ventrally; TI with distinct ad serration of 5-6 setae in distal half, and with row of pale ventral setae along distal half (MSSC): It ${ }_{1}$ longer than distal tarsomeres combined (MSSC), with 3 strong basoventral setae (MSSC), and with black apicoventral beak-like projection (MSSC); It ${ }_{2}$ curved and flattened, with ventral concave excavation (MSSC), black dorsally and pale ventrally; distal tarsomeres short with short porrect hairs (MSSC); II: 7.0; 7.5; 3.2/ 1.5/ 1.0./ 0.6/ 0.5; FII with strong anterior and shorter av subapical, and with 3 long pale ventral setae in basal quarter (MSSC); TII with ad setae at $1 / 6,1 / 3$, and $2 / 3$, and pd setae at $1 / 5$ and $2 / 3$; III: $7.0 ; 6.5$; $1.7 / 2.0 / 1.5 /$ $0.8 /$ 0.5; FIII with strong anterior and shorter av subapical setae, but with weaker pv subapical seta only, and bare basally; TIII with 3-4 strong dorsals, ventral seta at about $1 / 2$, TIII with 3-4 strong dorsals, ventral seta at about $1 / 2$, and with circle of short subapical setae.

Wing: membrane hyaline; $\mathrm{R}_{4+5}$ and $\mathrm{M}$ subparallel; anal angle not strong; $\mathrm{CuAx}$ ratio: 0.4; lower calypter yellow with fan of black setae; halter yellow.

Abdomen: tergum 1 dark brown; tergum 2 mostly translucent yellow but infuscated dorsomedially; remainder of abdomen dark brown; distal segments not expanded; hypopygium dark brown with yellowish cerci (Figure 10c); hypopygial foramen left basolateral; hypandrium broad and hood-like; ventral margin of epandrium strongly curved and bearing 2 strong setae; surstylus fused to epandrium, and with dorsal section which bears 2 strong setae; cercus short and broad.

\section{Female}

Similar to male except lacks MSSC and as noted: face wide, with grey pruinosity, clypeus tectiform; arista unmodified; TI without distal pale ventral setae; It ${ }_{1}$ shorter than distal tarsomeres combined, and unmodified; It ${ }_{2}$ unmodified; FII unmodified.

\section{REMARKS}

Sympycnus lacrimulus is known from two localities in tropical Australia, from eastern Arnhem Land in the Northern Territory and the Pilbara region of Western Australia. The tear-shaped male aristal flag (MSSC) of this small species is diagnostic.

Sympycnus lacrimulus is close to Sympycnus pistillus sp. nov., as both species share the following male characters: arista with widened apical flag, $\mathrm{It}_{1}$ with two strong ventral setae in basal third, expanded apicoventrally, and longer than the distal tarsomeres combined, and femur II with 2-3 long pale ventral setae in basal quarter.

\section{ETYMOLOGY}

The specific epithet lacrimulus is from the Latin meaning "little tear", in reference to the tear-shaped aristal flag.

\section{Sympycnus pistillus Bickel sp. nov.}

Figures $10 d-f$

urn:Isid:zoobank.org:act:C99AF5FA-4899-4E51-84EEDD627865F2AE

\section{MATERIAL EXAMINED}

\section{Holotype}

Australia: New South Wales: 1 d, Warrumbungle National Park, Dead Cow Creek, dry sclerophyll forest, $600 \mathrm{~m}, 16$ November 1990, yellow pans, D.J. Bickel (AMS, K.364689).

\section{Paratypes}

Australia: New South Wales: 3 Oे, Warrumbungle National Park, Mapra Creek, dry sclerophyll forest, 460 m, 16 November 1990, yellow pans, D.J. Bickel (AMS).

\section{Additional records}

Australia: Australian Capital Territory: 3 के, Paddy's River, 29 November 1962 (ANIC). New South Wales: 1 त, Nadgee Nature Reserve, 14-15 February 1986; 2 ô, Boonoo Boonoo National Park, NE of Tenterfield, 9 January 1988; Wingabutta Creek, $40 \mathrm{~km} \mathrm{~N}$ of Mendooran, 26 March 1971 (AMS); Brockelos Creek, S of Bermagui, 24-27 January 1974; Cabbage Tree Creek, Clyde Mtn, 22 February 1965 (ANIC); 1 Oे, Buladelah, 26 December 1968 (UQIC). Queensland: 2 Oे, Crediton Creek, Eungella National Park, 920 m, 12 December 1961, 30 November 1992, rainforest, yellow pans; $1 \mathrm{~d}$, Girraween National Park, Bald Rock Creek, 25 November 1992, yellow pans (AMS); 1 ก, Big Mitchell Creek, Mareeba Molloy Road, 4 May 1967; 2 ऽે, Rocky Creek, 11 km N of Atherton, 3 May 1967; 2 ${ }^{\lambda}$, Annan River, $3 \mathrm{~km} \mathrm{~W}$ by S of Black Mtn., 26 April 1981; 1 O , Little Forks, Annan River, $15.49^{\circ} \mathrm{S}$ $145.14^{\circ} \mathrm{E}, 19$ October 1980; 1 ${ }^{\lambda}, 11 \mathrm{~km}$ ENE of Mt Tozer, $12.43^{\circ} \mathrm{S} 143.18^{\circ} \mathrm{E}, 11-16$ July 1986 (ANIC); 1 Oे, Shiptons Flat, $15.47^{\circ} \mathrm{S} 145.14^{\circ} \mathrm{E}, 19$ October 
1980, Malaise trap; $5 \hat{\partial}$, Goldmine and Davies Cks, Kuranda-Mareeba Rd, 3 May 1967 (ANIC); 1 Oे, Mudgeeraba, 15 March 1947 (UQIC). Western Australia: 1 d, Karijini National Park: Johnson Gorge, $22^{\circ} 27^{\prime} 05^{\prime \prime} \mathrm{S}, 118^{\circ} 27^{\prime} 14^{\prime \prime} \mathrm{E}, 684 \mathrm{~m}, 14-20$ May 2003, $684 \mathrm{~m}$, drying pool in rocky creek with Eucalyptus-Acacia, Malaise trap, Lambkin (ANIC).

\section{DESCRIPTION}

\section{Male}

Length: $2.1 \mathrm{~mm}$; wing: $1.7 \times 0.7 \mathrm{~mm}$.

Head: frons metallic blue-violet; setae black; strong verticals, strong diverging ocellars present; postverticals represented by $4-5$ short black setae, continuation of postorbitals; face narrowed beneath antennae and covered with silvery pruinosity; eyes meeting at centre of face (MSSC); eyes with tiny hairs between facets; palp and proboscis brown; antenna dark brown; 1st flagellomere prolonged and rather broad (MSSC); arista thick with lanceolate apical flag (MSSC) (Figure 10e).

Thorax: dark metallic blue-green with some grey pruinosity; pleura metallic blue with grey pruinosity; postscutellum evident with distinct median longitudinal mound; proepisternum bare; setae black; ac uniseriate, with 6-8 short but distinct setae; 6 strong dc present; 1 pa, $2 \mathrm{sa}, 2 \mathrm{sr}$, $2 \mathrm{npl}, 1 \mathrm{hm}, 1 \mathrm{pm}$ present; median scutellar seta strong, lateral present as fine short hair.

Legs: CI yellow; CII and CIII mostly yellow with some lateral infuscation; trochanters and remainder of legs mostly yellow, except distal fifth of FIII dark brown, and distal tarsomeres infuscated; CI with some black distolateral setae; CIII with black lateral seta; I: 2.7; 2.3; 2.2/ 0.6/ 0.3/ 0.2/ 0.2; FI bare ventrally; TI with weak ad serration in distal half; It longer than distal tarsomeres combined (MSSC), with 2 strong ventral setae in basal third (MSSC). and slightly expanded apicoventrally (MSSC), and distal tarsomeres unmodified; II: 3.5; 4.0; 2.2/ 0.8/ $0.6 / 0.4 / 0.3$; FII with 2 long pale ventral setae in basal fifth (MSSC); TII with ventral seta at $2 / 3$, ad setae at $1 / 6,1 / 3$, and $2 / 3$, and pd setae at $1 / 5$ and 2/3; FIII with strong anterior subapical seta and weaker posterior subapical seta; III: 3.7; 4.7; 0.8/ 1.1/ 0.7/ 0.6/ 0.4; FIII ventrally bare; TIII with $3-4$ strong dorsals, ad setae at $1 / 4$ and $3 / 4$, and ventral seta at 3/5; TIII unmodified.

Wing: membrane hyaline; $\mathrm{R}_{4+5}$ and $\mathrm{M}$ subparallel; anal angle not strong; $\mathrm{CuAx}$ ratio: 0.5; lower calypter yellow with fan of black setae; halter yellow.

Abdomen: entirely dark metallic green-black; distal segments not expanded; hypopygium (Figure 10f) black with yellowish cerci; hypandrium broad and hood-like; ventral margin of epandrium straight; surstylus fused to epandrium and bearing
2 strong ventral setae; dorsal surstylus digitiform with curved seta; cercus short and lobate.

\section{Female}

None reliably associated with males.

\section{REMARKS}

Sympycnus pistillusis a distinctive species whose known distribution is primarily eastern Australia, from Iron Range in northern Cape York Peninsula to southern New South Wales and the Australian Capital Territory. Its presence in Karijini National Park in the Pilbara is a remarkable disjunction. This species has been collected from a variety of habitats, including tropical rainforest and dry sclerophyll woodland. The male antenna with its prolonged first flagellomere and apical aristal flag is diagnostic. Females are not reliably associated with Sympycnus pistillus, and possibly females lack the distal dark brown colouration on femur III (also see "Remarks" under S. lacrimulus).

\section{ETYMOLOGY}

The name pistillus is from the Latin and meaning "shaped like a pestle," in reference to the shape of the aristal flag.

\section{Sympycnus ephydroides Bickel sp. nov.}

Figures 11a-c

urn:Isid:zoobank.org:act:BA592FDD-CDA3-47ABA2E1-AC06F4A97378

\section{MATERIAL EXAMINED}

\section{Holotype}

Australia: Queensland: 1 ô, Captain Billy's Creek, $11.40^{\circ} \mathrm{S} 142.50^{\circ} \mathrm{E}, 9-13$ July 1975 , G. Monteith (ANIC).

\section{Paratypes}

Australia: Queensland: $1 \hat{0}, 4$, same data as holotype (ANIC).

\section{Additional records}

Australia: Northern Territory: Batten Creek, 31 km WSW of Borroloola, 16 April 1976; Koongarra, $15 \mathrm{~km}$ E of Mt. Cahill, 6-9 March 1971; Surprise Creek, $45 \mathrm{~km}$ SW by S of Borroloola, 15 April 1976; 22 km WSW of Borroloola, 17 April 1976; Lee Point, June 1964; Berry Springs, 15 June 1964; 20 km W of Humpty Doo, 10 June 1964; Cooper Creek, 19 km E by S of Mt. Borradaille, 2 November 1972; Birraduk Creek, 17 km WSW of Nimbuwah Rock, 5 June 1975; Darwin, July 1956 (ANIC); Litchfield Park, Ada Creek at jumpup, 23 March 1992 (AMS). Queensland: 3 $\mathrm{km}$ NE of Mt. Webb, $15.03^{\circ} \mathrm{S} 145.09^{\circ} \mathrm{E}, 30$ April-11 May 1981, and 2 October 1981; Palm Creek, S of 
Miriam Vale, 6 May 1970; Mt. Cook National Park, $15.29^{\circ} \mathrm{S} 145.16^{\circ} \mathrm{E}, 10$ May 1981; Annan River, $3 \mathrm{~km}$ W by S of Black Mtn., 26 April 1981, 28 September 1980; $1 \mathrm{~km} \mathrm{~N}$ of Rounded Hill, $15.17^{\circ} \mathrm{S} 145.13^{\circ} \mathrm{E}, 6$ May 1981, 7 October 1980; Iron Range, 14 June 1971; $11 \mathrm{~km}$ ENE of Mt Tozer, $12.43^{\circ} \mathrm{S} 143.18^{\circ} \mathrm{E}, 11-16$ July 1986; (ANIC); Heathlands, $11.45^{\circ} \mathrm{S} 142.35^{\circ} \mathrm{E}, 5-25$ July 1992, 18 August-16 September 1992, 18 September-21 October 1992; 2 March-5 April 1993, 5 April-23 May $1993 ; 3 \mathrm{~km} \mathrm{~W}$ of Batavia Downs, $12.40^{\circ} \mathrm{S} 142.39^{\circ} \mathrm{E}$, 18. June-22 July 1992, 22 July-23 August 1992, 18 September-21 October 1992; 23 November-11 December 1992; $7 \mathrm{~km} \mathrm{~S}$ of Batavia Downs, $12.42 \mathrm{~S}$ 142.42E, 8 March- 4 April 1993; 4 km NE of Batavia Downs, 12.39S 142.41E, 11 December 1992-17 January 1993, 17 February-8 March 1993; 5 km S of Batavia Downs, 12.41S 142.41E, 18 June-22 July 1992; Split Rock, 15.39S 144.31E, 27 April-28 May 1992, Malaise trap; Giles Hwy., 3 km W of Little Mulgrave, 16 April 1967; $11 \mathrm{~km} \mathrm{~W}$ by N Bald Hill, McIlwraith Range, 500 m, 13.44S 143.20E, 26 June-13 July 1989; Hann River, 15.12S 143.52E, 27 May 1986; $3.5 \mathrm{~km}$ SW by S of Mt Baird, 15.10S 145.07E, 3-4 May 1981, Malaise trap; Big Mitchell Creek, Mareeba-Mt. Molloy Road, 4 May 1967; Desailly Creek, $10 \mathrm{~km} \mathrm{~W}$ by N of Mt. Carbine, 16.30S 144.55E, 19 May 1981; Mt Garnet Rd, 20 km W of Ravenshoe, 2 May 1967; W of Herberton via Watsonville, 1 May 1967; 19.25S 144.20E, Einasleigh River, $22 \mathrm{~km} \mathrm{~S}$ by W of Lyndhurst H.S., 11 November 1981; $14 \mathrm{~km} \mathrm{~W}$ by N of Hope Vale Mission, 15.16S 144.59E, 7 May 1981, at light; Lockerbie Scrub, 29-31 May 1984, at light (ANIC); West Claudie River, 12.44S 143.15E, 11 December 1986; Clohesy River, Atherton Tableland, 20 May 1958; Archer River Crossing, 13.25S 142.56E, 7 April 1989; 26 km W of "Fairview", 13.25S 144.04E, 19 April 1989 (AMS); Cape York Pen., Crystal Top Rocky yard, between Rocky River and Massey Creek, 30 April 1961 (BPBM); Coen area, 6-12 May 1975 (QDPI). Western Australia: Drysdale River, Site A1, 15.02S 126.55E, 3-8 August 1975; Carson Escarpment, Site B1, 14.49S 126.49E, 9-15 August 1975; Morgan Falls. Site C1, 15.02S 126.40E, 16-17 August 1975; "The Crusher", CALM Site 9/1, $4 \mathrm{~km}$ SW of Mitchell Plateau mining camp, 14.52S 125.50E, 2-6 June 1988; Karijini National Park, Weano Gorge Rd: $22^{\circ} 21^{\prime} 16^{\prime \prime} \mathrm{S}, 118^{\circ} 15^{\prime} 11^{\prime \prime} \mathrm{E}$, Malaise trap over running creek above Hancock Gorge, 699 m, 15-25 May 2003, Lambkin and Weir (ANIC). (more than 600 specimens examined).

\section{DESCRIPTION}

\section{Male}

Length: 1.9-2.2 mm; wing: 1.5-1.6 x $0.6 \mathrm{~mm}$.

Head: frons dark metallic blue-green, with little pruinosity; setae black; 2 short postocellars present; strong verticals, strong diverging ocellars present; postverticals represented by 4-5 short black setae, continuation of postorbitals; face narrowed beneath antennae and with grey pruinosity; eyes almost meeting along face; palp and proboscis brown; antenna black; 1st flagellomere subtriangular; arista slightly shorter than head height.

Thorax: dorsum dark brown with metallic green reflections, and with dusting of brown pruinosity; pleura brown; setae black; ac as single row of 6-7 setae; 6 strong dc present; 1 pa, 2 sa, 2 sr, 2 npl, 1 $\mathrm{hm}, 1 \mathrm{pm}$ present; median scutellar setae strong, laterals absent.

Legs: CI yellow; CII and CIII brownish, with varying infuscation, and becoming yellow distally; remainder of legs yellow except FIII slightly infuscated on distal fifth; leg vestiture black; CI with short dark anterior hairs and some slightly stronger distolateral setae; $\mathrm{CII}$ and $\mathrm{CIII}$ each with black lateral seta; I: $2.3 ; 2.0 ; 1.2$ / $0.4 / 0.3 / 0.2$ / 0.2; FI bare ventrally but with short preapical posterior and pv setae; TI with strong ad comb of 4-5 black setae in distal half; $\mathrm{It}_{1}$ with 2 weak ventral setae in basal quarter; II: 3.0; 3.2; 1.3/ 0.6/ 0.5/ 0.3/ 0.3; FII with short erect ventral seta at 1/10 (MSSC); FII with strong subapical anterior and posterior setae; TII with ad setae at $1 / 5.1 / 3$, and $2 / 3$, pd seta at $1 / 5$, and with strong av at $1 / 2$; III: $3.2 ; 3.6 ; 0.7 / 0.8 /$ 0.6/ 0.4/ 0.3; FIII with strong anterior subapical seta subtended by a strong av seta, and with weak pv seta only, posterior subapical seta absent; TIII with dorsals at $1 / 3,3 / 5$, and subapically, with short black dorsal setal serration between setae from $1 / 3$ to apex, with ad setae at $1 / 5,3 / 4$ and subapically, and with strong ventral seta at $3 / 5$; IIIt ${ }_{1}$ with $1-2$ outstanding mid-ventral setae (MSSC).

Wing: membrane hyaline; $\mathrm{R}_{4+5}$ and $\mathrm{M}$ subparallel; anal angle not strong; $\mathrm{m}-\mathrm{cu}$ straight; $\mathrm{CuAx}$ ratio: 0.5 ; lower calypter yellow with fan of black setae; halter yellow.

Abdomen: mostly dark brown but tergum 2 yellowish laterally; distal segments not expanded; hypopygium (Figure 11c) dark brown with yellowish cerci; hypopygial foramen left basolateral; hypandrium broad and hood-like; ventral section of surstylus with 3 strong setae, dorsal section with single strong seta; cercus short.

\section{Female}

Similar to male except lacks MSSC and as noted: face wide; clypeus tectiform and bearing 4-5 distinct setae in 2 rows, although strength and number of setae variable (Figure 11b); $\mathrm{It}_{1}$ also with two basoventral setae, but shorter than in male; FII without erect ventral seta; IIIt ${ }_{1}$ without outstanding mid-ventral setae; abdominal tergum 2 yellowish laterally, and tergum 3 yellowish posterolaterally.

\section{REMARKS}

Sympycnus ephydroides is found across tropical monsoonal Australia, from Cape York Peninsula, 
Queensland to the Pilbara region and Kimberley Ranges, Western Australia. It is common in monsoonal woodland and often abundant in Malaise trap samples. The female clypeus is tectiform and bears $4-5$ setae (Figure 11b). $S$. ephydroides is one of a number of rather nondescript Sympycnus species from tropical Australia that lack strong male secondary sexual characters.

\section{ETYMOLOGY}

The term ephydroides reflects the similarity of the setose female clypeus with the clypeus of some genera in the fly family Ephydridae.

\section{Sympycnus colliepa Bickel sp. nov.}

Figures $12 \mathrm{e}-\mathrm{g}$

urn:Isid:zoobank.org:act:EDB5D992-F0C1-46D4-A3288871D0CF3784

\section{MATERIAL EXAMINED}

\section{Holotype}

Australia: South Australia: 1 \%, Mt Crawford State Forest, 6 August 1968, D.H. Colless and Z. Liepa (ANIC).

\section{Paratypes}

Australia: South Australia: paratype 2 ภ, 2 ,, same data as holotype (ANIC).

\section{Additional records}

Australia: Australian Capital Territory: Black Mtn, 10 February 1968; Paddy's River, 29 November 1962, Wombat Creek, nr Piccadilly Circus, 750 m, 5 November 1984 (ANIC). New South Wales: Fowler's Gap Research Stn, 31,05S, 141.42E, 29 November-2 December 1986; $6.8 \mathrm{~km} \mathrm{~N}$ of Ballata, 13 December 1974; Therribri, November 1932; Darlington Pt, Murrumbidgee River, 25 October 1973 (ANIC); 35 km N of Bourke, 28 August 1983; Coocoran Lake, nr Lightning Ridge, 16 October 1984; Rankins Spring, nr West Wyalong, 23 November 1977; Pullabooka State Forest, $33.7944822^{\circ} \mathrm{S}, 147.79798^{\circ} \mathrm{E}$, 23 November 1996, J. Gollan; Monumea Gap State Forest, $33.78053^{\circ} \mathrm{S}, 147.83716^{\circ} \mathrm{E}, 26$ November 1996, J. Gollan (AMS). Northern Territory: 32 km WNW of Alice Springs, 9 October 1972; Roe Creek, 12 km SW by W of Alice Springs, 10 October 1978; 12 km SW of Alroy Downes, at light, 10 April 1976 (ANIC). Queensland: Darr River, $31 \mathrm{~km}$ NW by W of Longreach, 7 April 1976; $66 \mathrm{~km} \mathrm{NW}$ of Mt Isa, at light, 9 April 1976; Nogoa River, Emerald, at light, 9 May 1970; $25 \mathrm{~km} \mathrm{NW}$ by $\mathrm{N}$ of Boulia, at light, 8 April 1976; $15 \mathrm{~km} \mathrm{~S}$ of Charleville, 6 April 1976; 20 km W of Ravenshoe, Mt Garnet Rd, 2 May 1967 (ANIC); Waterpark Creek, nr Byfield, 2 December 1992, rainforest (AMS). South Australia: Cooper

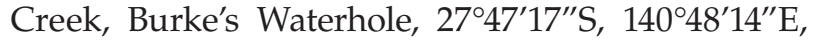

1 August 1997, yellow pans (AMS); Old Alton Downs, Simpson Desert, 19 September 1972; 10 $\mathrm{km} \mathrm{N}$ of Laura, 6 October 1977; Winnininnie, 17 $\mathrm{km}$ NE of Yunta, 29 September 1975; $48 \mathrm{~km}$ E by N of Nullarbor, 31.23S 131.24E, 16 September 1981 (ANIC); Yumbarra National Park, 11 November 1975 (SAM). Western Australia: Millstream, 11 April 1971; Cocklebiddy, 25 October 1977; $15 \mathrm{~km} \mathrm{~N}$ by E of Mt Singleton, 29 September 1981 (ANIC); Mt William, 150 m, 6 November 1963 (BPBM); 50 km NW Yuna, 6 September 1981; $60 \mathrm{~km}$ NE of Wobin, 29.43S 117.04E, 27 September 1981; Moirs Rock, 42 km NNW Salmon Gums, 32.39S 121.25E, 3 January 1987; 28 km W of Yalgoo, 2 September 1981, Holloway (AMS). [194 $\lesssim, 67$ o examined].

\section{DESCRIPTION}

\section{Male}

Length: $2.7-2.8 \mathrm{~mm}$; wing: $3.2 \times 1.0 \mathrm{~mm}$.

Head: vertex and frons covered with brownish pruinosity; setae black; male verticals weak, but with strong diverging ocellars; postverticals represented by $4-5$ short black setae, continuation of postorbitals; face narrowed beneath antennae and with silvery pruinosity; eyes very narrowly separated on face (may appear touching in shrunken specimens); clypeus narrow; palp and proboscis brown; scape and pedicel red-yellow; first flagellomere dark brown, distinctly rounded and relatively short; arista shorter than head height; arista finely haired.

Thorax: dorsum metallic green-bronze and covered with dense rusty brown pruinosity; metallic blue-violet band between dc rows along middle of mesonotum and onto disc of scutellum (this band especially evident when viewed at oblique angle to dorsum); pleura covered with grey pruinosity; posterior slope of mesonotum slightly flattened anteriad of scutellum; postscutellum evident with distinct median longitudinal mound; setae black; ac absent; 6 strong dc present, the posterior most offset laterally; $1 \mathrm{pa}, 2 \mathrm{sa}, 2 \mathrm{sr}, 2 \mathrm{npl}$, $1 \mathrm{hm}, 1 \mathrm{pm}$ present; median scutellar setae strong, laterals absent.

Legs: CI yellow with pale pruinosity; CII and CIII dark brown; trochanters and remainder of legs yellowish, except FIII brownish in distal quarter, and distal tarsomeres darkened; CI with short pale and anterior hairs and 2-3 black distolateral setae; CIII with black lateral seta at $1 / 3$; I: $6.0 ; 5.5 ; 2.5 / 0.8 /$ $0.5 / 0.4$ / 0.5 ; TI with short dorsal seta at $1 / 4$ and strong posterior seta at $7 / 8$, and with ad serration of 6-7 black setae in distal 1/4; II: 7.5; 8.5; 5.0/ 2.0/ 1.2/ 0.7/ 0.5; FII and strong anterior and weaker posterior subapical seta at 9/10; TII with ad-setal pair at $1 / 5$, dorsal seta at $1 / 3$, and anteriors at $2 / 5$, $2 / 3$ and subapically; III: 8.0 ; $9.5 ; 2.8 / 3.2 / 1.8 / 0.8 /$ 0.5 ; FIII with anterior preapical seta at $9 / 10$, and 
weaker subapical pv seta; TIII with row of $4-5$ short dorsal setae and circlet of short subapical setae.

Wing: membrane hyaline; $\mathrm{R}_{4+5}$ and $\mathrm{M}$ slightly diverse from base, but becoming subparallel beyond flexion in vein $\mathrm{M}$, with $\mathrm{M}$ ending in apex; anal angle not strong; $\mathrm{m}-\mathrm{cu}$ straight; $\mathrm{CuAx}$ ratio: 0.4 ; lower calypter yellow with fan of pale yellow setae; halter yellow.

Abdomen: brown with black vestiture, although terga 2 and 3 mostly yellow with brown posterior margin and yellowish venter; margin of tergum 1 with black setae; hypopygium dark brown (Figure $12 \mathrm{~g}$ ); short epandrial seta present; surstylus with broad expanded ventral lobe which bears 3 strong spine-like apical setae; dorsal lobe surstylus with 2 strong curved setae; cercus short subtriangular and somewhat truncated distad.

\section{Female}

Similar to male in all respects except lacking MSSC and as noted: female more robust with broader thorax; face slightly wider and produced shelf-like over clypeus; ac band also with blue-violet colour; TI with somewhat weaker posterior seta at 7/8 and also with anterodorsal serration; TIII also with pair long anteroapical setae and IIIt $_{1}$ with row strong pv setae; wing normal; $\mathrm{CuAx}$ ratio: 0.6; abdomen brown but with terga 2 and 3 mostly yellow.

\section{REMARKS}

Sympycnus colliepa has a broad distribution across arid and semi-arid Australia south of the monsoonal zone, from the Pilbara (Millstream site) south along the western margin and southwest of Western Australia, Alice Springs and the Barkley Tablelands of the Northern Territory, South Australia, to the western slopes of the Great Dividing Range in New South Wales, the Australian Capital Territory, and Queensland. Some sites are quite arid (e.g., Nullarbor Plains and Simpson Desert).

The closely related S. anomalipennis Becker, with its strongly modified male wing (see Becker 1922), is common along the eastern Australian coast and ranges and western slopes of the Divide. Males of both species have been collected together near Canberra, and at different dates at Charleville and Emerald, Queensland. Both species have similar blue-violet vittae along the ac band. They are readily separated by the distinctively modified male wing of $S$. anomalipennis, and the strong surstylar setae and brown pruinose frons of Sympycnus colliepa, contrasted with the unmodified surstylus and metallic blue frons of $S$. anomalipennis.

\section{ETYMOLOGY}

The specific epithet "colleipa" is an amalgam using the surnames of Don Colless and Zenta Liepa. These two individuals together built the superb ANIC Diptera collection housed in Canberra. This name should be regarded as a noun in apposition.

\section{Sympycnus hamulitarsus Bickel sp. nov.}

Figures $12 b-d$

urn:Isid:zoobank.org:act:2B2B9A9A-BA2B-4CEA-9074ADCE4AB8E620

\section{MATERIAL EXAMINED}

\section{Holotype}

Australia: Western Australia: 1 กे, Millstream-

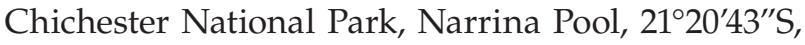
$117^{\circ} 16^{\prime} 08^{\prime \prime} \mathrm{E}, 150 \mathrm{~m}, 27$ April-7 May 2003, Malaise beside bank of rocky creek bed, C. Lambkin and T. Weir (ANIC).

\section{Paratypes}

Australia: Western Australia: MillstreamChichester National Park: $1 \hat{\delta}$, same but Yarraloola $\mathrm{Rd}$, Fortescue River, $21^{\circ} 37^{\prime} 38^{\prime \prime} \mathrm{S}, 117^{\circ} 07^{\prime} 27^{\prime \prime} \mathrm{E}, 28$ April-3 May 2003, Malaise trap in rocky creek bank with drying pools, Lambkin and Weir (ANIC).

\section{Additional records}

Australia: Western Australia: Karijini National Park: 1 Ĵ, Juna Downs Road, 19-25 April 2003, Malaise trap, drying pool in rocky Turee Creek, $789 \mathrm{~m}, 22^{\circ} 41^{\prime} 57^{\prime \prime} \mathrm{S}, 118^{\circ} 25^{\prime} 06^{\prime \prime} \mathrm{E}$, Lambkin and Weir (ANIC).

\section{DESCRIPTION}

\section{Male}

Length: $2.7 \mathrm{~mm}$; wing: $2.5 \times 0.8 \mathrm{~mm}$.

Head: almost ovate in anterior view, higher than wide; frons and face dark metallic blue-violet without pruinosity; ventral postoculars white, dorsal postoculars black, with two dorsalmost setae distinctly stronger than other; strong vertical and diverging ocellar setae present; face and clypeus narrowed beneath antennae, but distinctly separating eyes and covered with silvery pruinosity; eye facets enlarged anteriorly; palp brownish with black apical seta; proboscis brown; scape and pedicel yellowish; first flagellomere short subtriangular and dark brown; arista dorsal and longer than head height.

Thorax: dorsum dark brown with shining metallic green/ bronze reflections; pleura brown with metallic reflections and with grey pruinosity; metepimeron dark brown, but yellow at very base; humeral callus partially yellow; setae black; ac present as 7 long setae; 5 strong long dc present, posterior most slightly offset laterally; $1 \mathrm{pa}, 2 \mathrm{sa}, 1$ sr, 2 National Parkl, 1 hm, 1 pm present; median scutellar setae strong, lateral scutellars reduced to tiny weak hairs; lower pronotum with 2 short yellow 
setae just above CI.

Legs: CI pale yellow; CII and CIII yellow although CII slightly infuscated anteriorly and laterally; remainder of legs yellow although FIII with brown band from $2 / 3$ to $7 / 8$, and distal tarsomeres infuscated; setae black; CI with some short fine setae on basal half, and with 5-6 stronger distolateral setae; CII with anterolateral seta at $1 / 2$ and some short anterior setae; CIII with strong black lateral seta at $1 / 3$, subtended distally by 1 or 2 very short setae; trochanter II and III each with external seta; I: 3.2; 2.8; 1.8/ 0.6/ 0.4/ 0.2/ 0.4; FI mostly bare but with subapical pv seta; TI bare except for long curved apical ventral seta (MSSC); anterior claw on It5 greatly thickened and enlarged, recurved back on itself (MSSC) (Figure 12d); II: 4.1; 4.5; 2.5/ 1.3/ 1.0/ $0.7 / 0.6$; FII with rather weak anterior subapical seta at $7 / 8$, and with short subapical pv seta respectively; TII with ad seta at $1 / 8$ (short), $1 / 4$ and $2 / 3$, pd seta at $1 / 4$, ventral seta at $2 / 5$ and $2 / 3$, and with short apical ad, av, pv and pd seta; III: 4.5; 5.0; 0.6/ 1.0/ 1.3/ 0.9/ 0.5 ; FIII with strong anterior preapical seta at $7 / 8$, subtended by weaker av seta, with weak subapical pv seta only; TIII with 3 strong dorsal setae spaced along distal three-fifths, and with short apical anterior av, and pv seta.

Wing: hyaline; elongate with anal angle absent; $R_{2+3}$ and $R_{4+5}$ parallel almost for length of wing, joining costa just basad of apex at 11/12 and 15/16, respectively; $M$ slightly diverging from $R_{4+5}$ until one third of distance beyond crossvein $\mathrm{dm}-\mathrm{cu}$, when veins become subparallel with $\mathrm{M}$ joining margin at wing apex; $\mathrm{CuAx}$ ratio: 0.8; lower calypter yellow with fan of black setae; halter yellow.

Abdomen: tergum 1 brown; tergum 2 mostly translucent yellow with varying amounts of brown posterodorsal infuscation; remaining terga brown with metallic green reflections; terga covered with short black vestiture with longer marginal setae; sterna 1-3 yellow; hypopygium (Figure 12c) elongate; mostly brown with dark brown distal surstylus, and yellow cercus; hypandrium wide, hood-like and pointed apically; phallus narrow basally, and distally expanded, clavate; surstylus comprises curved subrectangular lobe with sharp apex; cercus lobate.

Female

Unknown

\section{REMARKS}

Sympycnus hamulitarsus is known only from the Fortescue River drainage, and is readily recognized by the distinctive MSSC on leg I, the long curved apicoventral seta on the tibia, and the enlarged and strongly recurved anterior claw on tarsomere 5.

\section{ETYMOLOGY}

The name hamulitarsus is derived from the Latin hamulus, meaning "hook", and refers to the recurved hook-shaped claw on tarsus I.

\section{Sympycnus weano Bickel sp. nov.}

Figures $11 \mathrm{~d}-\mathrm{e}$

urn:Isid:zoobank.org:act:3686A1B7-EDB1-4235-A4D8BBE6303EBB72

\section{MATERIAL EXAMINED}

\section{Holotype}

Australia: Western Australia: 1 , Karijini National Park, Weano Gorge Road, 22 21'16"S, $118^{\circ} 15^{\prime} 11^{\prime \prime} \mathrm{E}$, Malaise trap over running creek above Hancock Gorge, 699 m, 15-20 May 2003, C. Lambkin and T. Weir (ANIC).

\section{DESCRIPTION}

\section{Male}

Length: $2.6 \mathrm{~mm}$; wing: 3.0 x $0.9 \mathrm{~mm}$.

Head: setae black; postocular setae black along dorsal third, white ventrally; vertex with 2 pairs postvertical setae; vertical and diverging ocellar setae present; frons dark brown and covered with grey pruinosity; face narrowed to small silvery triangle beneath antennae and eyes joined along face; exposed clypeus silvery; anterior eye facets enlarged; palp yellowish with short brownish hairs; proboscis yellowish; antenna yellow; scape and pedicel subequal; pedicel with circle of short black setae; $1^{\text {st }}$ flagellomere short triangular; arista dorsal.

Thorax: dorsum brown with metallic blue reflections, but with yellow humeral callus; pleura yellow except for small black triangle on aniepimeron; setae black; ac totally absent; $6 \mathrm{dc}$ present, with $\mathrm{dc}_{2}$ shorter than adjacent dc setae (MSSC); 1 pa, 2 sa, $2 \mathrm{sr}, 1 \mathrm{hm}, 1 \mathrm{pm}$, and $2 \mathrm{npl}$ present; median scutellar setae strong, laterals as minute weak hair; propleuron with some whit hairs.

Legs: coxae and remainder of legs yellow, except FIII brownish along distal half; CI with 3 black distal setae; CII with anterolateral seta at 3/4 and CIII with black lateral seta at $1 / 2$; legs rather bare of major setae; I: 3.4; 3.3; 1.8/ 0.8/ 0.6/ 0.4/ 0.3; TI with very short setal serration in distal third; pulvilli unmodified; II: 4.2; 5.7; 3.1/ 1.0/ 0.8/ 0.5/ 0.3; FII with relatively short anterior and weaker posterior subapical setae; TII with strong ad setae at $1 / 3$ and $2 / 3$, and with weak pd seta at $3 / 4$, and with weak ventral at $3 / 4$, and apical corona of ad, av, pv and dorsal seta; III: 5.3; 7.2; 1.1/ 1.6/ 0.9/ 0.6/ 0.4; FIII with anterior subapical seta at 9/10, subtended by weak av and pv setae; TIII with some stronger dorsal setae, and corona of ad, av, pv and dorsal seta.

Wing: hyaline; elongate with wing base narrowed and anal angle absent; $\mathrm{R}_{2+3}$ and $\mathrm{R}_{4+5}$ parallel almost for length of wing, joining costa just basad of apex at 11/12 and 15/16, respectively; M slightly 
diverging from $R_{4+5}$ until one third of distance beyond crossvein $\mathrm{dm}-\mathrm{cu}$ (position of vein flexion or bosse alaire), when veins become subparallel, with $\mathrm{M}$ joining margin at wing apex; $\mathrm{CuAx}$ ratio: 0.3; lower calypter yellow with black rim and open fan of some 7-8 black setae; halter yellow.

Abdomen: mostly brown with black vestiture; hypopygium often retracted somewhat under tergum 6; hypopygium mostly yellow except for dark brown surstyli (Figure 11e); hypandrium appears expanded in lateral view; epandrial lobe with apical seta; phallus distally curved; surstylus expanded, with ventral lobate arm and dorsal tapering digitiform arm; cercus elongate curved triangular, basally expanded, and tapering distally, and with pale yellow setae.

\section{Female}

Unknown.

\section{REMARKS}

Sympycnus weano is based on a slightly damaged male from Karijini National Park. This species is near a group of mostly undescribed species from eastern Australia and western Melanesia that includes Sympycnus marginatus Parent. They all have the antennae inserted high on the head, usually a sharply triangular first flagellomere, male eyes joined across the face, narrow body, elongate legs with sparse setation, the setal serration on tibia I highly reduced, $6 \mathrm{dc}$ and ac setae absent.

\section{ETYMOLOGY}

The specific epithet weano is an indigenous place name and is regarded as a noun in apposition.

\section{Genus Teuchophorus Loew, 1857}

\section{REMARKS}

Teuchophorus is especially diverse in the Oriental and Australasian tropics. There are a number of undescribed species from the eastern Australian coast and ranges, as well as the monsoonal north. I have seen a badly damaged male Teuchophorus sp. from Barrow Island ( $\hat{\jmath}$, Barrow Island, WGS84: 340102 7700434, 19-29 September 2011 MOFZ1WIN1, N. Gunawardene and C. Taylor), but better material is required for description.

\section{Subfamily Diaphorinae Meigen, 1824}

\section{Genus Asyndetus Loew, 1869}

\section{REMARKS}

Asyndetus is a cosmopolitan genus usually associated with marine coastal habitats, such as mudflats, mangroves, and beaches. Two species have been described from tropical Queensland and Northern Territory (see Bickel 1996), and I suspect the genus might be found in tropical Western Australia. The weakened or broken vein $\mathrm{M}$ is diagnostic for the genus.

\section{Genus Diaphorus Meigen, 1824}

\section{REMARKS}

Diaphorus is a rich cosmopolitan genus that is readily recognized by the key characters given above. The Australian fauna is particularly diverse, but is mostly undescribed. A number of species are commonly found resting on smooth-barked eucalypts.

\section{Diaphorus karijini Bickel sp. nov.}

Figures 13a-b

urn:Isid:zoobank.org:act:F897B2A6-3F7D-4965-A6B1DEFB099310C3

\section{MATERIAL EXAMINED}

\section{Holotype}

Australia: Western Australia: 1 $\widehat{\partial}$, Karijini National Park, Weano Gorge Road, 15-20 May 2003, grassy dry creek, $695 \mathrm{~m}, 22^{\circ} 21^{\prime} 19^{\prime \prime} \mathrm{S}, 118^{\circ} 15^{\prime} 00^{\prime \prime} \mathrm{E}$, Malaise trap, C. Lambkin and T. Weir: Malaise (ANIC 2141).

\section{Paratypes}

Australia: Western Australia: Karijini National Park: (a) 16 ठ, 12 ㅇ, same data as holotype; (b) 23 ô, 9 ㅇ, Hamersley-Mt Bruce Rd, 22 $34^{\prime} 14^{\prime \prime} \mathrm{S}$, $118^{\circ} 17^{\prime} 52^{\prime \prime}$ E, 25 April-14 May 2003, dry rocky creek bed, $757 \mathrm{~m}$, Malaise trap, Lambkin and Weir (ANIC 2056); (c) 8 §, 9 \%, Juna Downs Road, 19-25 April 2003, drying pool in rocky Turee Creek, 789 $\mathrm{m}, 2^{\circ} 41^{\prime} 57^{\prime \prime} \mathrm{S}, 118^{\circ} 25^{\prime} 06^{\prime \prime} \mathrm{E}$, Lambkin and Weir, Malaise trap (ANIC 2059); (d) 56 ô, 9 ㅇ, Johnson Gorge, 23 April -14 May 2003, drying pool in rocky creek, Eucalyptus-Acacia scrub, $684 \mathrm{~m}, 22^{\circ} 21^{\prime} 19^{\prime \prime} \mathrm{S}$, $118^{\circ} 15^{\prime} 00^{\prime \prime} \mathrm{E}$, Lambkin and Weir, Malaise trap (ANIC 2070).

\section{Additional records}

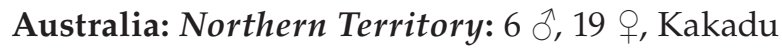
National Park, Koongarra, $16 \mathrm{~km}$ NE of Mt Cahill,

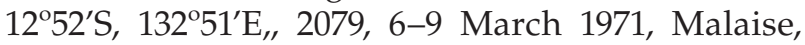
Colless; 2 0 , Birraduk Creek, $17 \mathrm{~km}$ WSW of Nimbuwah Rock, $12^{\circ} 19^{\prime} \mathrm{S}, 133^{\circ} 13^{\prime} \mathrm{E}, 5$ June 1973, Colless; 5 3̊, 3 ㅇ, Kakadu National Park, Baroalba Creek Springs, $19 \mathrm{~km}$ NE of Mt Cahill, $12^{\circ} 48^{\prime} \mathrm{S}$, $132^{\circ} 49^{\prime} \mathrm{E}, 29$ October 1972, 13 June 1973, Colless, ANIC; 1 , Nourlangie Creek, $8 \mathrm{~km} \mathrm{~N}$ of Mt Cahill, 26 October 1972, Colless; 1 ô, Kakadu National Park, Jim Jim Creek, 19 km WSW of Mt Cahill, 20 
November 1972, Colless; 2 $\hat{\text {, }}$, Kakadu National Park, East Alligator River, $1 \mathrm{~km} \mathrm{~N}$ of Cahills Crossing, 9 June 1973, Colless; 3 ô, 4 ㅇ, Surprise Creek, 45 km SSW of Borroloola, 14-15 April 1976, 5 November 1975, Colless; 8 ภ, 9 ㅇ, McArthur River, 40 km SW by S of Borroloola, 14 April 1976, Colless; 3 D. McArthur River, $2 \mathrm{~km}$ SSE of Borroloola, 20

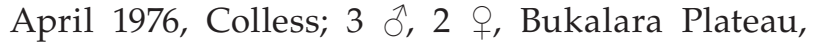
46 km SSW of Borroloola, 23 April 1976, Colless; $2 \lambda$, Goose Lagoon, $11 \mathrm{~km}$ SSW of Borroloola, $16^{\circ} 10^{\prime} \mathrm{S}, 136^{\circ} 01^{\prime} \mathrm{E}$, 31 October 1975, Upton; 4 ㅇ, 7 우, Caranbirini Water Hole, $33 \mathrm{~km}$ SW of Borroloola, 3 November 1975, 22 April 1976, Colless; 2 đ, 3 ㅇ, Batten Creek, $31 \mathrm{~km}$ WSW of Borroloola, 16 April 1976, Colless; 1 o, 4 \&, 22 km WSW of Borroloola, 17 April 1976, Colless; 2 ô, Waterhouse Range, 39 km SSW of Alice Springs, 12 October 1978, Colless; 1 ऽ̋, 1 , $41 \mathrm{~km}$ SE of Alice Springs, 4 October 1978, Colless; 1 गे, 2 क, $32 \mathrm{~km}$ WNW of Alice Springs, 9 October 1978, Colless; 2 O, 5 ㅇ, Todd River, 9 km NE of Alice Springs, 11 October 1978, Colless; 1 ô, Plenty Hwy, $268 \mathrm{~km}$ ENE of Alice Springs, 14 October 1978, Colless (all ANIC). Queensland: 2 ڤે, 1 ㅇ, Heathlands, $11^{\circ} 45^{\prime} \mathrm{S}, 142^{\circ} 35^{\prime} \mathrm{E}, 18$ September-21

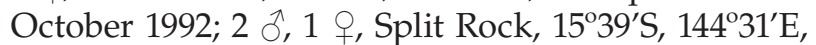
30 October-24 November 1992; 4 Oे, Hann River, $15^{\circ} 11^{\prime} \mathrm{S}, 143^{\circ} 52^{\prime} \mathrm{E}, 17$ August-15 September 1993; 4 के, 1 , $4 \mathrm{~km}$ NE of Batavia Downs, $12^{\circ} 39^{\prime} \mathrm{S}, 142^{\circ} 41^{\prime} \mathrm{E}$, 17 February-8 March 1992, 4 April-23 May 1992; $3 \mathrm{O}^{\lambda}, 5 \mathrm{~km} \mathrm{~S}$ of Batavia Downs, $12^{\circ} 41^{\prime} \mathrm{S}, 142^{\circ} 41^{\prime} \mathrm{E}$, 15 February-8 March 1992; 19 June-22 July 1992; 2 ก, 1 ㅇ, $7 \mathrm{~km} \mathrm{~S}$ of Batavia Downs, 12 $43^{\prime} \mathrm{S}, 1$, $3 \mathrm{~km} \mathrm{~W}$ of Batavia Downs, $12^{\circ} 40^{\prime} \mathrm{S}, 142^{\circ} 39^{\prime} \mathrm{E}, 23$ October-11 December 1992 (all P. Zborowski, ex Malaise/ FIT, ANIC); 1 ภ, 8 ㅇ, $13 \mathrm{~km} \mathrm{SE}$ of Weipa, $12^{\circ} 40^{\prime} \mathrm{S}, 141^{\circ} 50^{\prime} \mathrm{E}, 22$ June-14 July 1993, 14 July-15 August 1993, Malaise, Halfpapp and De Faveri; 1 ${ }^{\lambda}$, Black Braes National Park, Simpson Spring, 9.7 $\mathrm{km}$ NNE of homestead, $19^{\circ} 28^{\prime} 01^{\prime \prime} \mathrm{S}, 144^{\circ} 15^{\prime} 29^{\prime \prime} \mathrm{E}$, $820 \mathrm{~m}$, sandy dry creek bed, $820 \mathrm{~m}$, Malaise trap, 2-4 November 2001, Yeates, et al.; 1 o, 66 km NW of Mt Isa, 9 April 1976, Colless (ANIC). 3 万, 2 ㅇ, Torres Strait, Horn I., $10^{\circ} 06^{\prime} \mathrm{S}, 142^{\circ} 03^{\prime} \mathrm{E}, 29$ March-5 April, 2006, Karlin and Cookson (AMS). Western Australia: Millstream-Chichester National Park: (a) 36 今, 28 우, Roebourne Road, sandy creek bed, Eucalyptus/spinifex grassland, 27 April-3 May 2003, $337 \mathrm{~m}, 21^{\circ} 26^{\prime} 29^{\prime \prime} \mathrm{S}, 117^{\circ} 09^{\prime} 28^{\prime \prime} \mathrm{E}$, Malaise, Lambkin and Yeates (ANIC 2088); (b) 2 ก, 3 ㅇ, Yarraloola Rd, Fortescue River, 28 April-3 May 2003, Malaise

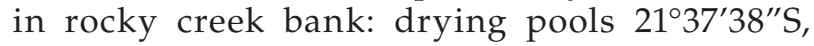
$117^{\circ} 07^{\prime} 27^{\prime \prime} \mathrm{E}$, Lambkin and Weir (ANIC 2116); (c) 13 $\mathrm{O}^{\top}, 3$ ㅇ, McKenzie Spring, $21^{\circ} 20^{\prime} 18^{\prime \prime} \mathrm{S}, 117^{\circ} 12^{\prime} 38^{\prime \prime} \mathrm{E}$, 299 m, 28 April-3 May 2003, Malaise over spring in rocky ravine, Lambkin and Weir (ANIC 2126); 3 17, 6 ㅇ, Millstream, 7-12 April 1970, 22-25 October 1970, Colless (ANIC); 4 O, 20 ㅇ, Carson Escarpment, Drysdale River, $14^{\circ} 49^{\prime}$ S, 1264'ㄹ, 9-15 August 1975, Common and Upton (ANIC).

\section{DESCRIPTION}

\section{Male}

Length: 2.3-2.6 mm; wing: 2.4 x $1.2 \mathrm{~mm}$.

Head: head almost circular in anterior view, but slightly wider than high; vertex and frons totally covered by dorsally holoptic eyes, so that only ocellar tubercle visible, and antennae at midlevel on the head; pairs of rather short diverging ocellars present; verticals and postverticals absent; faceclypeus metallic green covered by grey pruinosity, and parallel-sided, as wide as antennal bases; frontoclypeal suture evident; clypeal margin not reaching base of eyes; palp yellow with some weak black hairs and strong distal sea; proboscis yellowish with fine pale hairs; antenna brownish; scape and pedicel short; first flagellomere rounded short subrectangular, with dorsal arista which is about as long as head height; ventral postcranium with pale white hairs.

Thorax: mostly metallic green-bronze with grey pruinosity; setae black; ac uniseriate comprising 6 sort setae; 5 pairs dc present; 1 pa, 2 sa, 2 sr, 2 npl, $1 \mathrm{hm}$, and $1 \mathrm{pm}$ present; propleuron with distinct ventral seta subtended dorsally by shorter seta; median scutellar setae strong, lateral scutellars as weak side hairs, about $1 / 4$ their length.

Legs: CI yellowish; CII and CIII brown with weak metallic green reflections but apically yellow; all trochanters and very bases of femora yellow; FI basally brown but distal half to third and remainder of leg I yellow; FII and FIII brown but with distal fifth yellow and remainder of legs II and III yellow; setae black and legs with short black vestiture; CI with 3-4 strong anterior setae and some scattered short setae; CII with some anterior setae and 2 stronger distolateral setae; CIII with strong lateral seta near base and short seta near 3/4; I: 3.4; 3.0; 1.7/ 0.7/ 0.4/ 0.3/ 0.4; FI with short subapical pv seta, otherwise mostly bare; TI with short apicoventral seta, otherwise bare of major setae; $\mathrm{It}_{5}$ with pulvilli greatly enlarged and almost twice length of pulvilli on legs II and III (MSSC), and with claws distinct, not fused with enlarged pulvilli; II: 3.7; 3.4; $2.0 / 0.8 / 0.5 / 0.2 / 0.3$; trochanter II with long seta and adjacent short ad seta; FII with short subapical pv seta;TII with short slightly offset ad-pd pairs at $1 / 6$ and $2 / 3$, and with strong subapical av and pv seta, and weak ad seta; III: 4.3 ; 4.3 ; 1.4 / 1.0/ 0.6/ 0.5/ 0.5; trochanter III with dorsal seta; FIII with short subapical av and pv seta; TIII short ad at 1/8 and 4-6 spaced setae along length of dorsal surface; strong subapical av and ventral seta, and with shorter subapical adseta.

Wing: hyaline; $\mathrm{R}_{4+5}$ and $\mathrm{M}$ subparallel; $\mathrm{M}$ with slight flexion or bosse alaire half distance between $\mathrm{dm}-\mathrm{cu}$ and apex; CuAx ratio: 0.4; lower calypter yellowish with fan of pale yellow setae; halter yellow. 
Abdomen: dark brown-black with green-bronze reflections; vestiture black; sternum 8 (Figure 13b) with 4 strong black projecting setae; hypopygium dark brown with yellowish cercus; epandrium circular; hypandrium reduced; phallus elongate, tapering; epandrial lobe elongate tapering with two short apical setae; surstylus with two elongate arms, ventral arm apically clavate, and with internally arising strongly recurved U-shaped arm which curves outside surstyli and stops near apex of ventral arm, and with shorter dorsal arm distally expanded and bears some long distal setae; cercus short and subtriangular with elongate setae.

\section{Female}

Similar to male except as noted: eyes not holoptic; frons wide, metallic green covered with grey pruinosity; frons slightly wider; legs II and III with unmodified pulvilli; leg setation similar.

\section{REMARKS}

Diaphorus karijini is a widespread and common species across northern tropical Australia. It is found both in the northern monsoonal belt and further south in the arid zone, including central Queensland and the area around Alice Springs, Northern Territory. It is also known from the Torres Strait Islands, so it probably also occurs in New Guinea. It is closely related to $D$. garnetensis which has a distribution largely to the south of the monsoonal belt.

Diaphorus karijini shows some minor variation in size and colouration across its broad range. Also, the epandrial lobe in Cape York Peninsula specimens is blunt with two apical setae, whereas in the Pilbara region it is tapering with an apical and subapical seta. Otherwise it has a set of diagnostic somatic and hypopygial characters which enable it to be identified with confidence using the key.

The males of many Diaphorus species have enlarged tarsal pulvilli which are often fused with the claws (MSSC). Of interest here is that the pulvilli of male $D$ karijini are greatly enlarged on tarsus I only, but the claws are still present, while legs II and III are unmodified with distinct claws and short pulvilli. By contrast, in D. garnetensis, both legs I and II have enlarged subequal pulvilli, but the claws are missing and appear to be fused to the enlarged pulvilli, while leg III has normal puilvillii and claws.

\section{ETYMOLOGY}

The specific epithet karijini is a place name of indigenous origin, and refers to the type series from Karijini National Park. It should be regarded as a noun in apposition.

\section{Diaphorus garnetensis Bickel sp. nov.}

Figures $13 c-e$

urn:Isid:zoobank.org:act:3898A60A-FB72-46A3-97DF0E4F19A2BC50

\section{MATERIAL EXAMINED}

Holotype

Australia: Queensland: 1 त, Forty Mile Scrub National Park, $55 \mathrm{~km}$ SW by W of Mount Garnet, at light, 29-30 November 1981, D.H. Colless (ANIC).

\section{Paratypes}

Australia: Queensland: 14 ก, 6 , same data as holotype (ANIC).

\section{Additional records}

Australia: Northern Territory: $6 \hat{0}, 53 \mathrm{~km}$ E by W of Alice Springs, 6-7 October 1978, Colless; 2 त, $32 \mathrm{~km}$ WNW of Alice Springs, 9 October 1978, Colless; 6 d, Todd River, 9 km NE of Alice Springs, 11 October 1978, Colless; 3 ô, Roe Creek, $12 \mathrm{~km}$ SW by W Alice Springs, 10 October 1978, Colless (ANIC). Western Australia: Millstream-Chichester National Park: 2 Ô, 1 ㅇ, Roebourne Road, sandy creek bed, Eucalyptus/spinifex grassland, 27 April-3 May 2003, $337 \mathrm{~m}, 21^{\circ} 26^{\prime} 29^{\prime \prime} \mathrm{S}, 117^{\circ} 09^{\prime} 28^{\prime \prime} \mathrm{E}$, Malaise, Lambkin and Yeates; Karijini National Park: (a) 1 1. Weano Gorge Rd 15-20 May 2003, grassy dry creek, 695m, $22^{\circ} 21^{\prime} 19^{\prime \prime} \mathrm{S}, 118^{\circ} 15^{\prime} 00^{\prime \prime} \mathrm{E}$, Malaise trap, C. Lambkin and Weir; (b) 2 O, 7 , Hamersley-Mt Bruce Rd, 22 $34^{\prime} 14^{\prime \prime} S, 118^{\circ} 17^{\prime} 52^{\prime \prime}$ E, 25 April-14 May 2003, dry rocky creek bed, 757m, Malaise, Lambkin and Weir; (c) 1 d, Juna Downs Road, 19-25 April 2003, drying pool in rocky Turee Creek, $789 \mathrm{~m}$, $22^{\circ} 41^{\prime} 57^{\prime \prime} \mathrm{S}, 118^{\circ} 25^{\prime} 06^{\prime \prime} \mathrm{E}$, Lambkin and Weir, (ANIC); 1 §ิ, Barrow I., N18 SUC, WGS84 (50) 331248 7694562, 1 May 2007, Callan and Edwards (WAM 83885)

\section{DESCRIPTION}

\section{Male (similar to $D$. karijini except as noted).}

Length: 2.9-3.2 mm; wing: $3.1 \times 1.2 \mathrm{~mm}$.

Thorax: mostly dark metallic blue-green; otherwise similar.

Legs: CI brownish becoming yellowish distally; CII and CIII dark brown; all trochanters yellow; all femora dark brown; tibia I and reminder of leg yellow with tarsomeres becoming infuscated distally; TII and tarsus II yellowish; TIII and remainder of leg brownish; setae and short vestiture black; CI with 3-4 strong anterior setae and some scattered short setae; CII with some anterior setae and 2 stronger; distolateral setae; CIII with strong lateral seta near base and short seta near 3/4; I: 4.2; 3.7; 1.8/0.8/ 0.6/ 0.4/ 0.4; FI with irregular row of ventral and pv setae along length; TI with short ad near $1 / 5$, dorsal near $1 / 3$ and stronger 
dorsal 3/5, and with strong apicoventral seta; $\mathrm{It}_{5}$ with pulvilli greatly enlarged (MSSC) and subequal to pulvilli on leg II, and with claws apparently fused with enlarged pulvilli (MSSC); II: 4.4; 4.2; 1.9/ 1.2/ 0.8 / 0.5/ 0.5; trochanter II with long seta and adjacent short ad seta; TII with short slightly offset ad-pd pairs at $1 / 6$ and $2 / 3$, and with strong subapical av and pv seta, and weak ad seta; IIt5 with pulvilli greatly enlarged (MSSC), and with claws apparently fused with enlarged pulvilli (MSSC); III: 5.2; 5.3; 1.3/ 1.2/ 0.8/ 0.6/ 0.6; trochanter III with dorsal seta; TIII short 2-3 ad setae and 4-6 dorsal setae surface; strong subapical av and ventral seta, and with shorter ad subapical; IIIt5 with pulvilli and claws unmodified.

Wing: CuAx ratio: 0.4; lower calypter yellowish with fan of black setae; halter yellow.

Abdomen: dark metallic blue-green, vestiture black; sternum 8 (Figure 13d-e) with 4 strong black projecting setae; hypopygium dark brown with yellowish cercus; epandrium circular; hypandrium reduced; epandrial lobe distinctly curved with two short apical setae; surstylus with two elongate arms, ventral arm longer and apically clavate, and with internal gently curved arm arising medially from ventral surstylar arm, and with slightly curved dorsal arm that tapers distally; cercus projecting from epandrium (visible in external view, Figure $13 e)$ and subtriangular with setae as Figured.

\section{Female}

Similar to male except as noted: eyes not holoptic; frons wide, metallic green covered with grey pruinosity; frons slightly wider; legs II and III with unmodified pulvilli; FI bare, without ventral and pv seta; TI usually with only single dorsal seta near $1 / 2$, otherwise leg setation similar.

\section{REMARKS}

Diaphorus garnetensis is found across tropical northern Australia, including central Queensland, the Alice Springs district, and the Pilbara. By contrast its apparent sister species, D. karijini, has a distinctly more monsoonal distribution in Australia.

Specimens of Diaphorus garnetnensis from the Forty Mile Scrub type locality are somewhat larger and darker (tibiae II and III more infuscated) than in specimens form the Pilbara, but the hypopygia are similar. I have seen Diaphorus specimens from western New South Wales and South Australia (ANIC) that appear to be close to D. garnetensis, but are larger and with distinctly different setation. (also see "Remarks" under D. karijini).

\section{ETYMOLOGY}

The specific epithet "garnetensis" refers to this species occurrence at Mt. Garnet, Queensland.

\section{Genus Chrysotus Meigen, 1824}

\section{REMARKS}

Chrysotus is a complex cosmopolitan genus of more than 250 described species, with many more awaiting description. However, it is not clearly defined with respect to other diaphorine genera, and it is probably polyphyletic. This generic name has been used for many small-sized diaphorine species, an agglomeration of scattered and mostly inadequate descriptions. Nevertheless, Chrysotus is useful as a bearer of names, and final resolution awaits future study. Some species with this genus have distinctive male antennal modifications (MSSC).

\section{Chrysotus austrotropicus Bickel sp. nov.}

Figures $14 d-g$

urn:Isid:zoobank.org:act:18CAAB85-3EEC-44EC-858866ED8F0CF378

\section{MATERIAL EXAMINED}

\section{Holotype}

Australia: Northern Territory: 1 त, October Creek, rest area on Carpentaria Hwy, west of Cape Crawford, 16 $6^{\circ} 38^{\prime} 00^{\prime \prime}$ S, 134 $4^{\circ} 51^{\prime} 27^{\prime \prime}$ E, 20 January 2004, 225 m, yellow pans, S. Cowan (AMS, K. 364690).

\section{Paratypes}

Australia: Northern Territory: $9 \hat{0}, 4$, same data as holotype; 60 , $55 \mathrm{~km}$ E of Top Springs, Buchanan Hwy, $16^{\circ} 44^{\prime} 08^{\prime \prime} \mathrm{S}, 132^{\circ} 14^{\prime} 36^{\prime \prime}$ E, 26 January 2004, yellow pans, S. Cowan; paratypes 2 O, Edith River (14 $\left.11^{\prime} 06^{\prime \prime} \mathrm{S}, 132^{\circ} 01^{\prime} 41^{\prime \prime} \mathrm{E}\right)$ 21-22 January 2004, yellow pans, S. Cowan; paratypes $2 \delta, 148 \mathrm{~km}$ North of Barkly Roadhouse, Tablelands Hwy, $18^{\circ} 20^{\prime} 30^{\prime \prime}$ S, 135 58'41"E, 19 January 2004, yellow pans, S. Cowan (AMS).

\section{Additional records}

Australia: Northern Territory: 2 , McArthur River, $40 \mathrm{~km}$ SW by S of Borroloola, 14 April 1976, Colless; 1 J, $12 \mathrm{~km}$ SW of Alroy Downs, 10 April 1976, Colless (ANIC); 4 +, Surprise Creek, 45 km SSW of Borroloola, 15 April 1976; 2 गे, 3 ㅇ, Koongarra, $15 \mathrm{~km}$ E of Mt Cahill, 15 November 1972, Colless (ANIC). Queensland: 3 त, 3 ㅇ․ Heathlands, $11^{\circ} 45^{\prime} \mathrm{S}, 142^{\circ} 35^{\prime} \mathrm{E}, 21$ October-22 November 1992, Malaise, Zborowski; 13 $\widehat{\text { N }} 7$ ㅇ, Split Rock, $15^{\circ} 39^{\prime} \mathrm{S}, 144^{\circ} 31^{\prime} \mathrm{E}, 30$ October-24 November 1992, Malaise, Zborowski; 3 ô, 1 ㅇ, Hann River, $15^{\circ} 11^{\prime} \mathrm{S}, 143^{\circ} 52^{\prime} \mathrm{E}, 20$ October-17 November 1993, Malaise, Zborowski; 6 गे, 4 ㅇ, $2 \mathrm{~km} \mathrm{~N}$ of Rokeby, $13^{\circ} 39^{\prime} \mathrm{S}, 142^{\circ} 40^{\prime} \mathrm{E}, 17$ January-15 February 1994, Malaise, Zborowski and Shaw; 42 ㅇ, $4 \mathrm{~km} \mathrm{NE}$ of Batavia Downs, $12^{\circ} 39^{\prime} \mathrm{S}, 142^{\circ} 41^{\prime} \mathrm{E}$, 24 October-23 November 1992, Malaise, Zborowski; 6 ㅇ, 5 km S 
of Batavia Downs, $12^{\circ} 41^{\prime} S, 142^{\circ} 41^{\prime} E$, 15 February-8 March 1992, Malaise, Zborowski; 6 1, 3 ㅇ, $7 \mathrm{~km} \mathrm{~S}$ of Batavia Downs, 12 $43^{\prime}$ S, 142 $42^{\prime}$ E, 23 November-11 December 1992, Malaise, Zborowski; $1 \hat{\jmath}$, Mt Webb National Park, $3 \mathrm{~km}$ NE of Mt Webb, 15어의, 14509'E, 27-30 April 1981, Malaise, Naumann; 1 ô, Musselbrook Camp, $18^{\circ} 36^{\prime} \mathrm{S}, 138^{\circ} 08^{\prime} \mathrm{E}, 8-21$ May 1995, Naumann; 1 กิ, 1 ㅇ, Flinders River, 59 km SW of Normanton, $18^{\circ} 10^{\prime} \mathrm{S}, 140^{\circ} 51^{\prime} \mathrm{E}, 2$ December 1981, Colless; 1 ふै, Darr River, $31 \mathrm{~km} \mathrm{NW}$ by $\mathrm{N}$ of Longreach, 7 April 1976, Colless; 1 j, 2 km of S of Horseshoe Lookout, Blackdown Tableland, 23-24 April 1981, Colless; 1 Õ, 3 , $6 \mathrm{~km}$ SE of Chillagoe,

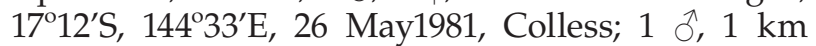

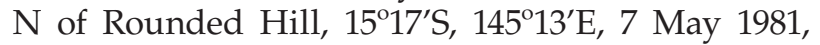
Colless (all above ANIC). 3 ก, 3 q, Quamby, $20^{\circ} 22^{\prime} 23^{\prime \prime}$ S, 14016'58” E, 181 m, 16 January 2004, yellow pans, S. Cowan; 72 o, 6 \%, Slaty Creek, S of Cloncurry, 20 $53^{\prime} 19^{\prime \prime} S, 140^{\circ} 20^{\prime} 45^{\prime \prime} \mathrm{E}, 6$ January 2000, yellow pans, Moulds; 4 ऽ, 4 , Bowling Green Bay, $19^{\circ} 24^{\prime} \mathrm{S}, 147^{\circ} 01^{\prime \prime \prime} \mathrm{E}$, tidal mudflats, 9-10 April 1994, yellow pans, Bickel; 7 O 6 ㅇ, Escot Stn, W of Burketown, $17^{\circ} 45^{\prime} \mathrm{S}, 139^{\circ} 25^{\prime} \mathrm{E}, 19$ December 1991, yellow pans, Moulds; 2 ๙̃, 3 , 16 km NW of Hell's Gate, $17^{\circ} 22^{\prime} \mathrm{S}, 138^{\circ} 16^{\prime} \mathrm{E}, 20$ December 1991, yellow pans, Moulds; $1 \hat{\jmath}$, Dugald River crossing, $75 \mathrm{~km}$ NNW of Cloncurry, 200's, $140^{\circ} 20^{\prime} 45^{\prime \prime} \mathrm{E}, 6$ January 2000, yellow pans, Moulds; $1 \hat{\sigma}$, Carnarvon National Park, Carnarvon Creek, 16 km E of park, pools in creek bed, yellow pans, Bickel (all above AMS). Western Australia: 1 ग, Hamersley Stn, Nanutarra-

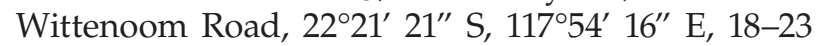
November 2004 (AMS); 1 ऽ, Barrow I., WGS84 (50) 340913 7707558, 6 May 2007, Callan and Edwards (WAM 83886) 1 ㅇ, Carson Escarpment, Drysdale River, $14^{\circ} 49^{\prime} \mathrm{S}, 126^{\circ} 49^{\prime} \mathrm{E}$, 9-15 August 1975, Common and Upton (ANIC).

\section{DESCRIPTION}

\section{Male}

Length: $1.4 \mathrm{~mm}$; wing: $1.3 \times 0.5$.

Head: vertex and frons metallic green with bronze reflections; setae black; strong diverging ocellars, strong verticals, and short postverticals present; eyes joined across face-clypeus, with face as small triangle beneath the antennae; anterior eye facets greatly enlarged; palp pale yellow; proboscis brown, and narrow somewhat prolonged; antenna entirely black; scape and pedicel short and pedicel with apical dorsal and ventral seta; first flagellomere asymmetrically cordate (MSSC), covered in short fine hairs, arista dorsal, almost apical, ventral postcranium with pale postorbitals but dorsal third with black postorbitals.

Thorax: mesonotum shining metallic green with bronze reflections; some pruinosity present on pleura; 4-5 pairs short ac present; 5 strong dc; 1 pa, 2 sa, 2 sr, 2 npl, 1 hm, and 1 pm present; median scutellar seta strong, lateral seta as short hair.
Legs: CI yellow; CII and CIII brown; trochanters, femora, tibiae and basal tarsomeres pale yellow, with distal tarsomeres dark brown; major setae black except those of coxae and trochanters yellow; CI with 3-4 distolateral setae; CII with some short anterior setae and strong anterolateral seta at $1 / 4$; CIII with strong lateral seta at $1 / 4$; all pulvilli short and unmodified; I: $1.6 ; 1.7 ; 0.8 / 0.4$ / 0.3/ 0.2 / 0.2; FI bare of major setae; TI with short black apical ventral seta; II: $2.1 ; 2.0 ; 1.0 / 0.5 / 0.3 / 0.2$ / 0.2 ; trochanter 2 with strong lateral seta; FII with distinct anterior subapical seta at $7 / 8$ and posterior subapical seta at 7/8; TII with ad-pd setal pair at $1 / 3$ with ad seta much stronger, and subapically with strong av seta and ventral seta, and weaker ad and dorsal seta; III: $2.4 ; 2.3 ; 0.7 / 0.5 / 0.3 / 0.2$ / 0.2; FIII with row 2 strong brownish av setae along distal fifth; TIII with strong ad seta at $1 / 4$, and 2-3 outstanding dorsal setae along length, and with short ventral apical seta.

Wing: hyaline; $\mathrm{R}_{4+5}$ and $\mathrm{M}$ somewhat close and positioned on anterior third of membrane, parallel with gentle curve beyond crossvein $\mathrm{dm}-\mathrm{cu}$, and $\mathrm{M}$ ending at margin just anteriad of apex; crossvein $\mathrm{dm}-\mathrm{cu}$ straight and positioned far from wing margin; CuAx ratio: 0.2; lower calypter pale yellow with fan of yellow setae; halter pale yellow.

Abdomen: shining metallic green-bronze, and covered with short black vestiture; hypopygium (Figure 14d) dark brown with yellow cerci; epandrium circular; phallus elongate projecting; hypandrium short; surstylus blade like with ventrally upcurved apex with short apical seta; cercus short subtriangular.

\section{Female}

Similar to male, and lacking MSSC otherwise as noted: (Figure 14g). face-clypeus wide; eyes distinctly separated by wide face covered in grey pruinosity; first flagellomere subrectangular, with arista arising just dorsal of mid-position; leg colour similar; legs with similar setation.

\section{REMARKS}

Chrysotus austrotropicus is found across much of northern tropical Australia, in Western Australia from the Pilbara Hamersley Ranges and Barrow Island to the Kimberley Ranges, monsoonal Northern Territory, and much of monsoonal and interior Queensland, from the Cape York Peninsular south to the Blackdown Tableland and Carnarvon Gorge. It is one of a group of similarly small and mostly undescribed species from the Australian tropics that have the male first flagellomere modified into a cordate shape and finely hirsute (MSSC). One of the commoner undescribed species of this group, sympatric with C. austrotropicus in Queensland, has a yellow first flagellomere 


\section{ETYMOLOGY}

The specific epithet "austrotropicus" refers to this species' distribution across the tropical region of the Australian continent.

\section{Chrysotus pilbarensis Bickel sp. nov.}

Figures $14 a-c$

urn:Isid:zoobank.org:act:35ADE0EB-D7B8-42ED-B3B7C765F5F00A2C

\section{MATERIAL EXAMINED}

\section{Holotype}

Australia: Western Australia: 1 के, Millstream, 8 April 1970, D. H. Colless (ANIC).

\section{Paratypes}

Australia: Western Australia: 12 $\hat{0}, 8$ 옹 same

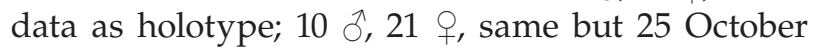
1070; 5 ภे, 1 O, Millstream-Chichester National

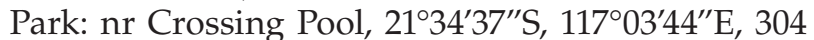
m, 28 April-5 May 2003, Malaise trap in Melaleuca riverine forest, Lambkin and Weir (ANIC 2007).

\section{DESCRIPTION}

\section{Male}

Length: $1.6 \mathrm{~mm}$; wing: $1.5 \times 0.5$.

Head: vertex and frons metallic blue-green; setae black; strong diverging ocellars, strong verticals, and short postverticals present; eyes joined across face-clypeus, with face as small triangle beneath the antennae; anterior eye facets distinctly enlarged; palp dark brown with black apical seta; proboscis brown with some brownish hairs; scape and pedicel brownish, 1st flagellomere brown; scape and pedicel short and pedicle with apical dorsal and ventral seta; first flagellomere short, rounded subrectangular; arista apical, arising on the dorsal third of the outer surface; ventral postcranium with pale postorbitals but dorsal third with black postorbitals.

Thorax: brown shining cuticle with metallic bluegreen reflections; setae black; 8 regular pairs short ac; 5 pairs strong dc present; 1 pa, 2 sa, $2 \mathrm{sr}, 2 \mathrm{npl}$, $1 \mathrm{hm}$, and $1 \mathrm{pm}$ present; propleuron with distinct ventral seta dorsad of CI; lateral scutellar seta about one quarter length of median.

Legs: coxae, trochanters, femora and remainder of leg III dark brown; TI and tarsus I yellow, but $\mathrm{It}_{5}$ brown; TII and tarsus II yellowish; setae black; CI with 3-4 distolateral setae; CII with some short anterior setae and strong anterolateral seta at $1 / 4$; CIII with strong lateral seta at $1 / 4$; all pulvilli short and unmodified; I: 2.1; 1.7; 0.8/ 0.3/ 0.2/ 0.2/ 0.2; FI bare of major setae; TI with short dorsal near $1 / 5$ and short apical ventral seta; II: $2.3 ; 2.0 ; 1.0 / 0.4$ /
$0.3 / 0.2$ / 0.2; trochanter 2 with strong lateral seta; FII with some short av setae along distal half, and short subapical av and pv seta; TII with short ad seta at $1 / 5$ and $1 / 2$, and subapically with strong av and ventral seta and weaker ad and dorsal seta; III: 2.5 ; 2.3 ; 0.7/ 0.6/ 0.4/ 0.3/ 0.3; FIII row of 7-10 av setae along length, stronger along the distal half (MSSC) and with short subapical pv seta; TIII slightly laterally flattened, and covered with dense short seta on anterior surface (MSSC), with 2-3 outstanding dorsal setae along length, and with strong ventral apical seta.

Wing: hyaline; $\mathrm{R}_{4+5}$ and $\mathrm{M}$ somewhat close and positioned on anterior third of membrane, parallel with gentle curve beyond crossvein $\mathrm{dm}-\mathrm{Cu}$, and $\mathrm{M}$ ending at margin just anteriad of apex; crossvein $\mathrm{dm}-\mathrm{cu}$ straight and positioned far from wing margin; CuAx ratio: 0.2; lower calypter yellow with brown margin and with fan of brownish setae; halter dark brown with black club.

Abdomen: metallic blue-green with bronze reflections, and covered with short black vestiture; brownish vestiture; hypopygium (Figure 14c) dark brown with yellow cerci; epandrium circular; phallus elongate projecting; hypandrium short; epandrial lobe present as short mound bearing two short setae basad of surstylus along ventral margin; surstylus blade like with ventrally upcurved apex and short apical seta; cercus elongate and subtriangular.

\section{Female}

Similar to male, and lacking MSSC otherwise as noted: face-clypeus wide, eyes distinctly separated by wide face; leg colour similar; FIII with only 3-4 strong av setae along distal quarter: TIII not flattened, unmodified.

\section{REMARKS}

Chrysotus pilbarenis is a distinctive species known only from the Millstream site on the Fortescue River, Western Australia. The row of 8-10 strong anteroventral setae along the male femur III are diagnostic. This species is part of a widespread Australasian/Pacific species group in which all males have some strong av setae on femur III and ventrally holoptic eyes. It includes Chrysotus cockerellae Curran, which has a distribution covering many south-west Pacific islands and eastern Australia. I have seen additional undescribed Australian species of this group in collections (ANIC, AMS) from Cape York Peninsula and Christmas Island.

\section{ETYMOLOGY}

The specific epithet "pilbarenis" refers to this species occurrence in the Pilbara region, Western Australia. 


\section{Genera incertae sedis}

Genus Acropsilus Mik, 1878

\section{Acropsilus protractus Robinson, 1963}

Figures 7c-d

Acropsilus protractus Robinson 1963: 830.

MATERIAL EXAMINED

\section{Additional records}

Australia: Western Australia: $1 \hat{\mathrm{O}}$, Hamersley Gorge, upstream, $\left(22^{\circ} 15^{\prime} 31^{\prime \prime} \mathrm{S}, 117^{\circ} 59^{\prime} 09^{\prime \prime} \mathrm{E}\right), 29$ May6 June 2004, pit trap, Bulbert, Tartanic and Britton (AMS K.248807).

\section{REMARKS}

Acropsilus is an Old World genus of mostly smallsized species less than $1.5 \mathrm{~mm}$ in length. Four species are known from Australia where species are often abundant and widespread after monsoonal rains, but confined to permanent water during the drier periods (see revision in Bickel 1998).

Acropsilus protractus is widespread across northern Australia, New Guinea and the Solomon Islands, and is common in lowland habitats. In Australia, it is found along the Queensland coast south to the Tropic of Capricorn, and across the monsoonal north, including the Northern Territory, and the Kimberleys and the Pilbara in Western Australia.

\section{Genus Phrudoneura Meuffels and Grootaert, 1987}

\section{Phrudoneura collessi Bickel, 2013}

Figure 12a

Phrudoneura collessi Bickel 2013: 44.

\section{REMARKS}

Phrudoneura is easily recognized by the males having a shortened vein $M$ that ends in the wing membrane halfway between crossvein $\mathrm{dm}-\mathrm{cu}$ and the wing apex. It is known from New Caledonia (a particularly rich fauna), New Guinea and Australia (two species). As well there are undescribed species from South-East Asia (see Bickel 2013).

Phrudoneura collessi is distributed across northern Australia, but apparently south of the monsoonal belt. It occurs in the Cairns district rainforests then along the Queensland coast to northernmost New South Wales, and with a strange disjunction to the Fortescue River drainage (Millstream-Chichester and Karijini National Parks) in the Pilbara region of Western Australia (see Bickel 2013 for records).
Phrudoneura collessi is the sister taxon of the northern Australian and Melanesian P. abbreviata Meuffels and Grootaert.

\section{FAUNAL SUMMARY AND BIOGEOGRAPHY}

The Pilbara region in north-western Australia comprises an eroded Precambrian shield with a deeply incised drainage pattern. It is a hot arid region and receives only irregular rainfall, the result of its position south of the northern monsoonal belt. However, the Pilbara gorges maintain a moist environment and pools for much of the year which allows many moisture-adapted Dolichopodidae to survive an otherwise hostile environment. As well, there are arid and saline adapted species that are able to survive outside these moist refugia (for information on the Pilbara and its environment, see McKenzie, et al. 2009, and Pepper, et al. 2013).

The distribution of the Pilbara Dolichopodidae is summarized in Table 1. Based on described species and undescribed species (known only from distinctive females or damaged males), 41 putative species are recorded. Two of the districts are briefly discussed below.

a) Barrow Island. Although the Barrow Island fauna was the impetus for undertaking this study, it has been rather poorly sampled for Dolichopodidae, and only seven species are recorded. Most of these were collected in pitfall traps, more as accidental strays than the result of targeted trapping. By employing sampling methods for aerial insects, such as Malaise and yellow pan (water) traps, as well as sweeping coastal habitats, I estimate that at least another 10 species would be found to occur on the island.

b) Fortescue River. The Millstream-Chichester and Karijini National Parks along the Fortescue River drainage have the richest faunas, with 25 and 17 species respectively, or 30 shared species in total. This region has been sampled intensively by several ANIC expeditions with Malaise traps and has produced large rich collections. The Millstream site also has maintained a taxonomically isolated endemic genus, Pilbara, discussed below.

Overall, the Pilbara fauna is rather rich in light of the region's aridity, and the fact most species found were "by-catch" from general collecting. However, with additional targeted collection techniques (e.g., tree trunk sticky traps, yellow pans near seeps and mangroves, and sweeping littoral zones), I would expect perhaps 15-20 additional species in the fauna. One problem in studying such large poorly known insect faunas is the variability of regional representation in collections. For example, as a result of the ANIC expeditions to the Fortescue River drainage, the Pilbara has been much more intensely sampled for Diptera than the Kimberley district further north. Although the Kimberley 
undoubtedly hosts a much richer fauna due to its monsoonal climate and presence of gallery rainforest pockets, this is not demonstrated by current collections.

\section{BIOGEOGRAPHY - I. PATTERNS}

The distribution patterns of the 41 species of Dolichopodidae known from the Pilbara are discussed below.

Endemic Pilbara. Seven species are known from a single site, and an additional three are known from two or more sites in the Pilbara. The two species of the genus Pseudoparentia, $P$. canalicula from Cape Range, and $P$. niharae from Barrow Island are characteristic of a genus whose species appear to restricted to single or few sites within interior Australia, and therefore could be considered part of the "Interior" pattern below. Pilbara octava is the most interesting dolichopodid species in the fauna, being known at the generic level only from the Millstream site. It is morphologically isolated within the subfamily Sciapodinae, and one must conclude it is old relict taxon.

Pilbara and Kimberley. Five species are known from both the Pilbara and Kimberley districts, two incised upland areas separated by a broad expanse arid lowlands in north-western Australia. With more collecting, some of these species probably will be seen to be part of the general northern monsoonal fauna.

Northern monsoonal Australia/ Melanesia. Eleven Pilbara species have distributions across the tropical northern Australia, either restricted to the monsoonal zone, or in a broader band that includes arid landscapes with more erratic rainfall. A number of these tropical species extend down the Queensland coast into the subtropics, such as Paraclius trisetosus and P. obtusus, both of which extend into northern New South Wales. Some species whose ranges extend to northern Cape York Peninsula are likely to occur in the nearby New Guinea which has similar eucalypt woodland habitats. However, collections from this southern region of New Guinea are almost non-existent, and the Torres Strait Islands provide the nearest records. Several Pilbara species have distributions into the Pacific. For example, Paraclius sexmaculatus, is widely distributed across northern Australia, New Guinea, Belau, Kiribati, Vanuatu, Fiji and New Caledonia, and has reached remote Pacific atolls, and Acropsilus protractus is found from the Pilbara to the Solomon Islands, with a coastal extension south to Bundaberg, Queensland.

Interior. This pattern is more difficult to describe, but it comprises species found in the interior of Australia, mostly west of the Great Dividing Ranges, and certainly south of the monsoonal belt.
It includes species from the arid tropics (e.g. Alice Springs), the Murray-Darling drainage, and from isolated uplands elsewhere. It includes some seven Pilbara species, as well as the two Pseudoparentia local endemics treated above, the genus itself having an "Interior" distribution pattern. Since Australian inland sites have not been as intensively sampled for Diptera as has the eastern Australian corridor, "Interior" species distribution records often appear desultory, yet these species are notable for their general absence in more mesic landscapes.

Also of interest are species that appear to have trans-continental tropical distributions but distinctly south of the monsoonal belt, usually including interior Queensland, the Alice Springs district and the Pilbara. These include Chaetogonopteron vexillum and C. bartaki, Sympycnus pistilus and S. colliepa, Diaphorus garnetensis, and Phrudoneura collessi.

Gondwanan. Parentia is regarded as a Gondwanan genus, being diverse in New Zealand, New Caledonia, Tasmania and southern mainland Australia, where it displays a classical Bassian distribution pattern. One species, Parentia vulgaris is widespread across southern Australia, but has crossed into the tropics in both Queensland and the Pilbara region. Otherwise there are no distinctly southern or putatively Gondwanan elements in the Pilbara fauna, and many of these taxa in Western Australia appear to reach their northern limit in sandy heathlands/ woodlands of near the Murchison River around Kalbarri National Park.

Coastal. Paraclius manglar is a mangrove associate known from coastal New South Wales, southeastern Queensland, and a disjunct population at Cape Range. I suspect this species will be found in mangrove habitats along the tropical Australian coast.

Widespread Australia. Thrypticus australis is found widely across Australia, including Tasmania, and is know from a variety of habitats, ranging from subalpine woodland to arid desert. Hydrophorus praecox is a widespread Old World tramp species that has adapted to a wide range of Australian habitats in addition to its favoured littoral associations.

\section{BIOGEOGRAPHY - II. PROCESSES}

What biogeographical processes account for the above patterns? Two processes frequently cited by systematists are dispersal and vicariance. Less cited although of great significance is the influence of extinction on patterns. Extinction is undervalued because absence can also be regarded as lack of data (for example, poorly sampled insect faunas), rather than the disappearance of a taxon within a region. Unfortunately, many biogeographers lock themselves into dogmatic stances and support a 
Barrow I. Millstream Karijini Other Pilbara

Other WA

Extralimital Distribution and Notes

\begin{tabular}{|c|c|c|c|c|c|c|}
\hline \multicolumn{7}{|l|}{ SCIAPODINAE } \\
\hline Amblypsilopus fortescuia & & $x$ & $x$ & Hamersley & Kimberley & \\
\hline Amblypsilopus gressitti & & & & Hamersley & Kimberley & Arnhem Land, Northern Territory \\
\hline Amblypsilopus putealis & & & & Cape Range & Kimberley & \\
\hline Chrysosoma nobile & & $X$ & $X$ & & & Torres Strait, coastal NT \\
\hline Dytomyia flaviseta & $X$ & & & Monte Bello Is & Kimberley & \\
\hline Mesorhaga flavicoma & & $X$ & & Hamersley & Kimberley & Interior NT, Qld \& SA ; SE Qld \\
\hline Mesorhaga longipennis & & $X$ & $\mathrm{X}$ & & Kimberley & \\
\hline Parentia vulgaris & & $X$ & $\mathrm{X}$ & Hamersley & & $\begin{array}{l}\text { Widespread temperate Australia, N Qld to S. } \\
\text { NSW; Norfolk I. }\end{array}$ \\
\hline Pilbara octava & & $X$ & & & & Locally endemic genus \\
\hline Pseudoparentia canalicula & & & & Cape Range & & \\
\hline Pseudoparentia niharae & $\mathrm{X}$ & & & & & \\
\hline \multicolumn{7}{|l|}{ DOLICHOPODINAE } \\
\hline Paraclius manglar & & & & Cape Range & & Mangroves; Sydney NSW to Se Qld \\
\hline Paraclius obtusus & & $X$ & & & & Sydney NSW to S. Cape York Pen.; tropical NT \\
\hline Paraclius sexmaculatus & & $\mathrm{X}$ & & & Kimberley & $\begin{array}{l}\text { Monsoonal Australia, N Guinea, Vanuatu, } \\
\text { Fiji, N. Caledonia, Micronesia }\end{array}$ \\
\hline Paraclius trisetosus & & $\mathrm{X}$ & $x$ & Tom Price & Kimberley & $\begin{array}{l}\text { Coast \& ranges, N NSW to Cape York Pen.; } \\
\text { tropical NT }\end{array}$ \\
\hline \multicolumn{7}{|l|}{ MEDETERINAE } \\
\hline Corindia capricornis & & $X$ & & & Kimberley & Tropical NT, Qld \\
\hline Corindia collessi & & $X$ & & & Kimberley & Tropical Qld \\
\hline Corindia sp. (female) & & $x$ & & & & \\
\hline Medetera junensis & & & $\mathrm{X}$ & Hamersley & & \\
\hline Thrypticus australis & & $\mathrm{X}$ & & & Cape Arid NP & $\begin{array}{l}\text { Widespread tropical \& temperate Australia, } \\
\text { Tasmania; Norfolk I. }\end{array}$ \\
\hline Thrypticus fortescuensis & & $\mathrm{X}$ & & & & \\
\hline \multicolumn{7}{|l|}{ HYDROPHORINAE } \\
\hline Hydrophorus praecox & $\mathrm{x}$ & $\mathrm{X}$ & & Hamersley & Widespread & $\begin{array}{l}\text { Widespread Australia, NZ, Asia, Europe, } \\
\text { some Pacific Islands }\end{array}$ \\
\hline Thinophilus eboricoxa & $X$ & & & & Kimberley & \\
\hline Thinophilus splendens & & $X$ & & & Kimberley & $\begin{array}{l}\text { Papua New Guinea, SE Qld to Cairns, } \\
\text { tropical NT }\end{array}$ \\
\hline Thinophilus yarraloola & & $X$ & $X$ & & & \\
\hline Thinophilus sp. (female) & $x$ & & & & & \\
\hline \multicolumn{7}{|l|}{ SYMPYCNINAE } \\
\hline Chaetogonopteron bartaki & & & $X$ & & Kimberley & Widespread interior Australia, all states \\
\hline Chaetogonopteron vexillum & & $x$ & $X$ & & & $\begin{array}{l}\text { Alice Springs, NT; Central Qld, S Cape York } \\
\text { Peninsula. }\end{array}$ \\
\hline Sympycnus colliepa & & $\mathrm{X}$ & & & $\begin{array}{l}\text { SW and W } \\
\text { coast }\end{array}$ & $\begin{array}{l}\text { Interior Australia S of monsoonal zone: } \\
\text { NSW, NT, Qld, SA, WA }\end{array}$ \\
\hline Sympycnus ephydroides & & & $X$ & & Kimberley & Tropical NT, Qld \\
\hline Sympycnus hamulitarsus & & $X$ & $X$ & & & \\
\hline Sympycnus lacrimulus & & $x$ & $x$ & & & Arnhem Land, NT \\
\hline Sympycnus pistillus & & & $X$ & & & Coast and ranges, S NSW to Cape York Pen \\
\hline Sympycnus weano & & & $X$ & & & \\
\hline Teuchophorus sp. ( damaged) & $x$ & & & & & $\begin{array}{l}\text { Genus widespread tropical and eastern } \\
\text { Australia }\end{array}$ \\
\hline \multicolumn{7}{|l|}{ DIAPHORINAE } \\
\hline Diaphorus karijini & & $x$ & $x$ & & Kimberley & $\begin{array}{l}\text { Tropical monsoonal and interior NT, Qld; } \\
\text { Alice Springs }\end{array}$ \\
\hline Diaphorus garnetensis & & $X$ & $X$ & & & Tropical central Qld; Alice Spring NT \\
\hline Chrysotus austrotropicus & $X$ & & & Hamersley & Kimberley & Monsoonal NT, Qld ; central Qld \\
\hline Chrysotus pilbarensis & & $x$ & & & & \\
\hline \multicolumn{7}{|l|}{ GENERA INCERTAE SEDIS } \\
\hline Acropsilus protractus & & & & Hamersley & Kimberley & $\begin{array}{l}\text { Monsoonal NT, Qld; coastal Qld S to } \\
\text { Bundaberg; New Guinea, Solomons }\end{array}$ \\
\hline Phrudoneura collessi & & $x$ & $X$ & & & N. NSW to Cairns, Qld \\
\hline
\end{tabular}


"one process fits all" approach. Reality is always more complex and messy.

Many treatments of the Pilbara fauna (see references in McKenzie, et al. 2009) regard the Pilbara as a centre of faunal endemism, but these studies are often based on taxa that have limited movement or are confined to circumscribed terrestrial habitats. By contrast, this study is based on a highly vagile fly family, and one dominant pattern shows the Pilbara as an endpoint in the distribution of tropical species from Melanesia to Western Australia, across Cape York Peninsula and Arnhem Land. During monsoonal periods when the landscape becomes sodden, these species are able to spread across otherwise inhospitable arid barriers. The Pilbara provides suitable habitats in terms of protected gorges and persistent waterholes that allow many moisture loving species to become established and persist. However, as a whole, both the Kimberley and Pilbara districts demonstrate progressive species impoverishment compared to Arnhem Land, showing a sweepstakes effect from east to west (see examples in the Sciapodinae, Bickel 1994). The Pilbara is indeed the "last stop" for many tropical and monsoonal species as the large intervening arid tract between the Pilbara and the south-west of Western Australia presents an insurmountable barrier for most taxa

The principal premise of vicariance biogeography is that a taxon has always occupied the landmasses on which it occurs, and that the ancient geographies have been changed by geological or climatic events, with barriers subsequently breaking up once contiguous distributions. Vicariance provides another explanation for the similarity of monsoonal Australian and Melanesian taxa (where known). During the Quaternary glacial maximun, a wide land bridge comprising the exposed Sahul Shelf stretched from Arnhem Land to the Cape York Peninsula, enclosing the then freshwater "Lake Carpentaia", and across to what is now the southern coast of New Guinea (Mulvaney and Kamminga 1999). The region would have shared a similar biota that became divided some 10,000 years BP by the by sea level rise, forming the present day Arafura Sea and Torres Strait. I suspect systematic sampling in southern New Guinea will reveal the presence of many more tropical "Australian" species.

Some patterns that include the Pilbara region are best explained by vicariance, especially those of some Australian "Interior" species. For example, species such as Chaetogonopteron vexillum and Diaphorus garnetensis show a disjunction between the Pilbara and Alice Springs. This distance is unlikely to be breached by long distance chance dispersal over an arid desert, and there are no annual monsoons and only infrequent rainfall to facilitate movement in a temporarily wet landscape. A more likely explanation for such distributions is the progressive drying of the Australian continent from the mid-Tertiary onwards, fragmenting once widespread species into favourable isolated pockets, such as the Fortescue drainage, where they persist. This also suggests that the taxonomically isolated and locally endemic genus Pilbara was part of a larger and richer Tertiary fauna. Any closely related taxa appear to be extinct, and it alone it persists at the Millstream site.

\section{ACKNOWLEDGEMENTS}

John Martin assisted with the photography, Hannah Finlay drew Figure 5, and Scott Ginn assisted with the layout of Plates. I thank Nihara Gunawardene for contact regarding the Barrow Island survey and for inviting me to contribute to this volume. Christine Lambkin and Neal Evenhuis provided provided useful comments and much needed corrections to an earlier draft of this manuscript. The respective curators of the following institutions provided the loan of specimens: (AMS)-D. Britton. (ANIC)-D. Colless, P. Cranston, D. Yeates; (BPBM)-K. Arakaki, N. Evenhuis; (CAS)-N. Penny; (CNC)-J. Cumming, S. Brooks; (QDPI)-G. Dahms; (QMB)-C. Burwell; (USNM)-F.C. Thompson, N. Woodley.

\section{REFERENCES}

Becker, T. (1922). Dipterologische Studien, Dolichopodidae der indo-australischen Region. Capita Zoologica 1(4): 1-247.

Bezzi, M. (1928). Diptera Brachycera and Athericera of the Fiji Islands based on material in the British Museum (Natural History). British Museum (Natural History), London. 220 pp.

Bickel, D. J. (1986). Thrypticus and an allied new genus, Corindia, from Australia (Diptera: Dolichopodidae). Records of the Australian Museum 38: 135-151. http:/ / publications.australianmuseum.net.au/pdf/179_ complete.pdf

Bickel, D.J. (1987). A revision of the Oriental and Australasian Medetera (Diptera: Dolichopodidae). Records of the Australian Museum 39: 195-259.

http:/ /dx.doi.org/10.3853/j.0067-1975.39.1987.170

Bickel, D.J. (1994). The Australian Sciapodinae (Diptera: Dolichopodidae), with a review of the Oriental and Australasian faunas, and a world conspectus of the subfamily. Records of the Australian Museum, Supplement 21: 1-394.

http:/ / publications.australianmuseum.net.au/pdf/50_ complete.pdf

Bickel, D.J. (1996). Australian Asyndetus Loew and Cryptophleps Lichtwardt (Diptera: Dolichopodidae), with notes on the Oriental and Western Pacific faunas. Invertebrate Taxonomy 10: 1151-1170.

Bickel, D.J. (1998). Australian, Melanesian, and Micronesian Acropsilus Mik (Diptera: Dolichopodidae). Tijdschrift voor Entomologie 141: 1-17.

Bickel, D.J. (2002). The Sciapodinae of New Caledonia 
(Diptera: Dolichopodidae). Zoologia Neocaledonica, Mémoires du Muséum National d'Histoire Naturelle 187: 11-83.

Bickel, D.J. (2008). The Dolichopodinae (Diptera: Dolichopodidae) of New Caledonia, with descriptions and records from Australia, New Zealand and Melanesia. Zoologia Neocaledonica, Mémoires du Muséum National d'Histoire Naturelle 197: 13-48.

Bickel, D. J. (2009a). Family Dolichopodidae, with annotated key to the New World genera, p. 671-694. In Brown, B.V. et al. (eds), Manual of Central American Diptera: Volume 1, NRC Press, Ottawa, Ontario, Canada. 714 pp.

Bickel, D. J. (2009b). The first species described from Cape York Amber, Australia: Chaetogonopteron bethnorrisae sp. nov. (Diptera: Dolichopodidae): 35-39. In: Berning, B. and Podenas, S. (eds), Amber-Archive of Deep Time. Denisia 26: 294 pp.

Bickel, D.J. (2013). Phrudoneura (Diptera: Dolichopodidae) from Australia and Melanesia. Zootaxa 3680: 38-54.

Brooks, S. E. (2005). Systematics and phylogeny of Dolichopodinae (Diptera: Dolichopodidae). Zootaxa 857: 1-158.

Cumming, J.M., Sinclair, B.J., and Wood, D.M. (1995). Homology and phylogenetic implications of male genitalia in Diptera-Eremoneura. Entomologica Scandinavica, 26: 120-152.

Grootaert, P. and Meuffels, H.J.G. (1984). Dolichopodidae (Diptera) from Papua New Guinea. II. Some new species of the genus Thinophilus Wahlberg, 1844, from the Lowland. Indo-Malayan Zoology 2: 209-223.

Grichanov, I.Y. (1997). A brief review of the Afrotropical fauna of the subfamily Hydrophorinae (Diptera: Dolichopodidae) with a description of Cemocarus stuckenbergi sp. n. International Journal of Dipterological Research 8: 149-157.

Hardy, G.H. (1939). Miscellaneous notes on Australian Diptera VI. Dolichopodinae. Proceedings of the Linnean Society of New South Wales 64: 345-352.

Lehmann, J.G.C. (1822). Indicem scholarum publice privatimque in Hamburgensium Gymnasio Academico a paschate 1822 usque as pascha a. 1823 habendarum. Observationes zoologicae praesertim in faunam hamburgensem. Pugillus primus. Hamburgi. 55 pp.

McAlpine, J.F. (1981) Morphology and TerminologyAdults, p. 9-64, In J.F. McAlpine, et al., Manual of Nearctic Diptera, Vol. 1, Research Branch Agriculture Canada, Ottawa, Monograph 27, 674 pp.

McKenzie, N.L., van Leeuwen, S. and Pinder, A.M. (2009). Introduction to the Pilbara Biodiversity Survey, 2002-2007. Records of the Western Australian Museum, Supplement 78: 3-89.

Meuffels, H.J.G. and Grootaert, P. (1997). Dolichopodidae (Diptera) from Papua New Guinea. XVI. Scotiomyia gen. nov., a new Sympycninae from the rain forest with notes on Papuan Sympycninae. Studia Dipterologica 4: 247-255.

Mulvaney, J. and Kamminga, J. (1999). The prehistory of Australia. Allen and Unwin, Sydney, 480 pp.

Olejní ek, J. and Kubík, Š. (2007). Chaetogonopteron bartaki, a new species of Sympycninae (Diptera, Dolichopodidae) from Australia. Acta Zoologica Universitatis Comenianae 47: 183-185.

Parent, O. (1933). Nouvelle étude sur les diptères dolichopodides de la region Australienne. Annales de la Société scientifique de Bruxelles (B) 53: 170-187.

Parent, O. (1941). Diptères Dolichopodides de la région Indo-australienne. Espèces et localités nouvelles. Annals and Magazine of Natural History (11) 7: 195-235.

Pepper, M., Doughty, P. and Keogh, J.S. (2013). Geodiversity and endemism in the iconic Australian Pilbara region: a review of landscape evolution and biotic response in an ancient refugium. Journal of Biogeography 40: 1225-1239.

Robinson, H. (1963). A new species of Acropsilus from the Solomon Islands (Diptera: Dolichopodidae). Canadian Entomologist 95: 830-831.

Yang D., Zhu Y., Wang M., and Zhang L. (2006). World Catalog of Dolichopodidae (Insecta: Diptera). China Agricultural University Press, Beijing, 704 pp.

MANUSCRIPT RECEIVED 23 MAY 2013; ACCEPTED 2 SEPTEMBER 2013. 